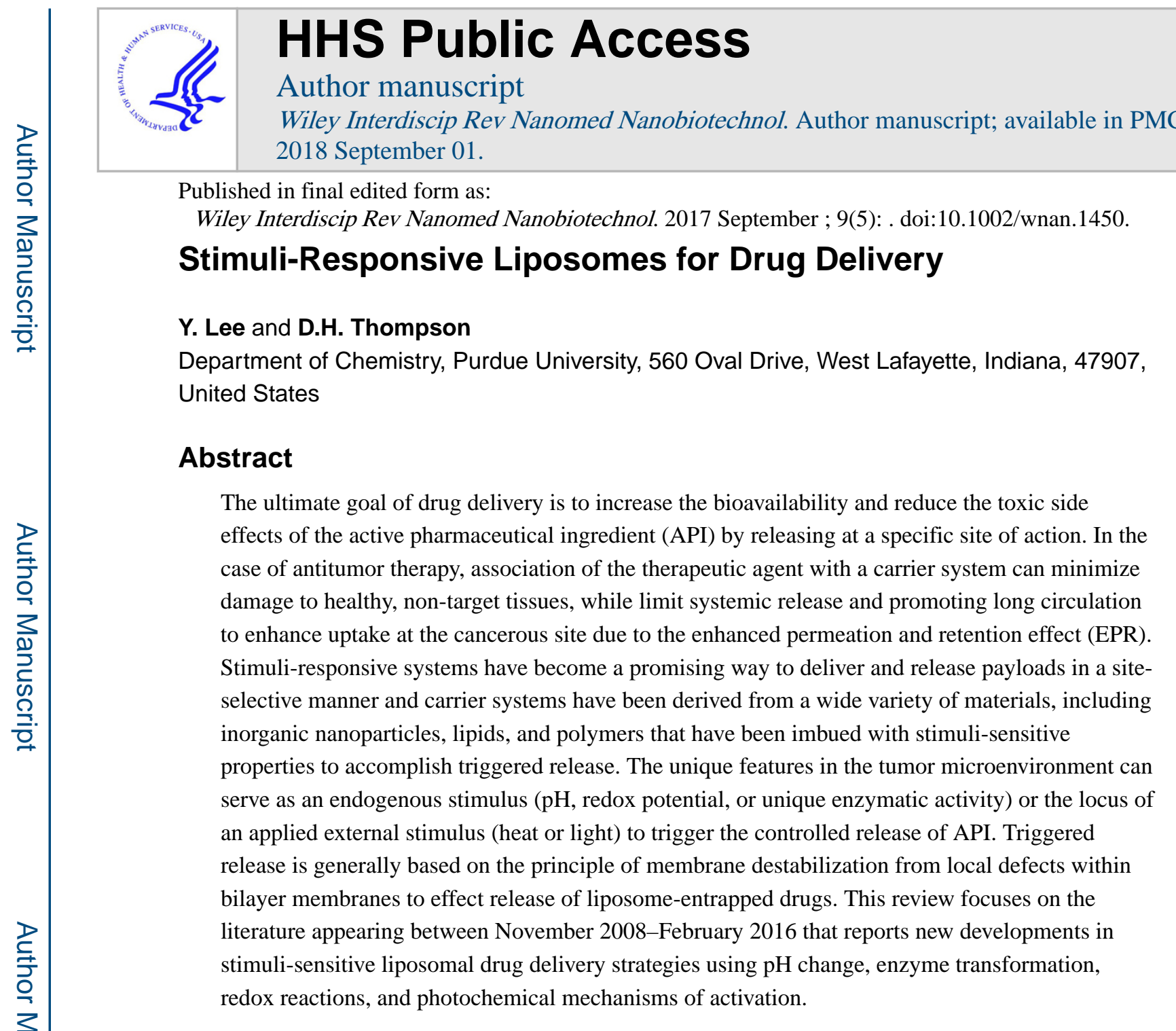

\title{
Introduction
}

Nanoparticle-based delivery of drugs to solid tumors is a promising approach to overcome the lack of tissue specificity of conventional cancer chemotherapy ${ }^{1,2}$. Liposomes have been widely used to deliver small molecule agents and nucleic acid cargo for cancer therapy. They are favored carrier systems because they are easily manufactured in a size controlled manner, can be produced in high drug/lipid ratios by remote loading ${ }^{3}$, are rendered longcirculating by the incorporation of stealth coating, and are typically composed of naturallyderived phospholipids that mimic the properties of biological membranes (Figure 1). Hydrophilic and amphiphilic molecules can be entrapped in the core whereas hydrophobic molecules can be partitioned into the lipid bilayer membrane to achieve selective loading of the therapeutic agent. Liposomal formulations have shown an ability to enhance the pharmacodynamics and pharmacokinetics of API, while hindering their associated off-target toxicity ${ }^{4}$. Since they can be produced on large scale in the $50-150 \mathrm{~nm}$ size range that favors EPR, they can extravasate from the blood vessels and accumulate within tumor tissues (Figure 2) ${ }^{5,6}$. They can also be further engineered with functional moieties to improve their performances in terms of circulation longevity, target-specific delivery, enhanced intracellular penetration, contrast enhancement for image-guided therapy, and stimuli- 
sensitivity ${ }^{1}$. Since conventional liposomes are recognized by the host's immune systems such as the mononuclear phagocyte system (MPS) and rapidly cleared by the reticuloendothelial system (RES), stealth properties are necessary to protect the liposomes from degradation in the liver and spleen to optimize the pharmacokinetics of encapsulated drugs $^{2}$. Poly(ethylene glycol) (PEG) is the most widely used polymer as a stealth coating on the liposome surface to reduce particle aggregation and minimize the recognition and binding of opsonins through the steric stabilization (Figure 3) 7,8 .

In point of clarification, several formulation techniques have been actively explored such as micelles ${ }^{9}$, polyelectrolyte complexes ${ }^{10}$, or polymeric nanoparticles ${ }^{11}$ in addition to the liposomal systems described in this review to achieve sustained release of drugs. There are benefits and drawbacks for each system, such that each unique application warrants selection of the appropriate vehicle for delivering a specific drug to its target tissue. Micelles are recognized for their ability to enhance the solubility of hydrophobic drugs; they are also easily prepared and shelf stable. Conversely, micelles are dynamic structures that readily lose their cargo by exchange, particularly when diluted below their critical micelle concertation (CMC), making them a challenge for drug delivery via long-circulation ${ }^{12,13}$. Polyelectrolyte complexes are favored in gene and protein drug delivery due to their stability and biocompatibility. However, their rapid clearance and heterogeneity remain drawbacks of this approach ${ }^{10,14}$. Lastly, polymeric nanoparticles gained popularity by showing controlled burst release and versatility, but they tend to aggregate easily and have low encapsulation efficiencies ${ }^{15,16}$.

Currently, different chemical activation methods ( $\mathrm{pH}$, enzyme, redox, and light) are used to confer stimuli-responsive properties to liposomes for drug delivery. The specific source of cellular intra- or extracellular activation by chemical, biochemical, or physical means can modify the structural state of the liposomes, thereby promoting the release of an agent within a specific biological environment ${ }^{1}{ }^{17}$. This review focuses on the various activation strategies that have recently been used to deliver agents effectively and selectively within tumor cells and tissues.

\section{pH-Responsive Liposomes}

pH-responsive liposomes can be employed to effect site-specific drug release. Since some pathological sites have different $\mathrm{pH}$ profiles from that of normal tissues (e.g., tumors are often slightly more acidic than healthy tissue, extracellular $\mathrm{pH}$ values averaging $\mathrm{pH}$ 6.8-7.0, but some as low as 5.7) ${ }^{6,18}$. These $\mathrm{pH}$ changes can trigger changes in permeability of the liposomal membrane by protonation/deprotonation of functional groups that induce morphological changes of the lipid bilayers. An important example of this is the polymorphic phase behavior of the natural phospholipid, 1,2-dioleoyl-sn-glycero-3phosphoethanolamine (DOPE), that adopts an inverted hexagonal phase II $\left(\mathrm{H}_{\text {II }}\right.$ phase) at low $\mathrm{pH}$ and a bilayer structure ( $\mathrm{L}_{\mathrm{a}}$ phase) at neutral $\mathrm{pH}$ to promote the membrane destabilization $(\text { Figure } 4)^{19}$. 


\section{Acid Groups}

1. Oleic Acid-In general, pH-responsive liposomes are formulated using a natural phospholipid component that is sensitive to $\mathrm{pH}$ changes that may be encountered as they traffic to or are internalized by target cells. Additionally, inclusion of negatively charged moieties into $\mathrm{pH}$-sensitive liposome compositions is a common strategy for destabilizing the liposome structure through the phase conversion, to enable rapid release of the payload ${ }^{6,17}$. These mechanisms enable release of the chemotherapeutic agent in a selective manner. The formation of liposomes using materials such as phosphatidylethanolamine (PE) or oleic acid (OA) are common methods for conferring $\mathrm{pH}$ sensitivity to a liposome formulation ${ }^{18}$. A 3:2:3:1 w/w PE/cholesterol (Chol)/OA/docetaxel (DTX) formulation has been used to achieve 1.3-fold higher cumulative drug release rate at $\mathrm{pH} 5.0$ than at $\mathrm{pH} 7.4$, although the activation mechanism for DTX entry into the cytosol is not clear. Redistribution processes between the liposomes and endosome membranes may have contributed to the destruction of pH-sensitive liposomes and release of the DTX cargo. Similarly, Ghanbarzadeh et al. demonstrated the formation of $\mathrm{pH}$-sensitive and plasma stable liposomes using $\mathrm{OA}$ and PEG-poly(monomethylitaconate)CholC6 (PEG-PMMI-CholC6) loaded with the immunosuppressant rapamycin ${ }^{20}$. PEG-PMMI-CholC6 is soluble at physiological $\mathrm{pH}$ due to the deprotonated state of the carboxylic acid groups but becomes protonated and precipitates at low $\mathrm{pH}$ due to increased lipophilic properties of the polymer backbone. This destabilizes the liposome surface and induce the rapid release. In vitro studies showed high physicochemical stability ( $<10 \%$ leakage in plasma over $3 \mathrm{~h})$ and efficient delivery $(>60 \%$ cell inhibition) in HT-29 cells at $\mathrm{pH} 6.5$.

2. Succinic Acid Derivatives-Kono et al. reported a biocompatible hyperbranched poly(glycidol) (HPG) polymer with temperature-sensitive oligo(ethylene glycol)s (OEGs) and $\mathrm{pH}$-sensitive succinyl groups ${ }^{21}$. This stimuli-sensitive polymer was grafted onto the liposome surface to produce dual stimuli-responsive liposomes that destabilized under mildly elevated temperature $\left(30-40^{\circ} \mathrm{C}\right)$ and mildly acidic $\mathrm{pH}(4.0-5.5)$ conditions due to protonation of carboxyl groups that causes a decrease in the polymer transition temperature. In addition, hydrogen bond formation between the polymer carboxyl groups and the phospholipid headgroups were also believed to contribute to liposome destabilization. Dual stimulation by acidic $(\mathrm{pH} 4.0-5.5)$ conditions and high temperatures $\left(40-50{ }^{\circ} \mathrm{C}\right)$ produced a more prominent release profile than temperature-induced enhancement alone.

2a) Cholesteryl Hemisuccinate: The properties of $\mathrm{pH}$-sensitive liposomes can be tuned by incorporation of titratable lipids within the liposomal membrane. Cholesteryl hemisuccinate (CHEMS) is a protonatable lipid that is widely used for acid-sensitive delivery systems ${ }^{22}, 23$. It is negatively charged at neutral $\mathrm{pH}$, but becomes neutral at acidic $\mathrm{pH}$, thereby causing bilayer disruption. Barbosa et al. formulated $\mathrm{pH}$-sensitive and targeted liposomes using CHEMS and lipid-PEG-folate, respectively, to deliver paclitaxel (PTX) for the treatment of metastatic breast cancer ${ }^{24}$. The $\mathrm{pH}$-sensitivity of the formulation was boosted by inclusion of the fusogenic lipid, DOPE, which promotes membrane-membrane fusion within acidic environments ( $<\mathrm{pH} 5.0)$. The folate-targeted, $\mathrm{pH}$-sensitive liposomes were more cytotoxic than non-targeted $\mathrm{pH}$-sensitive liposomes or free PTX in viability studies against MDAMB-231 and MCF-7 cell lines. MDA-MB-231 cells showed higher sensitivity to folate- 
targeted-CHEMS liposomes due to higher folate receptor expression. Similarly, Hu et al. described a hybrid nanoparticle system consisting of DOPE-based CHEMS-liposomes and an antigen packaged within a poly(lactic-co-glycolic) acid (PLGA) core ${ }^{25}$. The $\mathrm{pH}$-sensitive hybrid nanoparticle displayed faster degradation and corresponding antigen release compared to regular hybrid nanoparticle in dendritic cell cultures. Chang et al. used CHEMS-based $\mathrm{pH}$-sensitive liposomes bearing arginine-glycine-aspartic acid (RGD) peptide as a targeting moiety to enhance the effectiveness of docetaxel treatment ${ }^{26}$. The in vitro release of docetaxel was increased from 50\% to $80 \%$ upon acidification (pH 7.4 to 5.0), with correspondingly higher cytotoxicity/cellular uptake levels observed for the RGD-coated pH-sensitive liposomes. Recently, Paliwal et al. modified DOPE/CHEMS-based pHsensitive liposomes with hyaluronic acid for targeted intracellular delivery of doxorubicin $(\mathrm{DOX})^{27}$. The hyaluronic acid groups target overexpressed CD44 cell-surface receptors on tumor cells. HA-targeted $\mathrm{pH}$-sensitive liposomes were able to achieve higher drug release at pH $5.5(90 \%$ release in $6 \mathrm{~h})$ than at $\mathrm{pH} 7.4(<10 \%$ in $6 \mathrm{~h})$ and dramatically decreased the tumor volume compared to HA-targeted $\mathrm{pH}$-insensitive liposomes or free DOX likely due to the combined effect of targeting intracellular delivery of encapsulated anticancer drug in cell expressing high levels of CD44.

Interestingly, Xu et al. demonstrated enhanced pH-responsiveness of DOPE/CHEMS-based liposomes using a PEG-lipid post-insertion technique rather than conventional formulation approaches ${ }^{28}$. The post-insertion technique leads to presentation of the PEG corona only on the exterior side of the liposome. This is thought to lead to viscosity reduction in the inner liposomal monolayer, thus leading to increased bilayer fluidity and a lowered $\mathrm{L}_{\mathrm{a}}-\mathrm{H}_{\mathrm{II}}$ transition barrier in response to acidic $\mathrm{pH}$ environments. The $1 \%$ post-inserted liposome was able to enhance $\mathrm{pH}$-dependent release (> $10 \%$ at $\mathrm{pH} 5.0$ and $<2 \%$ at $\mathrm{pH} 7.4$ ) whereas the $1 \%$ pre-inserted liposome formulation was not able to induce significant release $(5 \%$ at $\mathrm{pH}$ 5.0 and $<2 \%$ at $\mathrm{pH}$ 7.4). These findings suggest that PEGylation by post-insertion may offer advantages for more effective $\mathrm{pH}$-sensitive delivery and superior liposomal pharmacokinetics.

2b) a-Tocopherol Hemisuccinate: The Terreno and Aime groups have used D-atocopherol-hemisuccinate (THS) as a pH trigger and membrane stabilizer for MRI studies $^{29,30}$. Since Gd-loaded, DPPE-based $\mathrm{pH}$-sensitive liposomes previously showed limited release under acidic conditions, they selected fusogenic POPE as the main membrane component and THS as the steric stabilizer that were further stabilized with cholesterol to form liposomes that were stable at physiological $\mathrm{pH}$, but leaky in an acidic environment. Membrane destabilization occurs upon protonation of the THS carboxylate sites on the outer surface of the liposomes, leading to fusion of the POPE liposomes and cargo release. Terreno and coworkers have reported a 10 -fold faster release rate of [GdAAZTA] $]^{-}$imaging agent at $\mathrm{pH} 6.5$ than at physiological $\mathrm{pH} 7.4$ (Figure 5) ${ }^{29}$. They also noted the improvements in the PEGylation application where the conjugations of PEGs with external surface of the $\mathrm{pH}$-sensitive liposomes were succeeded with disulfide bridges. This provides the stealth property while circulating, but restores the $\mathrm{pH}$ responsiveness after removal of PEG polymers at the biological target. 
3. Poly(Acrylic Acid)—Similarly, the release property can be tuned by surrounding the $\mathrm{pH}$-sensitive polymer networks around the liposomes. The insertion of cholesterolterminated poly-(acrylic acid) (Chol-PAA) followed by cross-linking with 2,2' (ethylenedioxy)-bis(ethylamine), created a membrane additive that promotes contents leakage through an acid-triggered conformational collapse upon protonation of the free acrylate groups in the cross-linked polymer cage (Figure 6$)^{31}$. The cross-linked polymers were more prone to membrane destruction due to concurrent collapses of the polymer networks. Significant enhancements in the release rate of hydrophilic $\left(\mathrm{Ni}^{2+}\right)$ and amphipathic $\left(\mathrm{As}^{3+}\right)$ anticancer agents were observed $\left(k\left(\mathrm{Ni}^{2+}, \mathrm{As}^{3+}\right)=8.25 \mathrm{~h}^{-1}, 14.7 \mathrm{~h}^{-1}\right.$, respectively) at $\mathrm{pH} 4.0$, while profiles at $\mathrm{pH} 7.4$ showed insignificant leakage $\left(k\left(\mathrm{Ni}^{2+}\right.\right.$, $\left.\mathrm{As}^{3+}\right)=<1 \mathrm{~h}^{-1}, 1.4 \mathrm{~h}^{-1}$, respectively). Jelezova et al. inserted poly(isoprene-b-acrylic acid) (pI-pAA) diblock copolymers into liposomes to confer $\mathrm{pH}$-dependent delivery of curcumin using polyoxyethylated tert-butylcalix[4]arene (BEC-X) $)^{32}$. The polyisoprene block served as the membrane anchoring moiety of the membrane disrupting agent and BEC-X forms nanosized spherical aggregates with high solubilization for curcumin inside the liposomes. The curcumin loaded $\mathrm{pH}$-sensitive liposomes were characterized by a high loading capacity and triggered release profile (35\% and $13 \%$ release at $\mathrm{pH} 4.5$ and 7.0 , respectively).

Another class of $\mathrm{pH}$-induced membrane perturbation-based systems was proposed using $\mathrm{pH}$ triggered transmembrane channel. These were prepared by co-assembly of poly(acrylic acid)-g-poly(monomethoxy ethylene glycol) (PAAc-g-mPEG) with the cationic lipid, didodecyldimethylammonium bromide (DDAB), through cooperative electrostatic interactions ${ }^{33}$. The reduced ionization of AAc groups and partial disruption of electrostatic interactions between the DDAB and AAc groups made the membranes more permeable to water influx at low $\mathrm{pH}$. Dox release of over $60 \%$ suggested the formation of transmembrane channels at $\mathrm{pH} 5.0$, which facilitated the release of the encapsulated drug.

Changes in $\mathrm{pH}$ can also be used to influence hydrogel properties, drug interactions, and release kinetics. $\mathrm{pH}$-sensitive hydrogels have been used to produce reversible changes in swelling profile for controlled drug release. These on-off swelling states arise from electrostatic repulsions between the polymer chains in the hydrogel networks. Wang et al. designed a lipogel with a PAA hydrogel core and liposome coating ${ }^{34}$. Since loading was achieved through strong electrostatic interactions between cationic drugs and anionic gels, the release rates were slow (50\% 17-DMAPG release in $54 \mathrm{~h}$ ). Therefore, although PAA nanogels could swell and shrink in response to the $\mathrm{pHs}$ and affect the encapsulation greatly, lipogels did not drastically respond to $\mathrm{pH}$-induced release due to the presence of an intact lipid bilayer. To further improve the sensitivity of hydrogels, Popescu et al. used zwitterionic liposomes that are compatible with hydrogels containing poly(2-vinyl pyridine)-bpoly(acrylic acid)-b-poly(n-butyl methacrylate) $\left(\mathrm{P}_{2} \mathrm{VP}_{25}-\mathrm{PAA}_{576}-\mathrm{PnBMA}_{36}\right)^{35}$. This copolymer switched between rigid and relaxed forms at different $\mathrm{pHs}(\mathrm{pH} 3.0$ and 7.4, respectively). Calcein release from these lipogels was found to depend on gelator concentration such that 1 and $1.5 \mathrm{wt} \%$ took 14 and $32 \mathrm{~d}$, respectively, to complete the release.

Several other $\mathrm{pH}$-responsive membrane-destabilizing polymers have been introduced that are more efficient toward interactions with cellular membranes to enhance the cytoplasmic 
delivery of therapeutics. Specifically, poly(methacrylic acid) displayed a transition from a hydrophilic state to a lipophilic state leading to enhanced interactions with cell membranes at acidic pHs. Sevimli et al. designed a delivery vesicle with poly(methacrylic acid-cocholesteryl methacrylate) P(MAA-co-CMA) that included cholesterol modifications to promote cellular membrane transport ${ }^{36}$. The greatest response in membrane-lytic activity was observed at $\mathrm{pH} 5.0$, where 2, 4, and $8 \mathrm{~mol} \%$ CMA resulted in 3-, 2-, and 1.4-fold higher lysis, respectively, than at $\mathrm{pH}$ 7.4. Further, $\mathrm{pH}$ - and thermo-sensitive liposomes modified with poly(N-isopropylacrylamide-co-methacrylic acid-co-octadecyl acrylate) P(NIPAM-coMAA-co-ODA) copolymers, containing MAA, served as the $\mathrm{pH}$-sensitive moieties to trigger the content release of liposomes under acidic conditions ${ }^{37}$. The highest berberine hydrochloride $(\mathrm{BH})$ release $(50 \%)$ was achieved at the phase transition temperature $\left(38{ }^{\circ} \mathrm{C}\right)$ and $\mathrm{pH}(6.7)$, where the combination of stimuli acted as permeability switches. Higher temperatures $\left(45-53{ }^{\circ} \mathrm{C}\right)$ decreased the levels of $\mathrm{BH}$ release due to stronger interactions between the copolymer and lipid membranes that suppress release from the inner compartment. Altered orientation of the phospholipid hydrophobic tails relative to the liposome surface upon heating above the phase transition temperature further opposed the release. Recently, Alves et al. prepared polymer liposome complexes (PLC) with the lipids of lactic acid bacteria and $\mathrm{pH}$-sensitive poly(N,N-dimethylaminoethyl methacrylate) that were covalently bound to cholesterol (CHO-PDMAEMA) ${ }^{38}$. Incorporation of CHOPDMAEMA into the bacterial lipid mixture produced stabilized liposomes with a $\mathrm{pH}$ sensitive functionality for stimuli-responsive drug delivery. A liposome-in-microsphere (LIM) system, wherein liposomes were surrounded by a shell of Eudragit S100, a methacrylic acid copolymer, showed a $\mathrm{pH}$-dependent content release profile for potential oral colonic drug delivery ${ }^{39}$. In vivo studies showed that conditions formed in the large intestine (> pH 7.0) promoted the degradation of the Eudragit S100 films, thus triggering the collapse of the microspheres and release of over $85 \%$ of the encapsulated agents (5-ASAs that are coated with chitosan), compared with $<10 \%$ release from simulated stomach and small intestine conditions ( $\mathrm{pH}$ 6.3). In good agreement with previous studies, the release profile in liposomes containing $\mathrm{pH}$-sensitive poly(ethylacrylic acid) (PEAA) was evaluated and found to be $\mathrm{pH}$ and PEAA polymer size dependent ${ }^{40}$. Maximum calcein release $(80 \%)$ was achieved at $\mathrm{pH} 4.5$ when the PEAA polymer size was larger than $8.4 \mathrm{kDa}$. The smaller PEAA polymer sizes $(1.2,1.9,6.5 \mathrm{kDa})$ showed lower release profiles $(8,35,70 \%)$ due to insufficient protonation of the carboxylic groups of PEAA that would trigger the conformational collapse.

Recently, polymersomes (polymeric vesicles) have been developed having better colloidal stability, higher mechanical strength, and lower chemical permeability than liposomes ${ }^{41}$. In agreement with the advantages of polymersomes, Zhong and coworkers reported a study on $\mathrm{pH}$-sensitive degradable chimeric polymersomes consisting of asymmetric poly(ethylene glycol)-b-poly(trimethoxybenzylidene tris(hydroxymethyl)ethane methacrylate)-bpoly(acrylic acid) (PEG-PTTMA-PAA) copolymers ${ }^{42}$. Upon acidification, the acetals in the PEG-PTTMA-PAA polymersomes undergo hydrolysis and cause swelling that eventually bursts the vesicles and releases the encapsulated contents. For instance, rapid acetal hydrolysis rates were evaluated, yielding half-lives that were approximately $3.0 \mathrm{~h}$ at $\mathrm{pH} 4.0$, $11 \mathrm{~h}$ at $\mathrm{pH} 5.0$, and $33 \mathrm{~h}$ at $\mathrm{pH}$ 7.4. The release study showed $83.3 \%$ and $69.5 \%$ release of 
$\mathrm{DOX}$ at $\mathrm{pH} 4.0$ and 5.0, respectively, while only $29.8 \%$ of release was observed on $\mathrm{pH} 7.4$ in $24 \mathrm{~h}$. Longer PAA lengths within the formulation showed faster drug release (slight increase at $\mathrm{pH} 4.0$ and 5.0 and 2-fold increase in $\mathrm{pH} 7.4$ ), likely due to the occurrence of autocatalytic degradation. Further, $\mathrm{pH}$-responsive chimeric polypeptide-based polymersomes have been constructed using asymmetric poly(ethylene glycol)- $b$-poly(L-leucine)- $b$-poly(Lglutamic acid) (PEG-PLeu-PGA) triblock copolymer for higher encapsulation and triggered intracellular delivery of $\mathrm{DOX}^{43}$. The chimeric polymersomes have polyion blocks in the hydrophilic core to provide electrostatic and hydrogen bonding interactions with hydrophilic drugs and proteins for efficient loading. These PEG-PLeu-PGA polymersomes are stable at physiological $\mathrm{pH}$, however, the acidic tumor environment alters the ionization state of carboxylic groups in PGA thus shifting the PGA blocks from hydrophilic random coil structure to a hydrophobic a-helical structure that promotes release of payloads upon destabilization. The release study showed $24.0 \%$ and $75.7 \%$ release of DOX at $\mathrm{pH} 7.4$ and 5.0, respectively, at $37^{\circ} \mathrm{C}$ in $24 \mathrm{~h}$.

4. Aspartic Acid-Wang et al. incorporated octylamine grafted polyaspartic acid (PASP$\mathrm{g}_{-} \mathrm{C}_{8}$ ) molecules into liposomes to render them $\mathrm{pH}$-sensitive to promote tumor targeted drug delivery ${ }^{44}$. The hydrophobic anchor $\left(\mathrm{C}_{8}\right)$ helps to immobilize the polymer in the membrane such that a moderate degree of substitution (7.8\%) and free carboxylate groups serve as the site of ionization which change conformation upon protonation to activate drug release. The cumulative release and resulting cytotoxicity was more significant at $\mathrm{pH} 5.0$ than at $\mathrm{pH} 7.4$ in HepG2 cell lines.

5. Glutaric Acid-Kono and coworkers reported cationic liposomes modified with 3methylglutarylated hyperbranched poly(glycidol) (MGlu-HPG) (Figure 7a) as a pH-sensitive polymer that alters its hydrophilic-lipophilic balance in response to acidic conditions ${ }^{45,46}$. 3,5-Didodecyloxybenzamidine (TRX) (Figure 7b) was used as a cationic lipid which further improved the $\mathrm{pH}$ sensitivity and association with murine dendritic cells (DC) under weakly acidic $\mathrm{pH}$ conditions ${ }^{45}$. The $\mathrm{pH}$-dependent delivery of the encapsulated antigenic protein ovalbumin (OVA) led to DC activation and triggered antigen-specific immune response, leading to efficient induction of Th1 cells and cytokine production. In addition, interferon (IFN)- $\gamma$-gene lipoplexes were added to the formulation along with OVA-encapsulated TRXliposomes to achieve enhanced induction of tumor-specific immunity ${ }^{46}$. As a result, the combination of liposome delivery and lipoplex delivery without complexation promoted the infiltration of OVA-specific cytotoxic T lymphocytes (CTLs) to tumors at an early stage of treatment reflecting a stronger tumor suppression than hybrid delivery system. The development of a synergetic effect via a combination delivery strategy led to an antigenspecific immunity activation system for cancer immunotherapy.

6. Zwitterionic_ZZhang and coworkers developed a zwitterionic poly(carboxybetaine) (PCB) as a pH-sensitive stabilizer moiety in liposome formulations ${ }^{47,48}$. The presence of PCB enhances the stability of liposomes similarly to that of PEG and reduces non-specific binding during blood circulation. The DSPE-based PCB-liposomes were able to avoid accelerated blood clearance and promote tumor accumulation ${ }^{47}$. Camptothecin (CPT) has also been ester linked with a $\mathrm{pH}$-sensitive PCB to construct a CPT-PCB prodrug that was 
blended with the cationic lipid, dimethyldioctadecylammonium bromide (DDAB), followed by siRNA, siPlk1, to form CPT-PCB lipoplex ${ }^{48}$. This system enabled a temporally controlled release system wherein siPlk1 was initially released from the acidic endosome/ lysosome compartment of the cells into the cytoplasm upon protonation of PCB leading to down-regulation of Plk1. Release of the conjugated CPT subsequently occurred in a sustained and esterase-dependent manner. This doubly activated delivery system accomplished rapid $\mathrm{pH}$-triggered siRNA release within $4 \mathrm{~h}$ and sustained CPT release in response to esterase activity to drive high drug accumulation within the nucleus after $12 \mathrm{~h}$, leading to synergistic cell apoptosis and cytotoxicity in vitro and tumor regression in vivo.

7. Charge Conversion/Structural Transformation-Liu et al. described malachite green carbinol base (MG) as the $\mathrm{pH}$ responsive molecules that incorporated into DOXcontaining liposomes to trigger a highly efficient release in tumor cells ${ }^{49}$. The structural transformation of bilayer- intercalated MG effectively regulates the drug release profile by conversion from the hydrophobic neutral formation to hydrophilic positively charged MG carbocation $\left(\mathrm{MG}^{+}\right)$in acidic $\mathrm{pH}$ condition (Figure 8). This transformation disturbs the electrostatic interactions which causes a disassociation and a release of the contents. The low $\mathrm{pH}(5.0)$ resulted higher cytotoxicity (> 80\%) in KB cells and MG-DOX-liposome showed less toxicity while inhibited the tumor growth to the mice more effectively (>2-fold) than DOX-liposome and similar to free DOX.

8. Amine-Protonation/Deprotonation-Amine functionalities have also served as the site of protonation and deprotonation to trigger $\mathrm{pH}$-dependent permeability changes in drug delivery systems. Hao et al. proposed $\mathrm{pH}$-sensitive bola-type triblock copolymers, composed of poly(2-(diisopropylamino) ethylmethacrylate) (PDPA) and mPEG segments ${ }^{50}$. The copolymers are amphiphilic and assemble to form vesicles under physiological conditions but become more hydrophilic upon protonation of di-isopropyl tertiary amines under acidic conditions to stimulate drug release. DOPC-based PDPA liposomes showed the most prominent DOX release profiles, releasing more than $80 \%$ of the drug cargo at $\mathrm{pH} 6.0$, whereas only $20 \%$ was released at pH 7.4 after $48 \mathrm{~h}$. Guo et al. incorporated 1,2-dioleoyl-3dimethylammonium propane (DODAP, $\mathrm{pK}_{\mathrm{a}} 6.6$ ) into a liposomal formulation to respond to acidic environments by fusing the carbonic protonated amphiphile membrane with negatively charged endosomal membranes to deliver encapsulated lipocalin-2 (Lcn2) siRNA $^{51}$. In addition, anti-chemokine receptor type 4 (CXCR4) antibodies were introduced on to the liposome surface to target metastatic breast cancer (MBC) cells and block the CXCR4 chemokine axis to inhibit MBC metastasis. The synergistic effect of $\mathrm{pH}$-triggered CXCR4-targeted Lcn 2 siRNA delivery efficiently inhibited the migratory pathway by $88 \%$ and $92 \%$ in MDA-MB-436 and MDA-MB-231 cells, respectively.

Chiang et al. developed extracellular matrix (ECM)-targeting liposomes composed of DPPC, crosslinked using $\mathrm{pH}$-sensitive methoxy-poly(ethylene glycol)-b-poly(N-2-hydroxypropyl methacrylamide-co-histidine)-cholesterol (mPEG-P-(HPMA-g-His)-Cholesterol) copolymers, and biotin-polyethylene glycol-biotin (biotin2-PEG) crosslinkers ${ }^{52}$. The imidazole ring of the histidine containing copolymer becomes protonated below $\mathrm{pH} 6.0$, creating positive charges that generate repulsive electrostatic interactions that exposes the 
biotin molecules to the tumor ECM for improved cellular uptake and enhanced drug delivery. Rapid DOX release in vitro was observed in acidic environments. Recently, Moku and coworkers presented the development of glutamic acid backbone-based cationic amphiphiles containing both $\mathrm{pH}$-sensitive histidine and solubility enhancing guanidine moieties ${ }^{53}$. The designed liposomes not only delivered two anti-cancer drugs, curcumin and PTX, but also significantly contributed to the inhibition of mouse tumor growth. The $\mathrm{pH}-$ dependent fusogenic and controlled release properties of this formulation induced the apoptosis of tumor cells that was found to be mediated by increased cell cycle crest in the G2/M phase. Next, Gu and coworkers synthesized DSPE-KLA-DMA (DKD) lipid endowed with $\mathrm{pH}$ response and mitochondrial targeting functionalities in PTX-containing liposomes for delivering PTX to overcome multidrug resistance (MDR) in cancer therapy ${ }^{54}$. The $\mathrm{pH}-$ sensitive 2,3-dimethylmaleic anhydride (DMA) unit was cleaved from the DKD-containing liposomes upon hydrolysis of the amide linkage in the lipid at acidic $\mathrm{pH}$, such that the surface charge is reversed (negative to positive) to facilitate KLA peptide-induced targeted internalization into mitochondria and PTX release. Increased cytotoxicity was observed in lung A549 cancer cells and drug-resistant A549/Taxol cells, compared to PTX-loaded liposomes and free PTX, which translated to strong tumor growth inhibition $(86.7 \%)$ in mice bearing A549/Taxol cells.

9. Phosphoethanolamine-The combination of various unsaturated species of phosphoethanolamine (PE) and amphiphilic stabilizer can create $\mathrm{pH}$-sensitive liposomes that can induce the undergo $\mathrm{L}_{\mathrm{a}}-\mathrm{H}_{\text {II }}$ phase transition as a contents release activation mechanism. The PE headgroups are zwitterionic at physiological $\mathrm{pH}$, allowing the PE-rich dispersion to adopt a lamellar phase. Upon acidification, the negatively charged phosphodiester groups are neutralized by protonation to induce the formation of a hexagonal phase II that destabilize the membrane and promotes contents leakage and membrane fusion. Sanchez et al. used dirhamnolipid secreted by Pseudomonas aeruginosa (diRL) as a bilayer stabilizer (biosurfactant) in a PE liposome system to exploit their acid-sensitive fusion activity (Figure 9) ${ }^{55}$. Liposomes containing $30 \mathrm{~mol} \%$ diRL were more stable than those containing $20 \mathrm{~mol} \%$ diRL, as measured by their relative calcein release within $60 \mathrm{~s}$ of acidification to $\mathrm{pH} 5.0$. Immunoliposomes have also been formulated with functionalized single walled carbon nanohorn (SWNH) and 1,2-dioleoyl-sn-glycero-3-phosphoethanolamine (DOPE) ${ }^{56}$. This strategy is based on a combination of two nanoparticles that may produce synergistic effects. The functionalized SWNHs served as a hydrophobic drug carrier and the core of the nanoparticle, while DOPE served as the tunable coating that mimicked the biological surface to facilitate cell recognition and internalization. Paclitaxel was loaded onto the carboxyethylmodified SWNH surface prior to encapsulation by a pH-sensitive DOPE bilayer. Release of $90 \%$ of the encapsulated PTX occurred upon acidification to $\mathrm{pH} 4.6$, compared with < $3 \%$ release at higher $\mathrm{pH}(6.5$ and 7.2) over $180 \mathrm{~h}$, suggesting that burst release may occur on entering lysosomes while minimizing leakage at normal physiological $\mathrm{pH}$. The hydrophobic interactions between the drug molecule and the SWNH core played an important role in controlling the release of the drug molecule.

10. pH-Responsive Fusion Activity-PEGylated liposomes have limited effectiveness in antimicrobial delivery, since the sterically-stabilizing PEG layer reduces interactions with 
the bacterial membranes. Zhang and coworkers reported $\mathrm{pH}$-responsive fusion activity based on a system using small chitosan-modified gold nanoparticles (AuChi) that detach from the liposomes after deprotonation at neutral $\mathrm{pH}$ and trigger contents release upon fusion with bacterial membranes ${ }^{8}$. In this system, small AuChis were electrostatically adsorbed onto the anionic liposome surface to inhibit liposome fusion and minimize non-specific drug leakage. This formulation was designed to target the mucus lining of the stomach (neutral $\mathrm{pH}$ ) for the treatment of Helicobacter pylori infection. Efficient doxycycline release was achieved at $\mathrm{pH}$ $7.4(90 \%)$, while only $10 \%$ release was observed at $\mathrm{pH} 1.2$ within $24 \mathrm{~h}$. The study on antimicrobial activity against $H$. pylori bacteria revealed that empty AuChi-liposomes did not display inhibitory activity at all tested concentrations. Overall, doxycycline-loaded AuChi-liposomes showed an enhanced therapeutic efficacy compared to free drug at all tested concentrations and were able to achieve eradication at a doxycycline concentration of $100 \mu \mathrm{g} / \mathrm{mL}$. Similarly, Alam et al. demonstrated liposomal drug delivery using chitosancoated liposomes containing the antiprotozoal and antibacterial agent, furazolidone ${ }^{57}$. The mucoadhesive behavior of chitosan-coated liposomes increased from $42 \%$ to $60 \%$ when $\mathrm{pH}$ changed from 1.3 to 4.5 , and the overall release also increased from $69 \%$ to $77 \%$ when $\mathrm{pH}$ changed from 1.3 to 4.5 . The cationic chitosan coating was introduced to promote interactions with the negatively charged sulfonic and sialic acid residues of mucus and the primary amino groups (pKa 6.3) of chitosan in a $\mathrm{pH}$-dependent manner.

Interestingly, Caddeo et al. also reported chitosan-coated liposomes for intestinal-targeted drug delivery that were designed to provide resistance to acidic conditions while promoting the release in alkaline $\mathrm{pH}^{58}$. The chitosan was complexed with sodium tripolyphosphate to form a polyelectrolyte that provided a $\mathrm{pH}$-sensitive shell layer for enhanced bioavailability and release of quercetin-incorporated liposomes. Similarly, Yan et al. reported native glycol chitosan (GC) as a pH-sensitive trigger that was used to coat liposomes with a $\mathrm{pH}$-dependent surface charge modulator ${ }^{59}$. The amino group of chitosan becomes positively charged under acidic conditions like those found in the tumor extracellular environment. Protonation in this region is believed to increase interactions with negatively charged cell membranes, thus leading to enhanced cellular uptake and improved cytotoxicity against HT1080 cells. Lastly, Yao et al. modified cationic liposome with carboxymethyl chitosan (CMCS), an amphoteric polysaccharide that bears both acidic $(-\mathrm{COOH})$ and basic groups $\left(-\mathrm{NH}_{2}\right)$, for introducing $\mathrm{pH}$-sensitivity into this formulation ${ }^{60}$. The CMCS-coated liposomes were negatively charged at physiological $\mathrm{pH}$ due to electrostatic adsorptions to the cationic liposome surface, but they become positively charged in the acidic environment of the tumor. Detachment of the protonated CMCS layer exposes the cationic liposomes so that their adsorption to the tumor cell surface leads to enhanced exposure to sorafenib and siRNA, thereby suppressing tumor progression in target site by inhibiting both angiogenesis and cell proliferation. Their in vitro and in vivo studies showed enhanced cellular uptake and antitumor efficacy at $\mathrm{pH} 6.5$ than at 7.4 .

11. Multistage-Multistage $\mathrm{pH}$-responsive liposomes $\left(\mathrm{HHG} 2 \mathrm{C}_{18}-\mathrm{L}\right)$ consisting of soy phosphatidylcholine (SPC), cholesterol, and 1,5-dioctadecyl-glutamyl 2-histidylhexahydrobenzoic acid $\left(\mathrm{HHG}_{2} \mathrm{C}_{18}\right.$ ) have been reported (Figure 10a) ${ }^{61}$. Based on their formulation, $\mathrm{HHG}_{2} \mathrm{C}_{18}$ carries two amino acid groups (glutamic acid and histidine) and one 
$\mathrm{pH}$-cleavable group (hexahydrobenzoamide (HHB)). Charge conversion is the first-stage $\mathrm{pH}$ response, where the surface charge of $\mathrm{HHG}_{2} \mathrm{C}_{18} \mathrm{~L}$ reverses to increase the tumor cellular uptake at low $\mathrm{pH}$. These $\mathrm{pH}$-sensitive liposomes are designed to exhibit a net negative charge in the blood and undergo charge conversion to a net positive charge upon exposure to acidic tumor extracellular $\mathrm{pH}(6.0-7.0)$. The resulting positively charged particles then undergo increased tumor cellular uptake via electrostatic absorptive endocytosis at the tumor site. Next, the putative proton sponge effect is believed to act as a second-stage $\mathrm{pH}$ response, where the imidazole groups act as buffering agents to increase osmotic pressures inside the endosomal compartment. Finally, acid-catalyzed hydrolysis of the linker is the third-stage $\mathrm{pH}$ response, where hexahydrobenzoamide degrades at low $\mathrm{pH}$ (4.0-6.0). Amide hydrolysis in $\mathrm{HHG}_{2} \mathrm{C}_{18}$ - $\mathrm{L}$ increased 5.56-fold and 7.5-fold after $8 \mathrm{~h}$ and $24 \mathrm{~h}$, respectively, at $\mathrm{pH} 4.5$ compared to $\mathrm{pH} 7.4$. Their in vitro study used $\mathrm{CCl}-779 / \mathrm{HHG} 2 \mathrm{C}_{18}$ containing liposomes to study cell viability against A498 tumor cells. An enhanced antiproliferation trend was observed with all CCl-770 concentrations compared to controls (Torisel ${ }^{\circledR}$, the commercial formulation of CCI-779, and CCI-779/SPC liposomes) and achieved a maximum cell killing (30\% cell viability) at $10 \mu \mathrm{g} / \mathrm{mL}, \mathrm{pH} 6.5$. In addition, $\mathrm{CCl}-779 / \mathrm{HHG}_{2} \mathrm{C}_{18}-\mathrm{L}$ displayed a promising effect on tumor-size inhibition after $22 \mathrm{~d}$ post-xenograft implantation (1.6-fold and 3-fold higher inhibition than CCI-779/SPC-L, Torisel ${ }^{\circledR}$ and saline, respectively).

PEGHG2 $\mathrm{C}_{18}$-L (HHG2C $\mathrm{C}_{18}+$ PEGHG2 $_{18}$ ) (Figure 10b) was developed in an attempt to improve the bioavailability and blood persistence in vivo for higher antitumor efficacy than $\mathrm{HHG}_{2} \mathrm{C}_{18}$ alone $^{62}$. The presence of PEGylation was confirmed by observing a decrease in zeta potential and cellular uptake for $5 \mathrm{~mol} \% \mathrm{HHG}_{2} \mathrm{C}_{18} \mathrm{~L}+\mathrm{PEGHG} 2 \mathrm{C} 18$ liposomes compared to bare $\mathrm{HHG}_{2} \mathrm{C}_{18}$-L liposomes. The $\mathrm{IC}_{50}$ of CCI-779/HHG2C 18 - $\mathrm{L}$ and CCI-779/ PEGHG2C $\mathrm{C}_{18}$-L were about $3 \mu \mathrm{g} / \mathrm{mL}$ and $5 \mu \mathrm{g} / \mathrm{mL}$ at $\mathrm{pH} 6.5$, a 1.67 -fold and 1.60 -fold improvement relative to $\mathrm{pH} 7.4$, respectively, against A498 tumor cells. Similarly, the total apoptotic ratio of CCI-779/HHG2 $\mathrm{C}_{18}$ - $\mathrm{L}$ and CCI-779/PEGHG2 $\mathrm{C}_{18}$ - $\mathrm{L}$ increased from $9.90 \%$ and $7.78 \%$ at $\mathrm{pH} 7.4$ to $19.53 \%$ and $12.10 \%$ at $\mathrm{pH} 6.5$, respectively. Overall, the reported data showed better tumor-size reduction and longer survival in mice treated with CCI-779/

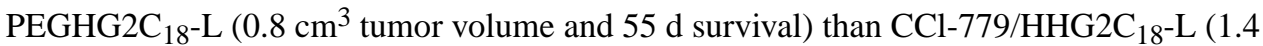
$\mathrm{cm}^{3}$ tumor volume and $47 \mathrm{~d}$ survival). Recently, a new formulation, HH-SS-E2 $\mathrm{C}_{14}$, containing one amino acid group (histidine) and one acid-cleaving group (hexahydrobenzoamide (HHB)) as well as a redox-sensitive disulfide bond, was investigated as a dual-activated liposome formulation for anticancer drug delivery ${ }^{63}$. The authors reported a pH-promoted cellular uptake and endo/lysosomal escape, combined with redoxtriggered intracellular DOX release, that led to an enhanced antitumor activity in this system.

12. $\mathrm{pH}$-Sensitive Peptide-Cell penetrating peptides (CPP) have the capability of delivering biologically active carriers to the cell interior by traversing the cell's plasma membranes in some cases without receptor-mediated interactions. Zhao et al. utilized the pH-responsive $\mathrm{CPP}_{7} \mathrm{~K}\left(\mathrm{R}_{2}\right)_{2}$ for enhancing antitumor drug delivery to the brain tumor cells ${ }^{64}$. This peptide contains a cell penetrating sequence $\left(\mathrm{R}_{2}\right)_{2}$ and a $\mathrm{pH}$ triggering sequence, $\mathrm{H}_{7}$. It has been reported that branched arginine (R)-rich peptides have the ability to cross cell membranes and polyHis sequences effect endosomal escape by transitioning from a hydrophobic to hydrophilic state under acidic conditions. Acid-triggered DOX 
release was observed in C6 and U87-MG glioma cell lines enhanced tumor suppression and antiangiogenic activity was also reported. Similarly, $\mathrm{He}$ and coworkers introduced the integrin $\alpha_{v} \beta_{3}$-specific vector-based $\mathrm{pH}$-sensitive cell penetrating peptide ${ }^{65,66}$ for transporting PTX across the blood-brain barrier (BBB) in a glioma model of disease ${ }^{65}$. Cyclic Arg-Gly-Asp (cRGD) was chosen as the ligand to selectively target overexpressed $a_{v} \beta_{3}$ integrin on the surface of endothelial cells. Histidine residues were included in the sequence to provide $\mathrm{pH}$-sensitivity for efficient drug delivery. Overall, $\mathrm{pH}$-dependent release and enhanced accumulation of PTX in the glioma tissue, producing strong antitumor activities, elimination of vasculogenic mimicry (VM) channels, and a reduction in brain cancer stem cells (CSCs).

Several different types of fusogenic peptides have been investigated for their ability to induce endosomal escape and facilitate the delivery of liposomal cargo into the cytosol. Burks et al. demonstrated the functionalization of $\mathrm{pH}$-sensitive influenza-derived peptide (INF7) using a liposomal carrier for delivery of molecular imaging probes to increase the intracellular signal and probe retention ${ }^{67}$. The INF7 peptide prepared was a glutamineenriched analogue of $\mathrm{HA} 2$ that has $\mathrm{pH}$-dependent membrane-disruptive activity. Coencapsulation of INF7 and the imaging probe was found to minimize the loss of intracellular probe, thus increasing the signal-to-noise ratio and lengthening the effective time window for in vivo imaging. Su et al. reported an electrostatic-based liposomal coating with a tryptophan (W)-rich pH-sensitive peptide ${ }^{68}$. The basic amino acids within this sequence were responsible for the $\mathrm{pH}$-dependent behavior wherein acidification of the media caused a 2 -fold increase in calcein release rate. Recently, Gopi et al. described a pH-sensitive coiled coil peptide as a new targeted drug delivery strategy ${ }^{69}$. Coiled coils are super secondary structural motifs found in some proteins that consist of a seven residue sequence repeats that governs its stability. Incorporation of environmentally sensitive fluorescent amino acids at the hydrophobic sequence revealed stable coiled coil structure at physiological $\mathrm{pH}$, but an unfolded peptides conformation at $\mathrm{pH}$ 5.0. Enhanced internalization and colocalization of $\mathrm{pH}$-sensitive coiled coil-liposomes as observed within acidic lysosomal compartments relative to $\mathrm{pH}$-insensitive control liposomes.

13. Reversible-Bandekar et al. introduced a liposome release system where tuning of acyl-tail dynamics of gel-phase lipid bilayers of different lengths could induce the formation of discontinuous interfaces at low $\mathrm{pH}^{70}$, thereby increasing the membrane permeability by hydrophobic mismatch. They showed a broad $\mathrm{pH}$ range (4.0 to 6.7) for release, with their in vivo data for BT474 breast tumor growth being more effectively controlled using a HER2/neu pH-triggered lipid composition that exhibited at least a $16 \%$ greater tumor volume decrease relative to the control group (anti-HER2/neu Doxil).

Another $\mathrm{pH}$-reversible system based on the formulation of a host-guest supramolecular amphiphile between cyclodextrins (CDs) and an anthraquinone derivative, 1-((3(dimethylamino)propyl)amino)anthracene-9,10-dion, was reported ${ }^{71}$. This system utilized $\beta$ CDs as the hydrophilic host molecule and the anthraquinone species as the hydrophobic guest molecule. The tertiary amine and ammonium ion states of the anthraquinone guest moiety were used to switch the charge state back and forth upon change in $\mathrm{pH}$ (4.4-7.0) for 
at least 5 cycles (Figure 11). The vesicles collapsed when acetic acid was added (pH 4.4) and reappeared when the $\mathrm{pH}$ was adjusted to 7.0.

14. Fliposomes-Fliposomes were developed by incorporation of trans-2morpholinocyclohexanol-based lipids into vesicle membranes that undergo a $\mathrm{pH}$-sensitive conformational flip in acidic media ${ }^{72}$. This protonation-induced conformational switch of the headgroups produces a transient packing defect in the lipid tails, thereby causing enhanced contents leakage. Specifically, protonation of amine nitrogen in the cyclohexane forces both ester groups to flip into the axial positions due to strong hydrogen bond interactions between the morpholine and hydroxy groups (Figure 12). Amphiphiles based on trans-3,4-bis(acyloxy)-piperidine were used as the $\mathrm{pH}$-switch and displayed an instant release with an estimated conformational energy change of $\geq 10 \mathrm{~kJ} / \mathrm{mol}^{73}$. Entrapped fluorescent dye (ANTS) and quencher (DPX) were stable at $\mathrm{pH} 7.4$ but were released at $\mathrm{pH}$ $<5.6$ for liposomes containing 25-50 mol\% morpholine lipid. Recently, trans-2aminocyclodexanol (TACH) was introduced into a lipoplex formulation for gene delivery, yielding significantly enhanced $\mathrm{pH}$-dependent transfection ${ }^{74}$. The cationic lipid 1,2dioleoyl-3-trimethylamminonio-propane (DOTAP) and TACH-lipids were formulated with plasmid DNA to form with a $\mathrm{pH}$-sensitive conformational switch. Their in vitro studies exhibited up to two orders of magnitude better transfection efficiency with a similar toxicity profile as lipoplex formed with conventional helper lipids (DOPE or cholesterol). Moreover, Viricel et al. reported $\mathrm{pH}$-triggered conformational change in lipid structure using di(methoxyphenyl)-pyridine-based lipids as the switchable element for systemic drug delivery ${ }^{75}$. Overall, this strategy offers fast destabilization of the lipid bilayer through conformational flip to potentially confer rapid release properties within acidic endosomal microenvironments.

15. Poly(2-ethyl-2-oxazoline)—Poly(2-ethyl-2-oxazoline) (PEOz) is water soluble, biocompatible, non-toxic, and non-immunogenic $\mathrm{pH}$-sensitive polymer ${ }^{76}$. It has been approved for use in a food additive by the US Food and Drug Administration and possesses broad application prospects in drug delivery systems ${ }^{23,77}$. The ionizable group, $\mathrm{NR}^{3+}$, is the key motif involved in driving hydration changes from water-solubilized hydrophilic interactions to hydrophobic water-insoluble states upon protonation/deprotonation reactions as a function of $\mathrm{pH}$. The hydrophobic deprotonated polymer inserts into the lipid bilayer of liposomes, producing bilayer membrane defects. Utilization of folate-poly(2-ethyl-2oxazoline)-distearoyl phosphatidyl ethanolamine (F-PEOz-DSPE) as a part of a liposomal formulation enabled targeting of folate-receptors (FR) that are overexpressed in the tumor cells and response to the $\mathrm{pH}$ changes in the endosome ( $\mathrm{pH}$ 5.5-6.0)-lysosome ( $\mathrm{pH} 4.5-5.0)$ system. Their in vitro data revealed a cumulative DOX release of $90 \%$ in $15 \mathrm{~min}$ at $\mathrm{pH} 5.0$, whereas $48 \mathrm{~h}$ was required for $50 \%$ release at $\mathrm{pH} 7.4^{76}$. In addition, $\mathrm{Xu}$ et al. blended $\mathrm{PEtOz}$ with CHEMS (cholesterol hemisuccinate) ${ }^{23}$ or CHMC (cholesteryl methyl carbonate) ${ }^{78}$ to produce $\mathrm{pH}$-sensitive and $\mathrm{pH}$-stable systems for intracellular targeted delivery.

16. Orthoester-Lipoplex represents one of the most enhanced non-viral gene delivery system where complexes of DNA and cationic lipids are entrapped and surrounded by the liposomes that have the $\mathrm{pH}$-sensitive or trigger moieties. Briefly, cationic lipoplexes adsorb 
onto the negatively charged cell membrane which causes endocytosis that transfers the lipoplexes to endosomal/lysosomal pathways ${ }^{79,80}$. Then cationic lipoplexes exchange lipids with the negatively charged endosomal/lysosomal membranes to destabilize the complex and release encapsulated DNA into the cytosol where it must traffic to the nucleus for transgene expression. Acid-degradable polymer-caged lipoplex have also been developed for delivery of small interfering RNA (siRNA) ${ }^{81}$. Novel cationic lipids containing linear acid-labile ortho ester linkers joining the cationic headgroups and lipid tails are highly $\mathrm{pH}$ sensitive (Figure $13)^{82}$. Meanwhile, Guo and coworkers used different approach, where helper lipids (DOPE and cholesterol) were established as the lipoplex components to help destabilize the endosome membranes ${ }^{82}$. Upon acidification, the ortho ester linker was hydrolyzed thus driving a $\mathrm{L}_{\mathrm{a}}-\mathrm{H}_{\text {II }}$ phase transition. Approximately $50 \%$ of the lipoplex were hydrolyzed after incubation at $\mathrm{pH} 5.5$, whereas only $10 \%$ was hydrolyzed at $\mathrm{pH} 7.4$ for $30 \mathrm{~h}$. ANTS release rates were similar, with $>80 \%$ release occurring at $\mathrm{pH} 5.5$, whereas $<20 \%$ release occurred at pH 7.4 within $300 \mathrm{~min}$. Nguyen and coworkers prepared an expanded orthoester motif in a novel delivery platform by direct loading of siRNA into a lipoplex core consisting of $\mathrm{pH}$ responsive cationic lipid, 1,2-dioleoyl-3-dimethylammonium propane (DODAP), whose tertiary ammonium headgroup has a pKa of 6.7. Then, a biocompatible polymer shell containing Chol-PAA and acid cleavable acetal diamine linkers were constructed around the lipoplex (Figure 14) ${ }^{81}$. Acid-catalyzed cleavage of the diamine linkers released significant amounts of encapsulated dsDNAs ( $60 \%$ in $12 \mathrm{~h}$ and $100 \%$ in $80 \mathrm{~h}$ ) from the core-shell structure, while PEG-grafted DODAP lipoplex and Chol-PAA-non-acid-cleavable diamine linker-DODAP lipoplex released less dsDNAs (10\% in $12 \mathrm{~h}$ and $40 \%$ in $80 \mathrm{~h}$ ) at $\mathrm{pH} 5.5$. EGFP knockdown efficiencies were then evaluated against MDA-MB-231 breast tumor and HeLa cervical tumor cell lines. The highest EGFP knockdown efficiencies were observed for Chol-PAA-acid-cleavable diamine linker-DODAP lipoplex (46\% and 40\%, respectively), with PEG-grafted DODAP lipoplex and Chol-PAA-non-acid-cleavable diamine linkerDODAP lipoplex showing lower EGFP knockdown levels (20\% and 25\%, respectively) at $500 \mathrm{nM}$ of siRNA ( 1\% EGFP knockdown at $500 \mathrm{nM}$ of free eGFP-siRNA).

17. Vinyl Ether-Thompson and coworkers reported a family of acid-cleavable mPEGvinyl ether-1,2-dioleylglycerol lipids (mPEG-VE-DOG) with 1,2-dioleoyl-sn-glycero-3phosphoethanolamine (DOPE) to study the release kinetics of calcein during acid-catalyzed hydrolysis of the vinyl ether linkages (Figure 15$)^{83}$. Upon acidification, the PEG headgroups were detached from the fusogenic liposome surface resulting in liposome destabilization by $\mathrm{L}_{\mathrm{a}}-\mathrm{H}_{\mathrm{II}}$ phase transition. Their findings revealed that the presence of a ketene acetal linkage between DOG and mPEG moieties on 90:10 mol\% DOPE:mPEG-VE-DOG liposomes triggered the most calcein release at all $\mathrm{pHs}(>95 \%$ at $\mathrm{pH} 3.5,60 \%$ at $\mathrm{pH} 4.5,35 \%$ at $\mathrm{pH}$ 7.5 ) in $600 \mathrm{~min}$, whereas an a-methylene substituted vinyl ether linkage showed slight lower release rates (>95\% at $\mathrm{pH} 3.5,50 \%$ at $\mathrm{pH} 4.5,10 \%$ at $\mathrm{pH} 7.5)$ in $600 \mathrm{~min}$. The lowest release was observed with a-amido substituted vinyl ether linkages due to carbocation destabilization after $\beta$-carbon protonation. The pharmacokinetic profile of the liposomes stabilized with $10 \mathrm{~mol} \% \beta$-alkyl-(Z) substituted vinyl ether linkage displayed a longer circulation half-life ( $7 \mathrm{~h}, 22 \%$ in blood) than those containing $10 \mathrm{~mol} \%$ a-methylene substituted vinyl ether linkage ( $3 \mathrm{~h}, 10 \%$ in blood) at $24 \mathrm{~h}$. These findings show that the more acid sensitive mPEG-VE-DOG derivatives produced faster release rate from 
DOPE:mPEG-VE-DOG liposomes, however it negatively affected their blood circulation time in mice.

Phenyl-substituted vinyl ether (PIVE) PEG lipids have also been developed for pH-sensitive drug delivery ${ }^{84}$. Over $70 \%$ calcein release pccirred from 1,3-bis(octadecyloxy)propan-2yl(7-(((4-methoxypoly(ethylene glycol[MW2000])carbamoyl)oxy)-butoxy)-7-(4' methoxyphenyl)hept-6-en-2-y)carbamate containing liposomes (90:10 mol\% DOPE:mPEG[MeO-PIVE]-DOG), whereas liposome containing a fluorophenyl substitute (mPEG-[FPIVE]-DOG) at the same molar ratio showed $22 \%$ release at $\mathrm{pH} 4.5$ after $12 \mathrm{~h}$.

18. Hydrazone-A cell penetrating peptide formulated with a degradable hydrazonelinked PEG polymer (PEG2k-Hz-PE) was introduced as a promising way to deliver the therapeutic agents at an acidic condition ${ }^{85}$. The long PEG chains are required to retain the functionality of the cell penetrating peptides without enzymatic degradation by human plasma. However, hydrolysis of the hydrazone bonds (Figure 16) detaches the PEG coating at low $\mathrm{pH}$, enabling cell penetration of the cell membrane. In vitro studies showed superior cytotoxicity and the lowest $\mathrm{LC}_{50}$ values $(1.0,1.0,1.8 \mu \mathrm{g} / \mathrm{mL}$, respectively) at mildly acidic conditions against MCF-7, B16-F10, and HeLa cells. Recently, Ding et al. constructed CPPmodified pH-sensitive PEGylated liposomes (CPPL) to improve the selectivity for tumor targeting in a pH-dependent manner ${ }^{86}$. The PEG was conjugated with STR (stearate) via an acid-degradable hydrazone bond ( $\left.\mathrm{PEG}_{2000}-\mathrm{Hz}-\mathrm{STR}\right)$. The presence of a methylene group (electron donating) next to the hydrazine bond that facilitated hydration under mild acidic conditions contributed the stronger acid sensitivity. In vitro and in vivo studies indicated enhanced $\mathrm{pH}$-sensitivity and higher internalization efficiency while remaining inactive and free from opsonins in systemic circulation. Moreover, mPEG-hydrazone-CHEMS has been established in a dual-sensitive liposome system for vaginal drug delivery ${ }^{87}$. This formulation was designed with poloxamers to provide a thermogel property at body temperature and degradation in an acidic environment through protonation.

19. Oxime Hydrolysis-Cationic liposomes containing aminoxy-PEG (oxime) linkages have been used to formulate $\mathrm{pH}$-triggered PEGylated siRNA-nanoparticles ${ }^{88}$. The nanoparticles are formed at $\mathrm{pH} 4.0$, where oxime formation occurs between available aminoxy and aldehyde functional groups (Figure 17). Nanoparticle hydrolysis occurs at $\mathrm{pH}$ 7.0 , however, the particles are subject to acid-catalyzed condensation as surrounding $\mathrm{pH}$ is lowered until $\mathrm{pH}$ is sufficiently low for oxime formation to dominated over hydrolytic decomposition once again. The partial release of PEG starts at low $\mathrm{pH}$ and the stability of the liposome complex diminishes due to oxime hydrolysis. Then the "exposed" liposomes fuse with the endosome membranes to collapse the liposomes and release inner contents. Nonetheless, it has been suggested that oxime hydrolysis alone does not contribute to $\mathrm{pH}-$ triggered release, rather the decomposition initiates other nanoparticle structural changes simultaneously to produce the observed effects. Their data show that the nanoparticles were uniformly stable at $\mathrm{pH} 7.4$ and 4.0, but released the siRNA payloads at $\mathrm{pH} 5.5$ within 30 min. Additional studies showed $>90 \%$ of specific knockdown in $\beta$-galactosidase levels at siRNA doses of $6 \mathrm{pmol} /$ well ([siRNA] concentration $6 \mathrm{nM}$ ) or higher against the HeLa, HepG2, and Huh7 cancer cell lines. 
20. Bicarbonate- $-\mathrm{pH}$-sensitive liposomes have also been prepared using encapsulated bicarbonate ion $\left(\mathrm{NH}_{4} \mathrm{HCO}_{3}\right)$ to produce pore-forming $\mathrm{CO}_{2}$ bubbles upon acidification of the inner compartment to collapse the liposomes (Lipo-c) ${ }^{89}$. A significant increase in DOX release was observed when the $\mathrm{pH}$ was changed from 7.4 to 5.0. Only $25 \%$ DOX release occurred over $48 \mathrm{~h}$ at $\mathrm{pH} 7.4$, while $60 \%$ DOX release occurred during the first $2 \mathrm{~h}$ at $\mathrm{pH}$ 5.0. This nanocarrier showed comparable toxicity to free DOX against the MCF-7S cells (IC 50 : Lipo-c $(1.14 \mu \mathrm{g} / \mathrm{mL})$ and DOX $(1.28 \mu \mathrm{g} / \mathrm{mL})$ after $24 \mathrm{~h})$. Additionally, Lipo-c was able to better overcome during resistance in the MCF-7R cell line compared to free DOX.

21. ETC-pH-triggered release systems are not limited to systems described above. Others have investigated $\mathrm{pH}$-responsive applications using a $\mathrm{pH}$-sensitive cationic lipid (YSK05) ${ }^{90,91}, \mathrm{pH}-$ dependent ring opening reactions ${ }^{92}$, sulfadimethoxine-based $\mathrm{pH}-$ sensitive copolymer that triggers phase transitions upon ionization ${ }^{93}$, $\mathrm{pH}$-sensitive ion channels that generates temporary pores upon protonation ${ }^{94}, \mathrm{pH}$-dependent hydrolysis of Schiff bases ${ }^{95}$, iron silicate hollow nanoparticles where $\mathrm{Fe}^{3+}$ competes with $\mathrm{H}^{+}$in acidic environments to stimulate payload release ${ }^{96}$, and zinc oxide nanoparticles that dissolve and etch the liposome surface upon protonation ${ }^{97}$.

\section{Enzyme-Responsive Liposomes}

Enzyme-sensitive release systems most often employ elevated enzyme expression levels to drive biochemical transformations that can activate drug release at specific tumor microenvironments. These enzymes may serve as biomarkers for diagnostics or prognostics for tumor staging. In general, enzyme-responsive carrier systems most often rely on the cleavage of esters or amides in short peptide sequences by esterases or proteases, respectively, to release the therapeutic agent selectively ${ }^{1,17}$.

Lipid-based prodrugs have been developed by several groups to improve drug:lipid ratios and hydrophobic drug retention in liposomal formulations. Enzymatic cleavage of the prodrug produces an alteration in the lipid bilayer packing that contributes to enhanced diffusion and release. Secretory phospholipase $\mathrm{A}_{2}\left(\mathrm{sPLA}_{2}\right)$, a small and water soluble esterase, is overexpressed in several tumor environments and present in the extracellular matrix ${ }^{98}$. Among many types of lipase enzymes employed in the developmental studies, $\mathrm{PLA}_{2}$ from snake venom and human $\mathrm{SPLA}_{2}$ subtype IIA are both widely utilized. Human ${ } \mathrm{PLA}_{2}$-IIA requires a negatively charged membrane surface for its hydrolytic activity ${ }^{99}$. $\mathrm{PLA}_{2}$ enzymes hydrolyze the fatty ester group at the $s n-2$ position of glycerophospholipids, therefore the $s n-1$ position is where most prodrugs are attached (Figure 18). Andersen and coworkers have explored several structural modifications at the $s n-1$ position of lipid in an effort to reveal the best drug release profile from the liposomes. They used purified snakevenom $\mathrm{SPLA}_{2}$ and showed the ability of capsaicin to be released through prodrug activation via an intramolecular cyclization process ${ }^{100}$. Their findings showed that $90 \pm 11 \%$ release was achieved within $24 \mathrm{~h}$ and no uncyclized lysolipid was detected. Furthermore, efforts to study the efficacy of two synthetic lipophilic methotrexate (MTX)-analogues upon exposure to $\operatorname{sPLA}_{2}$ (snake venom and human tear fluid)-catalyzed hydrolysis have been reported ${ }^{101}$. One analogue had a $\mathrm{C}_{16}$-alkyl chain attached to the MTX $\gamma$-carboxylic acid and a benzyl group attached to the a-carboxylic acid, while the other analogue had only the $\gamma$-carboxylic 
$\mathrm{C}_{16}$-alkyl chain. Two different cell lines were used to elevate the effectiveness of sPLA ${ }_{2}$ mediated hydrolysis of these prodrugs: KATO III cells that secrete sPLA $\mathrm{P}_{2}$ and HT-29 cells that do not secrete $\mathrm{SPLA}_{2}$. The MTX-containing $\gamma$-alkylated compound showed cytotoxicity against KATO III ( $\left.\mathrm{IC}_{50}: 55 \mathrm{nM}\right)$ and $\mathrm{HT}-29\left(\mathrm{IC}_{50}: 400 \mathrm{nM}\right)$ at levels that were equally toxic as free MTX, whereas the additional benzyl group rendered the compound nontoxic.

Subsequent in vivo studies used the $\gamma$-alkylated compound, however, the results did not correlate with $\mathrm{SPLA}_{2}$-mediated hydrolysis. Their findings suggested that the alkylated MTXanalogue was available for cancer cell uptake even in the absence of liposome hydrolysis due to exchange of the lipophilic MTX-analogues from the host liposome into the plasma membrane of the target cells, where they then undergo hydrolytic activation by intracellular $\mathrm{PLA}_{2}$.

A detailed study of the mechanistic properties of $\mathrm{sPLA}_{2}$-mediated hydrolysis has been reported using the thio-ester pro-anticancer ether lipid (S-ProAEL) ${ }^{102}$. Even though the thioester analogues are aligned in the catalytic site cavity to allow a water molecule to access the activation region to execute the lipid hydrolysis, this team found that the prodrug lipid experienced a slower hydrolysis rate than the natural phospholipid DSPG. Since chemical hydrolysis is the rate-limiting step in this interfacial catalysis, these findings were initially attributed to less efficient binding at the active site. More detailed follow up studies revealed that the inherent electronic differences between oxygen and sulfur were the biggest factor. The sulfo-ester has a higher energy barrier for tetrahedral intermediate formation than the corresponding oxo-ester (i.e., $\Delta \mathrm{G}$ was $12 \mathrm{~kJ} / \mathrm{mol}$ more favorable for the oxo-ester compared to the sulfo-ester).

Once the liposomes containing lipase-sensitive lipid prodrugs are hydrolyzed, fatty acid (FAs) and lysolipid (LLs) byproducts are formed. These metabolites are cytotoxic in $\mu \mathrm{M}$ concentrations and can cause programmed cell death (apoptosis) ${ }^{103}$. Clausen and coworkers constructed $\mathrm{sPLA}_{2}$-degradable retinoid-phospholipid prodrugs where $\mathrm{C}_{6}$-linkers were inserted between the lipid backbones and the all-trans retinoic acid (ATRA) prodrug moiety to overcome steric hindrance between ATRA and the enzyme active site in a systemic release application ${ }^{104}$. Upon $\mathrm{SPLA}_{2}$ activation, all of the prodrugs displayed $\mathrm{IC}_{50}$ values below $10 \mu \mathrm{M}$ in HT-29 cells. The cleaved lysolipids were also found to be cytotoxic, with the $s n$-1-ester lysolipid and $s n$-1-ether lysolipid displaying $\mathrm{IC}_{50}$ values close to $10 \mu \mathrm{M}(7 \pm 1$ and $11 \pm 6 \mu \mathrm{M}$, respectively) against HT-29 cells.

An improved lipid-prodrug liposomal formulation based on a sPLA 2 -hydrolyzable DPPC (1,2-dipalmitoyl-sn-glycero-3-phosphocholine) matrix lipid and a PEG-lipid fraction to accelerate the hydrolysis rate ${ }^{99}$. DPPC $\left(\mathrm{Tm}=41^{\circ} \mathrm{C}\right)$ was selected to provide a higher degree of membrane defects in the membrane to enhance the hydrolysis rate since PLA 2 is known to preferentially bind at defect sites. They found that DPPC-(C6-RAR prodrug) (1-Ostearyl-2-RAR-C6-sn-glycero-3-phosphoglycerol) bilayers showed a fast $\mathrm{SPLA}_{2}$-mediated activation with no initial lag-phase. The calcein release profile exhibited three phases: an initial fast release, a lag-phase, and a slower release regime. Enhanced calcein release rates and efficiencies were observed when the fraction of the prodrug in the mixtures was high (50 mol\%: 83\% release, $30 \mathrm{~mol} \%$ : $63 \%$ release, $10 \mathrm{~mol} \%: 30 \%$ release after $5 \mathrm{~min}$ ). The PEGlipids were found to shorten the lag-time of $\mathrm{SLA}_{2}$ activity by promoting strong binding of 
the cationic $\mathrm{SPLA}_{2}$ enzyme with the negatively charged PEG-lipid membrane. NonPEGylated liposomes (DPPC/prodrug, 7:3) required $72 \mathrm{~h}$ to achieve complete hydrolysis, whereas PEGylated liposomes required significantly shorter times (mostly $2 \mathrm{~h}$ ).

Additionally, increased temperatures $\left(36-41^{\circ} \mathrm{C}\right)$ and the presence of the negatively charged phospholipid, phosphatidylglycerol (PG), were found to boost human $\mathrm{SPLA}_{2}$ in this system $^{105}$.

Zhu et al. have used liposomes with mixed FA acyl chain lengths (C15:0/16:0) to produce membranes with different chain lengths $\left(\mathrm{C}_{31} \mathrm{PM}\right.$ and $\left.\mathrm{C}_{31} \mathrm{PC}\right)$ in an effort to achieve faster degradation of the lipid-based drug-carriers via different chain lengths ${ }^{106}$. Their study revealed that incorporation of 10 or $30 \mathrm{lipid}$ mol\% $\mathrm{C}_{31} \mathrm{PM}$ within the liposome formulation produced enhanced $\mathrm{SPLA}_{2}$-mediated release of 6-carboxyfluorescein (6-CF) (approximately $70 \%$ and $80 \%$ within first 4 hours, respectively) compared to the control liposomes ( $<2 \%$ until $48 \mathrm{~h}$ ). Liposomes containing 30 or 90 lipid mol\% of $\mathrm{C}_{31} \mathrm{PC}$ also showed greater or equal release (approximately $70 \%$ and $80 \%$ within first 4 hours, respectively) to those incorporating 10 lipid mole\% of DSPG (approximately $70 \%$ within first 4 hours).

Recently, Lu and coworkers demonstrated an application of DNA-PLA 2 conjugates to induce the rupture of DPPC-based liposome for multimodal detection ${ }^{107}$. The uranin loadedliposomes showed controlled release beginning after $15 \mathrm{~min}$ and reached a plateau after 40 min in the presence of $16 \mathrm{nM} \mathrm{PLA}_{2}$. Zhang and coworkers incorporated chitosan-modified gold nanoparticles (AuChi) onto anionic liposome surfaces to stabilize them against fusion activity and payload leakage, while remaining sensitive to $\mathrm{PLA}_{2}$ for triggered release ${ }^{108}$. The drug release rate correlated to the $\mathrm{PLA}_{2}$ concentration, such that 5, 50, and $67 \%$ rhodamine $B$ release was effected using 1,10 , and $100 \mu \mathrm{g} / \mathrm{mL}$ of $\mathrm{PLA}_{2}$, respectively, within $24 \mathrm{~h}$. Moreover, enhanced antimicrobial activity (4-fold) was shown using doxycyclineloaded AuChi-liposomes against H. pylori bacteria when compared to doxycycline-loaded AuChi-liposomes with $\mathrm{PLA}_{2}$ inhibitor.

A new polymer unmasked-masked protein therapy (PUMPT) ${ }^{109}$ delivery system has been introduced that mimics the action of the cascade releasing liposome system of Wymer et $a l^{10}$. This mechanism uses a dextrin-degrading agent. Dextrin initially masks the PLA 2 to reduce non-specific hemolytic activity. Once the dextrin is degraded in the presence of aamylase, the active $\mathrm{PLA}_{2}$ is released to engage in lipase-mediated liposome disruption to deliver the liposome-encapsulated therapeutic agents. Griffiths and coworkers used timeresolved small-angle neutron scattering (SANS) as a tool to analyze the structural details of the liposomes and their release characteristics ${ }^{109}$. In their study, substantial changes in the scattering intensity were observed in the native $\mathrm{PLA}_{2}\left(h_{66}-\mathrm{DPPC} / \mathrm{PLA}_{2} / \mathrm{D}_{2} \mathrm{O}\right)$ and unmasked $\mathrm{PLA}_{2}\left(h_{66}\right.$-DPPC/dex-PLA $/$ /amylase/ $\left.\mathrm{H}_{2} \mathrm{O}\right)$ samples, indicating the liposome breakage, however, changes were not observed in the masked $\mathrm{PLA}_{2}$ (dextrin-PLA 2 conjugate) or dextrin control.

Another class of phospholipases that act by hydrolyzing the glycerophosphate ester bond, phospholipase C (PLC), have been used to catalyze membrane fusion activity as a consequence of PLC action to promote intracellular drug delivery ${ }^{111}$. PLC-mediated membrane fusion was highly dependent on the lipid composition and $\mathrm{pH}$. Diacylglycerol 
(DAG), the direct products of PLC-mediated phospholipid hydrolysis, is an $\mathrm{H}_{\text {II }}$ phase lipid that destabilizes bilayer structures and mediates fusion between cell membranes and liposomes (maximized at around pH 5.0).

Matrix metalloproteases (MMPs) have attracted a great deal of attention in prodrug activation schemes due to their ability to degrade extracellular matrix (ECM), a process that is involved in angiogenesis, invasion, and metastasis of malignant tumors ${ }^{1,}{ }^{17}$. Specifically, type IV collagenases (MMP-2 and MMP-9) have played major roles in the development of triggered release systems ${ }^{112}$. Banerjee et al. demonstrated the release of liposomal contents using the cancer-associated enzyme matrix metalloproteinase-9 (MMP-9) ${ }^{113}$. Relatively high levels of MMP-9 within cancerous tissues could trigger drug release from liposomes that have been designed to release their cargo upon lipopeptide cleavage. In this study, a synthetic collagen-mimetic triple-helical lipopeptide bearing a MMP-9 cleavage site was shown to release $40 \%$ CF upon exposure to MCF7 breast cancer cells having high level of MMP-9, whereas less than 10\% release occurred in the presence of HT-29 colon tumor cells displaying low levels of MMP-9. Incorporation of a reduction-sensitive PEGylated lipid (POPE-SS-PEG 5000 ) within the liposome formulation leads to a reduction in the interfacial tension and hinders protein adsorption on the liposome surface. Selective removal of the PEG groups in the vicinity of the extracellular microenvironment of tumors having elevated levels of GSH facilitates the hydrolysis of the lipopeptide by MMP-9, leading to the destabilization and release encapsulated contents ${ }^{114}$. Improved release properties (2- and 9fold) were observed with both GSH $(50 \mu \mathrm{M})$ and MMP-9 $(2 \mu \mathrm{M})$ treatments compared to GSH only (50 and $2 \mu \mathrm{M}$, respectively). Moreover, PEGylated MMP-9 responsive liposomeencapsulating gemcitabine was able to decrease the PANC-1 tumor volumes effectively (1.5and 2-fold) compared to negative and positive controls (PBS and gemcitabine encapsulatedPEGylated liposome, respectively). In addition, Xu et al. designed a DTX-loaded nano delivery system with reduction (GSH)- and enzyme(MMP-9)-sensitive properties ${ }^{115}$. Incorporation of mPEG-SS-vitamin E succinate (PSV) into $\mathrm{mPEG}_{1000}-\mathrm{MMP}-9$ responsive peptide-vitamin E succinate (PPV)-based liposomes led to enhanced DTX release when the liposomes were pretreated with MMP-9. Complete cumulative release was achieved with 50 nM MMP-9 and $10 \mathrm{mM} \mathrm{GSH}$ after $10 \mathrm{~h}$, whereas the same treatments with non-reductive liposomes did not cause extensive release over the same time period. Moreover, tumor volume reductions were about $81 \%$ and $92 \%$, respectively, compared to the saline control group.

Recently, Sun and coworkers developed an enzymatically cleavable PEG-MMP-2-lipid for higher gene expression ${ }^{112}$. In order to complete the delivery system, they inserted a PEGylated MMP-2-substrate peptide/cholesterol (PPC) into the anionic adenovirus-based liposomes using the post-insertion method. They were able to enhance luciferase activity in cells treat with the MMP2-activatable liposomes over non-cleavable PEG-modified liposomes and naked vectors (adenovirus 5). The levels of innate immune response (IL-6) decreased by about a factor of 1.7 relative to naked adenovirus, with concomitant reduction in liver toxicity due to reduced hepatic uptake (1.2-1.7-fold reduction).

Controlled release of nucleic acids in tumors was reported by Yingyuad et al., who developed PEG-peptidyl lipids that were sensitive to elastase and MMP-2-mediated 
enzymatic dePEGylation (Figure 19) to promote release of siRNA ${ }^{116}$ and pDNA $^{117}$ from the endosomal compartment. The transfection efficiencies on MCF-7 cells increased about 10fold relative to control lipoplex and 2-3-fold relative to non-cleavable lipid-modified PEGylated nanocarriers. In HT 1080 cells, the enhancements were about 1.2-2.5-fold and 3-10-fold, respectively ${ }^{117}$.

A cell-penetrating TAT peptide (TATp) was modified with a 'short' PEG-PE lipid ( $\mathrm{PEG}_{1000^{-}}$ PE) for liposome incorporation ${ }^{118}$. The peptide contained two positively charged amino acids (arginine and lysine) to make it susceptible to cleavage by proteolytic enzymes. The PEG was tuned to avoid extra shielding toward proteolysis activity, since increasingly longer PEG blocks (2000 and 5000) and higher molar ratios were found to gradually decrease TATp enzymatic cleavage (20 mol\%: $90 \%$ and $80 \%, 40 \mathrm{~mol} \%: 80 \%$ and $65 \%, 80 \mathrm{~mol} \%: 55 \%$ and $30 \%$, respectively). Although significant toxicity as observed with TATp-modified liposomes against B16-F10 and HeLa cancer cell lines (43\% and 61\% viability, respectively), were liposomes pre-exposed to trypsin $(0.1 \mathrm{mg} / \mathrm{mL})$ for $1 \mathrm{~h}$ before $24 \mathrm{~h}$ cell incubation (no TATp, non-targeted) were not cytotoxic (100\% viability for both).

Song et al. described the cathepsin B-responsive stabilized plasmid-lipid particles (SPLPs) to overcome the limited endosomal escape and enhance the transfection efficiency ${ }^{119}$. The introduction of enzymatically-cleavable peptide linkers, GFLG (Gly-Phe-Leu-Gly), that act as recognition sequences make liposomes feasible to degradation by the endo-lysosomal enzyme, cathepsin B. Upon the linker cleavage, protective PEG layers detach and directly affect the stability of SPLPs to induce the collapse and controlled release of the encapsulated pDNA into cytoplasm. The luciferase assay confirmed 100 times higher transfection efficiency at pDNA concentration of $>0.38 \mu \mathrm{g} /$ well compared to control which lacks the enzymatic recognition sequences. Wang et al. demonstrated the utilization of recombinant protein tetra-H2A $(\mathrm{TH})$ as nucleic acid condensing agent and cathepsin D-responsive unit for improved targeted silencing efficacy ${ }^{120}$. TH is derivative of histone H2A consisting 4 tandem repeats and intervened by the cathepsin D cleavage sites. It was observed that multimeric feature of TH provided higher molecular weight which enhanced the binding affinity between the condensing agents and nucleic acid carriers and complete condensations of pDNA at N/P ratio of 2.5:1. In addition, presence of cathepsin cleavage sites enabled to show > 1.6-fold enzyme-triggered decondensation profile when compared to control which lacks the enzymatic recognition unit. In agreement, increased siRNA silencing efficiency (> 1.3-fold) was observed while cytotoxicity was negligible in H460-luc bearing mice.

Kim and coworkers reported a glucose-triggered releasing mechanism using liposomes that incorporated poly( $\mathrm{N}$-isopropylacrylamide-co-methacrylic acid-co-octadecylacrylate) (P(NIPAM-co-MAA-co-ODA)) (Figure 20) and glucose oxidase (GOD) ${ }^{121-123}$. GOD oxidizes glucose to gluconic acid, thus creating an acidic medium that protonates the MAA residues and diminishes their electrostatic repulsions (Figure 21). As a result, the enzyme actuated conformational changes (swelling and the de-swelling) of the $\mathrm{pH}$-sensitive polymer induces liposomal contents release. EPC liposomes bearing polym-GOD were able to achieve $56 \%$ calcein release, while DPPC liposomes bearing polym-GOD reached only $24 \%$ calcein release using glucose concentrations of $200 \mathrm{mg} / \mathrm{dL}$ over $90 \mathrm{~min}^{121}$. In parallel, Jang et al. demonstrated the triggered rupture of polymersomes comprised of poly(ethylene 
oxide-b-butadiene amphiphilic diblock copolymers through a two step cascade of enzymatic reactions ${ }^{124}$. The first enzymatic reaction involves hydrogen glucose oxidase (GOx), which subsequently generates hydrogen peroxide $\left(\mathrm{H}_{2} \mathrm{O}_{2}\right)$ that is converted by catalase-loaded polymersomes, to induce cargo release by oxygen radical-mediated rupture.

A glutathione reductase and disulfide-linked polymer-oligopeptide conjugate (PMA-KP9) were co-encapsulated into liposomes to deliver cargo via an enzyme-responsive cascade release system ${ }^{125}$. Glutathione is an essential cellular antioxidant to prevent free radical damage that also cleaves disulfide (S-S) bonds. The reduced sulfhydryl form of glutathione (GSH) can be obtained from oxidized glutathione disulfide (GSSG) through glutathione reductase (GR) activity. Encapsulated GR catalysis converted glutathione disulfide (GSSG) to its sulfhydryl (GSH) form with subsequent GSH-mediated cleavage of the peptide conjugate disulfide linkages to release encapsulated oligopeptides (Figure 22). The enzyme cascade system induced 50-70\% release, compared to control samples where only 10-20\% release after $24 \mathrm{~h}$ at $37{ }^{\circ} \mathrm{C}$ was observed. It should be noted that conversion of GSSG to GSH only occurred at $37^{\circ} \mathrm{C}$.

The use of bolaamphiphiles (compounds containing two hydrophilic headgroups that can be symmetric or asymmetric at each end of an alkyl chain as a drug carrier was reported (Figure $23)^{126}$. The asymmetric compounds were shown to form spherical vesicle with greater in vivo stability than those formed with symmetric bolaamphiphiles, because of better molecular packing that can accommodate the different curvature radii of the outer and inner membrane surface of monolayer membranes. The monolayer vesicles were disrupted when the choline ester headgroups were hydrolyzed by AChE (acetylcholine esterase), an enzyme of the central nervous system (CNS) (Figure 24). When AChEs were added to each batch of empty and acetylthiocholine-encapsulated vesicles, the latter construct showed 2-fold higher absorbance at $412 \mathrm{~nm}$. In vivo data showed a 2.3 -fold increase in fluorescence values in brain homogenates treated with FITC-dextran-encapsulated vesicles compared to empty vesicles plus an equivalent amount of non-encapsulated FITC-dextran.

Low molecular weight heparin (LMWHEP) was formulated with liposomes to act as a targeting and triggering moiety for lymph node metastasis ${ }^{127}$. The biodegradable, negatively-charged, and hydrophilic polysaccharide-based LMWHEP coats the surface of positively charged liposomes to promote the lymphatic drainage of LMWHEP-LP from interstitial sites into the lymphatic circulation. Next, LMWHEP binds with heparanase (HPA) secreted by metastatic tumor cells, to improve metastatic lymph node retention and uptake due to the heparin-degrading activity of HPA. A DTX-release study showed HPAdependent release, where the presence of $64 \mathrm{U} / \mathrm{mL}$ of enzyme promoted enhanced drug release (3.9- and 1.7-fold) compared to $4 \mathrm{U} / \mathrm{mL}$ and no HPA, respectively, after $12 \mathrm{~h}$. The in vivo targeting ability of LMWHEP-LPs to metastatic lymph nodes was evaluated. The AUC was found to be significantly higher than the DTX-LPs in the metastatic popliteal lymph node (3.1-fold increase) and in metastatic iliac lymph nodes (3.2-fold increase). 


\section{Redox-Responsive Liposomes}

Redox-responsive liposomes have been reported that use electron-transfer reactions to trigger drug delivery. Vesicles of this type have been destabilized by changes in charge and/or hydrophilicity of the amphiphile, chemical reducing agents, or removal of cross-links to drive phase transitions of the lipid system ${ }^{128}$. The high redox potential differences (100to 1000-fold) existing between the reducing environment of intracellular space and the more oxidative extracellular environment can serve as an activating stimulus for both tumor targeting and intracellular drug delivery ${ }^{1,129}$. The most common redox activation system involves the use of disulfide linkages within amphiphile that can be disrupted by powerful thiolytic reducing agents, such as dithiothreitol (DTT) (Figure 25). Upon the reduction, the critical micelle concentration (CMC) of the thiolytically cleaved amphiphile byproducts are typically increased ${ }^{128}$. A related strategy involves reductive fragmentation of the headgroups in fusogenic liposomes, leading to the aggregation and fusion of the activated liposomes and subsequent contents release ${ }^{128}$.

Candiani et al. performed a study using a liposome containing the redox-sensitive triazine based surfactant, SS14 (Figure 26), for the gene delivery. The disulfide linker in SS14 promotes the lipoplex destabilization through cleavage of the surfactant to single-chain amphiphiles in response to a reducing environment ${ }^{129}$. The presence of unsaturated acyl (dioleoyl) chains in the lipid, combined with PE polar headgroups, promoted cargo delivery via fusion processes that were facilitated by lamellar-to-hexagonal phase transition. An optimized liposome formulation (DOPC/DOPE/SS14; 16.7:33.3:50 molar ratio) was created to give the maximal transfection efficiency (2.7-fold higher than that of the control, Lipofectamine 2000, against U87-MG tumor cell lines. Furthermore, they demonstrated the unique role of glutathione (GSH) activation in the disulfide-containing lipoplex by mediating amphiphile cleavage and DNA release. The study showed a linear correlation between GSH content and transfection efficiency $\left(\mathrm{r}^{2}: 0.94, p<0.05\right)$ in MG 63 cancer cells transfected with bioreducible (DOPC/DOPE/SS14; 16.7:33.3:50 molar ratio)-lipoplexes. On the other hand, He and coworkers used GSH to activate redox-responsive targeted delivery by detaching disulfide-linked PEG layers to expose the cell-penetrating peptides (CPPs) moieties from the liposomes ${ }^{130}$. In response to changes in reductive potential at tumor site by exogenous reducing agent (GSH), PEG-detachment allow for the CPP-decorated liposomes to facilitate cell internalization and lysosomal escape. Increases in B16F1 cellular uptake (4.5-fold) were observed for disulfide-linked PEG-CPP-liposomes treated with GSH compared to disulfide-linked PEG-CPP-liposomes alone. In addition, uptake of disulfidelinked PEG-CPP-liposomes by B16F1 tumor spheroids in the presence of GSH showed 3.5fold higher internalization than disulfide-linked PEG-CPP-liposomes alone, indicating that steric hindrance by PEG was removed in the presence of GSH, thus this increasing the penetration of CPPs into the spheroids. Moreover, the cytotoxicity of disulfide-linked PEGCPP-liposomes was greatest (50\%) in B16F1 cells with $25 \mu \mathrm{M}$ PTX and $10 \mathrm{mM}$ GSH over $18 \mathrm{~h}$. Tumor volumes in mice treated with PTX-disulfide-linked PEG-CPP-liposomes were drastically reduced by $34.3 \%$ compared with non-cleavable PTX-PEG-CPP-liposomes.

Another thiol-triggered release mechanism was reported in a study of click-chemistry based polymerized liposomes ${ }^{131}$. The polymerization was accomplished through $\mathrm{Cu}(\mathrm{I})$-catalyzed 
click reaction, while depolymerization was achieved by cleaving the disulfide or ketal bonds embedded within the azide-containing cleavable linkers (Figure 27) upon addition of DTT or weakly acidic agents. Rapid CF release was observed upon DTT addition (up to 4.5 -fold increase) and the release profiles were nearly identical to those before polymerization. The explanation for the fast release behavior was based on the method of polymerization. Since the water-soluble copper catalyst was added after the formation of the liposomes and is not believed to easily permeate the bilayers, the polymerizations were anticipated to occur predominantly on the external leaflets of the bilayers. Therefore, these external disulfide groups were more prone to the external stimuli to cause the triggered-release than those in the interior.

Further, dual-activated liposomes bearing synthetic functional lipid 2-[2-(2carboxylcyclohexylformamido)-3,12-dioxy-1-(1H-imidazolyl-4)-7,8-dithio-4,11diazapentadecylamide]-glutaric acid ditetradecanol-diester (HH-SS-E2 $\mathrm{C}_{14}$ ) have been reported for enhanced antitumor efficacy after acid and redox activation ${ }^{63}$. HH-SS-E2 $\mathrm{C}_{14}$ contains histidine and one acid-cleavable group (hexahydrobenzoic (HHB) amide) as a hydrophilic block, and two tetradecyl chains as a hydrophobic block that were linked by a redox-sensitive disulfide bond. Protonation of the imidazole group initiates proton influx into the endocytic vesicles, followed by endo-lysosomal rupture due to increase in osmotic pressure and endo-lysosomal escape into the cytoplasm. Once the liposome contents migrate into the endosome, the higher GSH content there cleaves the disulfide linkage in HH-SS$\mathrm{E}_{2} \mathrm{C}_{14}$, leading to a prompt burst release. Their data showed a linear correlation behavior between GSH concentration and the extent of HH-SS- E2 $\mathrm{C}_{14}$ cleavage, wherein $4 \%, 30 \%$, and $70 \%$ of the linkages were cleaved after incubation with GSH at concentrations of 10 $\mu \mathrm{M}, 1 \mathrm{mM}$, and $10 \mathrm{mM}$, respectively. The cumulative amount of DOX released from DOX/HH-SS-E2 $\mathrm{C}_{14}$ was found to be $\sim 60 \%$ and $70 \%$ after incubation with $10 \mathrm{mM} \mathrm{GSH}$ at $\mathrm{pH} 7.4$ and 5.5 for $4 \mathrm{~h}$, respectively. Next, DOX/HH-SS-E2 $\mathrm{C}_{14}$ produced a stronger therapeutic response by providing total apoptotic ratio of $18.1 \%$, nearly a 2 -fold increase relative to $\mathrm{DOX} / \mathrm{HH}$, against HepG2 cells. These findings are consistent with a mechanism involving fast intracellular drug release, leading to elevated induction of tumor cell apoptosis. Reduction-cleavable cationic lipids (LHSSG2C ${ }_{14}$ ) have also been used to fabricate dual-functionalized cationic liposomes with redox responsiveness and clickability for siRNA delivery ${ }^{132}$. siRNA release was only observed when both HAase $(0.5 \mathrm{mg} / \mathrm{mL})$ and GSH $(10 \mathrm{mM})$ were present in the media.

McCarley and coworkers utilized a quinone propionic acid moiety as a lipid headgroup to trigger the destructive aggregation of liposomes via quinone reduction. Intramolecular cyclization upon two-electron reduction led to linker cleavage, followed by a lamellarinverted hexagonal-phase transition (Figure 28) ${ }^{128}$. In recent studies, they incorporated a quinone-dioleoylphosphatidylethanolamine lipid conjugate (Q-DOPE) for initiating calcein release upon reduction ${ }^{133}$. Burst release was achieved within 30 min after sodium dithionite addition at $\mathrm{pH}$ 7.4. Salt influences in these Q-DOPE liposomes has also been described ${ }^{134}$. Ion accumulation near the lipid headgroups of lipid due to ion-partitioning effects or nonelectrostatic dispersion forces were observed. The authors hypothesized that the presence of anions having varying polarizabilities/hydration levels would influence the aggregation and contents release from reduced Q-DOPE liposomes in a manner that would be dictated by the 
Hofmeister series. Their data show that less polarizable/more hydrated anions produced a faster initial calcein release rate (largest increase by 5.5 -fold), which directly correlated with a faster aggregation rate. Additionally, evaluation of kinetic parameters $\left(\mathrm{K}_{\mathrm{m}}, \mathrm{V}_{\mathrm{max}}, \mathrm{k}_{\mathrm{cat}}\right.$, $\mathrm{k}_{\text {cat }} / \mathrm{K}_{\mathrm{m}}$ ) for the human recombinant $\mathrm{NAD}(\mathrm{P}) \mathrm{H}$ :quinone oxidoreductase type I (NQO1) catalyzed by NADH cofactor was performed ${ }^{135}$. Since reduction of quinone propionic acids were shown to function as a triggering stimulus, the overexpression of human NQO1 in tumor cells qualified as a valuable target for reductive activation. Their mechanistic study illustrated the variations in enzyme-substrate steric interactions where more active moieties were able to penetrate more deeply into the active site.

Chemical oxidation of a redox-active, ferrocene-functionalized cationic lipids, bis(11 ferrocenylundecyl)dimethylammonium bromide (BFDMA) (Figure 29), that dissolves into smaller aggregates and micelles after oxidation has also been reported as a transfection agent ${ }^{136}$. Transgene expression levels were highly dependent on the oxidation state of the ferrocenyl groups. The lipoplexes formed using chemically-oxidized BFDMA showed the highest levels of transfection (7.0E+06 RLU/mg protein) than electrochemically-oxidized BFDMA $(<1.0 \mathrm{E}+01 \mathrm{RLU} / \mathrm{mg}$ protein) in COS-7 cells. The enhancement originated from the residual iron ions $\left(\mathrm{Fe}^{2+}, \mathrm{Fe}^{3+}\right)$ in the solution of chemically-oxidized BFDMA that caused the positive surface charges. The positive surface charges of lipoplexes can affect the efficiency of cell transfections by promoting the cell membrane interaction and internalization. The reversible mechanism illustrated the usage of Fe(III) sulfate as a chemical oxidant capable of stimulating rapid DNA release into the cells.

Bhattacharya and coworkers developed lipopolymers based on redox-active low molecular weight, branched polyethylenimine (BPEI $800 \mathrm{Da}$ ) that were hydrophobically modified using ferrocene terminated alkyl tails ${ }^{137}$. Liposomes bearing the lipopolymer and a helper lipid, DOPE, showed excellent pDNA delivery capability in HeLa and U251 cell lines in the presence of serum. The polymeric conjugates afforded significant levels of gene expression where BPEI-C6 spacer-ferrocene (15\% substitution), BPEI-C6 spacer-ferrocene (25\% substitution), and BPEI-C6 spacer-ferrocene (50\% substitution) showed 230-, 170-, and 80fold increases, respectively compared to native BPEI, whereas BPEI-C11 spacer-ferrocene (15\% substitution), BPEI-C11 spacer-ferrocene (25\% substitution), and BPEI-C11 spacerferrocene (50\% substitution) afforded 180-, 50-, and 30-fold increases, respectively. The lipopolymeric formulation, BPEI-C6 spacer-ferrocene (15\% substitution) with a lipopolymer/DNA (w/w) ratio of 4 showed maximum transfection capability with 10-fold higher luciferase activity than BPEI (25 kDa) and improved performance compared to Lipofectamine 2000. Transformation of a hydrophobic ferrocene [Fc(II)] to a hydrophilic ferrocenium $[\mathrm{Fc}(\mathrm{III})]$ was utilized to control the aggregation properties. The oxidation of ferrocene in the lipopolymer drastically reduced levels of gene transfection due to increase in the size and zeta potential (formation of ferrocenium ions) of the redox lipopolymeric aggregates. The transfection activity of the inactive oxidized lipopolyplexes could be resumed by the ascorbic acid (AA) that acts as a reducing agent. Similarly, redox-active monomeric and dimeric (gemini) cationic lipids based on ferrocenylated cholesterol derivatives were introduced for gene delivery ${ }^{138}$. Herein, the redox-active ferrocene group was attached as a cationic headgroup on the cholesterol A ring. Maximum transfection 
efficiencies were reached at DOPE/cationic cholesterol ratios of 2.5 and 4. Cationic lipid/ pDNA ratios of 1 and 0.5 for monomeric and gemini cholesterols, respectively, were used.

\section{Light-Responsive Liposomes}

Light can also be used as a physical stimulus to initiate the release of liposome-encapsulated molecules on demand. To use the light as a trigger, activating photons must safely pass through the biological tissues to initiate the release process. Light in the 600-900 nm wavelength range is transmissible deep into biological tissues due to low scattering and small absorption coefficients ${ }^{139}$. Photodynamic therapy (PDT), a therapeutic modality for cancer treatment, involves the use of photosensitizing agents that can be activated using different wavelengths, intensities, or pulse durations to achieve direct cell killing or selective drug release from a carrier system ${ }^{1,17}$. Light absorption by the photosensitizer acts as an energy transducer such that energy transfer to molecular oxygen leads to the formation of reactive species (ROS) that can subsequently react with the liposomes to induce contents release or directly attack target tissues to initiate apoptotic and necrotic cellular responses $^{140}$. Since most photosensitizers are hydrophobic, nanopreparations such as liposomes and micelles are widely used for enhancing the stabilization and tumor targeting of these agents. Light-induced reactions can involve either the irreversible modification (photocleavage) of a reactive amphiphilic molecule or reversible conformational changes in the lipids to trigger release via a localized increase in membrane permeability (Figure $30)^{141}$. PDT is a clinically approved therapeutic modality that can also provide diagnostic information, specific targeting events, and the possibility for combination with other therapies.

Light-sensitive liposomes can be prepared using photo-polymerizable phospholipids such as $\mathrm{DC}_{8,9} \mathrm{PC}$ (1,2-bis(tricosa-10,12-diynoyl)-sn-glycero-3-phosphocholine) ${ }^{140,142,143}$. The lateral phase separation and packing properties of polymerizable lipids in the liposome bilayer are the major determinants for photo-triggered contents release. The fatty acyl chain length and degree of unsaturation are important factors that govern the bilayer packing properties of liposomes ${ }^{140}$. UV irradiation initiates the polymerization reaction, forming chains of covalently linked lipid molecules within the bilayers, leading to defects in the liposome membrane. Puri and coworkers demonstrated that a $90 / 10$ or $80 / 20 \mathrm{~mol} \%$ DPPC/DC ${ }_{8,9} \mathrm{PC}$ ratio was optimal for effecting calcein release (100\%) in 40 and $25 \mathrm{~min}$, respectively, upon UV exposure $\left(254 \mathrm{~nm}\right.$ ). Although higher $\mathrm{DC}_{8,9} \mathrm{PC}$ compositions ( $\geq 20$ $\mathrm{mol} \%$ ) showed faster release profiles (100\% release in $15 \mathrm{~min}$ ), the significant spontaneous leakage rate of these dispersions made them unsuitable candidates for further development ${ }^{142}$. These studies were extended to probe the effects of the light-triggered release of the anticancer agent, DOX ${ }^{143}$. Laser treatment (5 min @ $514 \mathrm{~nm}$ ) on liposomal DOX showed at a least 2-3-fold improvement in cell killing compared to untreated cells after $48 \mathrm{~h}$ against the Raji and MCF-7 cell lines.

Guo et al. introduced UV cross-linkable 10,12-pentacosadiynoic acid (PCDA) into the phospholipid bilayer vesicles as tunable additives for photo release applications ${ }^{144}$. The polymerization of PCDA monomers occurs between adjacent diacetylene groups in the membrane to release entrapped molecules upon UV irradiation. This study also revealed a

Wiley Interdiscip Rev Nanomed Nanobiotechnol. Author manuscript; available in PMC 2018 September 01. 
decrease in the cumulative paclitaxel release with increasing PCDA molar ratio and irradiation time. The authors attributed these findings to an increased degree of polymerization that blocked the channels of drug-loaded polymerized vesicles. Paclitaxel release was $90.5 \pm 3.7 \%$ within $24 \mathrm{~h}$ with 20 min irradiation, whereas sudden decreases in paclitaxel release were observed when the irradiation time increased to $30 \mathrm{~min}$ and $40 \mathrm{~min}$ $(43.9 \pm 6.5 \%$ and $37.6 \pm 2.3 \%$, respectively) from vesicles containing a 1:1 molar ratio of PCDA/DSPC. It is worth noting that unpolymerized vesicles (DSPC liposomes) were ruptured upon exposure to Triton X-100, while polymerized vesicles retained their spherical structure, indicating enhanced stability through the UV-initiated polymerization.

Sine et al. further optimized a light-triggerable liposome formulatioin containing 2-(1hexyloxyethyl)-2-devinyl pyropheophorbide-a (HPPH) an anticancer photodynamic therapy drug that generates high yields of singlet oxygen ${ }^{145}$. Photoactivation of HPPH that is preferentially partitioned within the lipid bilayer causes liposomes destabilization. HPPHdependent release was found to be greater (> 3-fold) than HPPH-independent release after 5 min irradiation $(660 \mathrm{~nm}, 90 \mathrm{~mW})$; cell viability was also dose dependent with respect to HPPH concentration. A significant reduction in tumor volume (>90\%) was observed only in laser treated triple negative breast tumor-bearing mice exposed to HPPH-liposomes. Moreover, Lovell and coworkers demonstrated chemophototherapy using HPPH-lipid ${ }^{146}$ and $\mathrm{Cu} / \mathrm{Zn}-\mathrm{HPPH}$ lipid, ${ }^{147}$ a combination formulation that showed synergistic action and effect and enhanced antitumor efficacy. High amounts of HPPH-lipid cause phototoxicity under laser irradiation and can lead to dose-limit toxicities. Nonetheless, these phototoxicity effects can be reduced by chelating a metal ion $(\mathrm{Cu}$ or $\mathrm{Zn})$ that quenches singlet oxygen production $^{147}$. This finding may enable the use of large amounts of HPPH-lipid in applications safely without risk of phototoxicity.

Photosensitizers (PS) embedded in liposome membranes can destroy the phospholipid bilayers upon light exposure, leading to controlled release of encapsulated contents from liposome carrier. The chlorin-based photosensitizer, chlorin e6 (Ce6), has a high sensitizing efficacy and is rapidly eliminated from the body ${ }^{148,149}$. Bakowsky and coworkers formulated liposomes using 1,2-dioleoyl-3-trimethylammonium-propane (DOTAP) to improve Ce6 loading efficiency in the liposomal bilayer and included tetraether lipids (TELs) as a controlled release system. Their cell viability data showed a trend where dark exposure induced $40 \%$ and $60 \%$ cytotoxicity, while light treatment $\left(2.2 \mathrm{~mW} / \mathrm{cm}^{2}, 20 \mathrm{~min}\right)$ increased the cytotoxicity to $75 \%$ and $90 \%$ against SK-OV-3 and Neuro-2a cell lines, respectively. Most importantly, the in-situ chick chorioallantoic membrane (CAM) model showed effective localized vascular destruction $30 \mathrm{~min}$ post irradiation $\left(19.9 \mathrm{~J} / \mathrm{cm}^{2}\right)^{148}$. In addition, DOX and Ce6 were co-encapsulated in the liposomes to probe for synergistic toxicity effects $^{149}$. The DOX-Ce6-liposome produced higher cytotoxicity (> 3-fold) upon irradiation against different cell lines (A375 and C26), while the in vivo findings suggested a lower tumor growth rate than the physical mixture of DOX and Ce6-liposomes.

A second generation photosensitizer, m-THPC (meta-tetra[hydroxyphenyl]chlorin), has also been used in a PEGylated liposome formulation ${ }^{7,150,151}$. Aggregation of m-THPC with the lipid shell of the liposomes was observed and triggered the release of $\mathrm{m}$-THPC in the form of the monomeric photoactive state once the liposome was degraded. Optimized liposomal 
formulations consisting of $2 \%$ or $8 \%$ FosPEG was able to decrease the light-drug interval to achieve the efficient m-THPC-PDT treatment ${ }^{7}$. The FosPEGylated liposomes were able to increase m-THPC uptake (3-4.3-fold) compared to the Foscan (control) within $8 \mathrm{~h}$ in MC28 tumor tissues. The percentage of tumor necrosis area was also able to increase $\geq 10-20 \%$ for FosPEG 2\% and 8\% compared to controls with either reduced light energy or lower mTHPC doses ( $2 \mathrm{~J}$ of light at $100 \mathrm{~mW} / \mathrm{cm}^{2}$ or $0.05 \mathrm{mg} / \mathrm{kg}$ ).

Phthalocyanine photosensitizers can also be incorporated into liposomal formulations to provide tunable lipid bilayer stability and permeability. For example, aluminum phthalocyanine disulfonic acid $\left(\mathrm{AlPcS}_{2}\right)^{152}$ or trisulfonated aluminum phthalocyanine $\left(\mathrm{AlPcS}_{3}\right)^{153}$ were evaluated for their PDT activity. Singlet oxygen produced by the photosensitization reaction attacks unsaturated fatty acids to oxidize the lipids and increase membrane permeability via chain scission and/or the formation of pores (Figure 31). An $\mathrm{AlPcS}_{2}$-liposome system utilized type II photodynamic action (photosensitizer-oxygen) that led to significant increases in CF release (10-fold) over the dark reaction baseline after a 200 $\mathrm{s}$ irradiation (> $\left.590 \mathrm{~nm} @ 671 \mathrm{~nm}, 55 \mathrm{~mW} / \mathrm{cm}^{2}\right)^{152}$. On the other hand, an $\mathrm{AlPcS}_{3}$-liposome system was able to increase CF release by 3.5-fold compared to conventional liposomes (EggPC) and 1.3-fold compared to the liposome containing inactivated $\mathrm{AlPcS}_{3}$ after exposure to red light (> $580 \mathrm{~nm}, 0.4 \mathrm{~W} / \mathrm{cm}^{2}$ ) for $60 \mathrm{~s}^{153}$.

The relative photodynamic efficacy of a photosensitizer can differ significantly depending on whether the target for damage is a specific protein or a more general membrane target. Zinc phthalocyanine (ZnPC) has been used to photosensitize controlled release from liposomes. ZnPC-liposomes containing DMPC or DSPC showed various release trends for a reporter (ONPG) with different exposure light type ( $20 \%$ for red $\left(640 \mathrm{~nm}, 160 \mathrm{~mW} / \mathrm{cm}^{2}\right)$, > $13 \%$ for ambient $\left(400-700 \mathrm{~nm}, 5.6 \mathrm{~mW} / \mathrm{cm}^{2}\right)$, and $>2 \%$ for UV-A light $(\sim 365 \mathrm{~nm}, 50$ $\mathrm{mW} / \mathrm{cm}^{2}$ ) after $24 \mathrm{~h}^{154}$. In addition, the palladium-based phthalocyanine photosensitizer, $\operatorname{PdPC}(\mathrm{OBu})_{6}$, was used in a liposomal formulation to provide on-demand local anesthesia by delivering tetrodotoxin (TTX) upon near infrared radiation (NIR). Lipids containing biallylic hydrogens, 1,2-dilinoleoyl-sn-glycero-3-phosphocholine (DLPC), have also been used to increase the efficiency of the phototriggered reaction towards singlet oxygen. Under these conditions, TTX cumulative release data showed a 2-fold increase in irradiated samples (730 $\mathrm{nm}, 50 \mathrm{~mW} / \mathrm{cm}^{2}, 10 \mathrm{~min}$ ) compared to samples without light exposure after $9 \mathrm{~h}^{155}$.

Porphyrin-based photosensitizers have also been formulated with liposomes and investigated for their photocytotoxicity potential. Kozikowski et al. described a drug release mechanism based on a delayed photolysis using protoporphyrin IX (PpIX) as a photosensitizer ${ }^{156}$. The photosensitized sample in a delayed photolysis system takes advantage of two distinct steps: 1) light-initiated reaction followed by 2) thermally-initiated reaction. In an in vitro study, delayed photolysis-mediated calcein release was dependent on photosensitizer concentration where $100 \mu \mathrm{M}$ PpIX released $85 \%$ in $500 \mathrm{~min}$ and $1 \mu \mathrm{M}$ PpIX released $60 \%$ in $1600 \mathrm{~min}$ after the initial 5-min irradiation (> $600 \mathrm{~nm}$ ). Different irradiation times also created different release rates, such that longer activation times produced greater calcein release (50\% for $1 \mathrm{~min}$ and $90 \%$ for $15 \mathrm{~min}$ at $1 \mu \mathrm{M}$ PpIX). In vivo data confirmed that significant reductions in of total blood calcein levels were observed for activated PpIX-liposomes 
(controlled release) compared to the control liposomes that exhibited passive release (30\% and $60 \%$, respectively, in first $5 \mathrm{~h}$ ).

Teng et al. reported a nanoPDT system that utilized folate-targeted, phospholipid-capped, and PpIX-loaded mesoporous silica nanoparticles against folic acid receptor-presenting HeLa cells ${ }^{157}$. They observed greater (> 6-fold) intracellular delivery efficiency and decreased unfavorable dark toxicity compared to free PpIX. Their in vivo findings showed a PDT effect by showing tumor growth by nearly $65 \%$ in nude mice bearing B16F10 melanoma. Nakamura and coworkers have synthesized PpIX-lipids, that form micelles were able to demonstrated phototherapeutic effect ( $>3$-fold) by generating ROS after light irradiation $\left(88 \mathrm{~mW} / \mathrm{cm}^{2}, 2 \mathrm{~min}\right)$ in HeLa cells whether administered in micelle form or as PpIX-lipid liposomes ${ }^{158}$.

Araki et al. studied the effects of photo-triggered tumor vascular treatment (PVT) using PpIX-polymeric nanoparticles (PEG-block-polylactic acid) in Colon-26 (C26; high permeable vasculature) and B16/BL6 (B16; low permeable vasculature) tumor-bearing mice ${ }^{159}$. PVT enhanced the antitumor activity in these models by inducing apoptotic tumor vascular endothelial cell death and platelet aggregation. Recently, Basoglu et al. formulated PpIX inside of magnetoliposomes (MLs) that also contained magnetic nanoparticles $\left(\mathrm{Fe}_{3} \mathrm{O}_{4}\right)^{160}$. Hyperthermia induced by local magnetic field $(8.947 \pm 2 \%, 50 \mathrm{~Hz})$ reduced the MCF-7 cell viability to 66\% using $350 \mathrm{nM}$ PpIX-loaded MLs, however, complete cell death was observed when $250 \mathrm{nM}$ PpIX-loaded MLs were exposed to LED white light for $5 \mathrm{~min}$.

Hasan and coworkers have used benzoporphyrin derivative monoacid A (BPD) as photosensitizer in photo-immuno-conjugate-associating-liposomes (PICAL) for ovarian cancer ${ }^{161}$. They combined PDT with an antibody-based biologic treatment to trigger cell cycle arrest by blocking epidermal growth factor receptor (EGFR) activation. PICAL was able to enhance the observed photocytotoxicity by $>6$-fold compared to free BPD after irradiation $\left(10 \mathrm{~J} / \mathrm{cm}^{2}\right.$ at $\left.100 \mathrm{~mW} / \mathrm{cm}^{2}\right)$ in Ovcar-5 cell lines. Additionally, they targeted pancreatic ductal adenocarcinoma (PDAC) tissues and achieved a significant tumor regression by PDT-induced tumor cell apoptotic signaling and inhibition of VEGF signaling to suppress angiogenesis, vascular regrowth, and treatment escape pathways ${ }^{162,163}$.

Photo-controlled targeting based on the photocaging method involves the use of a photolabile protecting group to mask the adverse side effects of the agent and enhance its site specificity. Irradiation of the photocaged species leads to removal of the caging group and activation of the drug in a spatial, temporal, and concentration-dependent manner ${ }^{164-166}$. Compared with UV one-photon photolysis, near-infrared (NIR) two-photon photolysis can penetrate deep into living tissues while causing minimal tissue damage at the irradiation site. Mei and coworkers introduced a NIR two-photon photolysis system that converted a nonfunctional cell-penetrating peptide (CPP) to an active CPP by uncaging the photosensitive group (4,5-dimethoxy-2-nitrobenzyl group) from the CPP to promote siRNA delivery ${ }^{165-167}$. Inclusion of an asparagine-glycine-arginine peptide (NGR) sequence in the construct led to its improved uptake into target cells via receptor-mediated endocytosis. Decreased tumor volumes (> 1.8- and 1.5-fold) were observed using CPP/NGR-LP with NIR relative to CPP/NGR-LP without NIR and CPP-LP with NIR, respectively, in HT-1080 
tumor-bearing mice ${ }^{165}$. Additionally, vinorelbine bitartrate was incorporated into the liposome formulation to evaluate the cellular uptake and cytotoxic activity in MCF-7 cells as well as the antitumor efficacy in MCF-7 tumor-bearing mice ${ }^{47}$. Enhanced targeting efficiency using folate (FA) and controlled photocytotoxicity with photocleavable (4,5dimethoxy-2-nitrobenzyl)-Au nanoconjugates using UV light has also been reported by Fang et al. ${ }^{164}$.

Indocyanine dyes have also been extensively used for NIR-activated photodynamic therapy. Shemesh et al. optimized a thermosensitive liposome formulation using indocyanine green (ICG) to inhibit growth by MDA-MB-468 and HCC-1806 tumor cells ${ }^{168}$. Cell viability was found to be inversely dose dependent with regard to ICG concentration ( $0-37.5 \mu \mathrm{mol} / \mathrm{L})$ and irradiation energy $\left(0-14 \mathrm{~J} / \mathrm{cm}^{2}\right)$. Li et al. generated DOX-loaded stealth liposomes with heptamethine indocyanine dye IR 825 for a combined photothermal/chemo therapeutic cancer treatment ${ }^{169}$. The combined treatment improved overall HeLa cell killing efficiency ( $<20 \%$ cell viability) after $5-10 \mathrm{~min}$ of NIR irradiation $\left(808 \mathrm{~nm}, 0.5 \mathrm{~W} / \mathrm{cm}^{2}\right)$. Guo et al. designed a dual-functional thermosensitive bubble-generating liposome formulation (BTSL) with a conjugated targeted ligand (folate, FA) and photothermal agent (heptamethine indocyanine dyt IR780) to explore the effects of a targeted and controlled delivery system ${ }^{170}$. Encapsulated ammonium bicarbonate was used for generation of $\mathrm{CO}_{2}$ bubbles upon IR780-mediated photothermal heating from NIR irradiation. The resulting $\mathrm{CO}_{2}$ bubbles produce lipid bilayer defects that trigger drug release. The in vivo biodistribution of IR780-BTSL-FA showed an increased accumulation of the agent in the irradiated tumor (12.7-fold greater than free solution, 2.1-fold than IR780-TSL), with no evident side effect to normal tissues and organs. Lastly, Sano et al. introduced a monoclonal antibodyphotosensitizer (panitumumab-IR-700) conjugate for photoimmunotherapy (PIT) whose action enhanced tumor permeability and allowed greater extravasation and retention effects ${ }^{171}$. This process was most prominent in the first $6 \mathrm{~h}$, becoming less pronounced afterward in A431 tumor bearing mice. The combination of phototherapy and controlled drug delivery holds promise for maximum antitumor application while minimizing nontargeted side effects associated with conventional treatment.

Gold $(\mathrm{Au})$ is a biocompatible nanomaterial and can be designed into Au nanostructures for NIR excitation that has shown great potential for cancer photothermal therapy ${ }^{172,173}$. Recently, novel photoactive hollow, gold nanoshells (HGN) were developed to provide controlled release and specific targeting in liposome formulations. HGNs can be incorporated into liposomes by the interdigitated phase transition method, via thiol/PEGlipid linkages on the outer surface of liposomes, or by mixing preformed liposomes with HGN solutions ${ }^{174}$. Due to the ability of HGN to undergo surface plasmon resonance at NIR wavelengths, they can be coupled to liposomal formulations to provide NIR activation via femto- to nano-second pulsed laser light to rapidly produce localized heat. The resulting large temperature gradients between the HGNs and the surrounding fluids create microscopic vapor bubbles near the liposome surface. Collapse of these bubbles promotes content release by cavitative disruption on of the liposome membranes. Although the laser beam is focused on the target and the HGN heating can be intense, the surrounding environment experiences minimal heating due to the small overall energy input ${ }^{175,176}$. Irradiation with femtosecond NIR light pulses $\left(800 \mathrm{~nm},>2.2 \mathrm{~W} / \mathrm{cm}^{2}\right)$ can trigger the release 
of encapsulated contents, while control groups retained the inner contents. However, continuous-wave (unpulsed) laser irradiation $\left(800 \mathrm{~nm}, 89 \mathrm{~W} / \mathrm{cm}^{2}\right)$ was not able to induce the release even after $4 \mathrm{~h}$ of exposure due to existence of insufficient temperature gradients to create the microbubble formation (Table 1) ${ }^{174}$. Additionally, Xu and coworkers demonstrated photo-triggered release due to liposome membrane disruption from microbubble cavitation by loading hydrophilic gold nanoparticles within thermosensitive liposomes (TSL) (10 mol\% 1-palmitoyl-2-hydroxy-sn-glycero-3-phosphocholine $(\mathrm{MPPC})^{177}$.

Gold nanoparticles can also be used to trigger drug release from AuNPs-liposome due to photothermic effects that drive a lipid melting phase transition rather than rupturing the liposome structure. An et al. described AuNPs that selectively absorbed UV light to trigger a lipid phase transition that caused $>50 \%$ berberine release from AuNPs-liposomes $\left(\mathrm{C}_{\mathrm{AuNPs}}=\right.$ $9.0 \mu \mathrm{M})$ after a $5 \mathrm{~min} \mathrm{UV}$ irradiation $\left(250 \mathrm{~nm}, 60 \mathrm{~W} / \mathrm{cm}^{2}\right)^{178}$. They repeated the same experiments using a different photothermal switch (AgNPs) and obtained the data showing nearly $70 \%$ berberine release from the AgNPs-liposomes $\left(\mathrm{C}_{\mathrm{AgNPs}}=81 \mu \mathrm{M}\right.$ under the same conditions ${ }^{179}$. Kwon et al. used TSL (6.5 wt $\%$ MPPC) with gold clusters that achieved $90 \%$ DOX release upon NIR irradiation $\left(1.5 \mathrm{~W} / \mathrm{cm}^{2}, 30 \mathrm{~s}\right)$ and increased the antitumor efficacy (> 4-fold) with NIR (1.75 W/cm 2 , $3 \mathrm{~min}$ ) relative to liposome without NIR in MDA-MB-231 tumor bearing mice ${ }^{180}$. Zhan et al. demonstrated phototriggered local anesthesia using gold nanorods (GNRs) that were tethered to liposomes containing tetrodotoxin (TTX; site 1 sodium channel blocker) and dexmedetomidine (DMED; $a_{2}$-adrenergic agonist) ${ }^{181}$. This system enabled the light-triggered phase transition (ordered gel phase to disordered liquid crystalline phase) of lipid bilayers with a consequent release of payload. Moreover, Guo et al. incorporated the thermosensitive copolymer (poly(N-isopropylacrylamide-cobutylmethacrylate) PNIPAM-BMA) into a liposome formulation that displayed stepwise photothermal release behavior ${ }^{182}$. The membrane immobilized thermo-responsive polymers exhibit a lower critical solution temperature (LCST) response that imposes a mechanical stress on the membrane upon heat-induced contraction. The first step in the release process is due to the thermal contraction of the polymer, while the second step arises from liposome membrane phase transition.

Efforts focused on achieving synergistic impacts by combining photothermal and chemotherapeutic effects have been pursued by various research groups $^{149,169,173,180,183,184}$. A new delivery system based on silica-coated DOX liposomes bearing Au shells (Figure 32) ${ }^{173}$. The silica shells were modified to express an overall positive charge (- $\mathrm{NH}_{3}{ }^{+}$surface groups) in aqueous solution in order to capture negatively charged $\mathrm{AuCl}_{4}{ }^{-}$ions. Reducing agents $\left(\mathrm{NH}_{2} \mathrm{OH}\right)$ were then added to create the spherical Au outer shell. Cell growth inhibition was evaluated using different liposomal combinations (DOX, liposome/ $\mathrm{SiO}_{2} / \mathrm{Au}$, and DOX-loaded liposome/ $/ \mathrm{SiO}_{2} / \mathrm{Au}$ ) with and without NIR laser irradiation ( $\left.808 \mathrm{~nm}, 100 \mathrm{~mW} / \mathrm{cm}^{2}, 15 \mathrm{~min}\right)$ in human liver cancer cells (SMMC-7721) (Table 2). The DOX-loaded Au nanoshells irradiated by NIR light showed a higher cell growth inhibition rate than Au nanoshells or DOX alone, suggesting that chemotherapy and photothermal therapy can work together synergistically to inhibit tumor cell growth. 
Similarly, DOX-loaded hollow gold nanospheres (HAuNS)-thermal sensitive liposome (TSL) were developed to boost antitumor efficacy relative to free DOX ${ }^{183}$. The HAuNS were encapsulated inside of liposomes and NIR light $(808 \mathrm{~nm})$ was used to stimulated drug release. In vitro cytotoxicity assays revealed that $90 \%$ of the tumor cells (BEL-7402) were killed after NIR laser irradiation ( $\left.3 \mathrm{~W} / \mathrm{cm}^{2}, 2 \mathrm{~min}\right)$, whereas $60 \%$ of the tumor cells survived in the absence of NIR irradiation after $72 \mathrm{~h}$ incubation. NIR irradiation $\left(2 \mathrm{~W} / \mathrm{cm}^{2}, 5 \mathrm{~min}\right)$ performed in vivo once on Day 1 and three times on Day 2, 4, 6 produced a complete disappearance of tumors in 2 of the 6 mice upon analysis $22 \mathrm{~d}$ after the injection. Moreover, these liposome formulations have been improved by conjugating human epidermal growth factor receptor-2 (HER2) antibodies on the membrane surface to increase their target specificity ${ }^{184}$. HER2 Ab-mediated delivery of liposomes showed higher accumulation (> 2fold) in tumors with positive HER2 expression than with non-targeted liposomes. In vivo tumor inhibition efficiency was significantly enhanced (> 90\%) with NIR laser irradiation in the HER2 Ab-targeted case as well.

Light-mediated release methods reported include a photoresponsive mechanism with 7acetoxycoumarin dimer $(\mathrm{ACD})^{185}$, photochemical nitric oxide precursors ${ }^{186}$, azobenzene motifs as light-responsive membrane-interactive compound ${ }^{187}$, photodamage of lipid bilayers by irradiation of the peptide TAT labeled with tetramethylrhodamine (TMR) ${ }^{188}$, merocyanine 540 (MC 540) and upconverting nanoparticle (UCN) coloaded functional polymeric liposome ${ }^{189}$, fiber-optic triggered release of photothermally responsive liposomes formulated with gold nanoparticles ${ }^{190}$, Visudyne ${ }^{\circledR}$-mediated photodynamic therapy to increase the uptake of systemic liposomal cisplatin (Lipoplatin $\left.{ }^{\circledR}\right)^{191}$, and trigged release from thermosensitive liposomes by photothermal conversion of water using NIR ${ }^{192}$.

\section{Conclusion}

In this review, we have summarized the latest developments in stimuli-sensitive liposome research. Significant advances have occurred using a single strategy or combination of strategies. There have also been improvements in the field of trigger-release system for better formulating, targeting, and delivering drugs. Further advances are needed, however, to bring these developments closer to clinical reality.

\section{Acknowledgments}

Financial support from the Purdue University Center for Cancer Research (P30 CA023168), NIH Grant R01 GM087016, the Mass Spectrometry Shared Resource, the Bindley Bioscience Imaging Facility, and the Department of Chemistry at Purdue University are greatly acknowledged.

\section{References}

1. Zhu L, Torchilin VP. Stimulus-responsive nanopreparations for tumor targeting. Integr Biol. 2013; 5:96-107.

2. Perche F, Torchilin VP. Recent trends in multifunctional liposomal nanocarriers for enhanced tumor targeting. J Drug Deliv. 2013; 2013:705265. [PubMed: 23533772]

3. Akbarzadeh A, Rezaei-Sadabady R, Davaran S, Joo SW, Zarghami N, Hanifehpour Y, Samiei M, Kouhi M, Nejati-Koshki K. Liposome: classification, preparation, and applications. Nanoscale Res Lett. 2013; 8:102-102. [PubMed: 23432972] 
4. Torchilin V. Multifunctional and stimuli-sensitive pharmaceutical nanocarriers. Eur J Pharm Biopharm. 2009; 71:431-444. [PubMed: 18977297]

5. Barenholz Y. Doxil ${ }^{\circledR}$ — The first FDA-approved nano-drug: Lessons learned. J Controlled Release. 2012; 160:117-134.

6. Felber AE, Dufresne M-H, Leroux J-C. pH-sensitive vesicles, polymeric micelles, and nanospheres prepared with polycarboxylates. Adv Drug Delivery Rev. 2012; 64:979-992.

7. Bovis MJ, Woodhams JH, Loizidou M, Scheglmann D, Bown SG, MacRobert AJ. Improved in vivo delivery of m-THPC via pegylated liposomes for use in photodynamic therapy. J Controlled Release. 2012; 157:196-205.

8. Thamphiwatana S, Fu V, Zhu J, Lu D, Gao W, Zhang L. Nanoparticle-stabilized liposomes for pHresponsive gastric drug delivery. Langmuir. 2013; 29:12228-12233. [PubMed: 23987129]

9. Kataoka K, Harada A, Nagasaki Y. Block copolymer micelles for drug delivery: Design, characterization and biological significance. Adv Drug Delivery Rev. 2001; 47:113-131.

10. Srivastava, S., Tirrell, MV. Advances in Chemical Physics. John Wiley \& Sons, Inc; 2016. Polyelectrolyte complexation; p. 499-544.

11. Kumari A, Yadav SK, Yadav SC. Biodegradable polymeric nanoparticles based drug delivery systems. Colloids Surf, B. 2010; 75:1-18.

12. Trivedi R, Kompella UB. Nanomicellar formulations for sustained drug delivery: strategies and underlying principles. Nanomedicine (London, England). 2010; 5:485-505.

13. Kedar U, Phutane P, Shidhaye S, Kadam V. Advances in polymeric micelles for drug delivery and tumor targeting. Nanomedicine: Nanotechnology, Biology and Medicine. 2010; 6:714-729.

14. Rolland J, Guillet P, Schumers JM, Duhem N, Preat V, Gohy JF. Polyelectrolyte complex nanoparticles from chitosan and poly(acrylic acid) and polystyrene-block-poly(acrylic acid). J Polym Sci, Part A: Polym Chem. 2012; 50:4484-4493.

15. Chan, JM., Valencia, PM., Zhang, L., Langer, R., Farokhzad, OC. Polymeric nanoparticles for drug delivery. In: Grobmyer, SR., Moudgil, BM., editors. Cancer Nanotechnology: Methods and Protocols. Totowa, NJ: Humana Press; 2010. p. 163-175.

16. Soppimath KS, Aminabhavi TM, Kulkarni AR, Rudzinski WE. Biodegradable polymeric nanoparticles as drug delivery devices. J Controlled Release. 2001; 70:1-20.

17. Fleige E, Quadir MA, Haag R. Stimuli-responsive polymeric nanocarriers for the controlled transport of active compounds: Concepts and applications. Adv Drug Delivery Rev. 2012; 64:866884.

18. Zhang H, Li R-y, Lu X, Mou Z-z, Lin G-m. Docetaxel-loaded liposomes: Preparation, pH sensitivity, pharmacokinetics, and tissue distribution. J Zhejiang Univ Sci, B. 2012; 13:981-989. [PubMed: 23225853]

19. Soares DCF, de Oliveira MC, Gouvea dos Santos R, Andrade MS, Vilela JMC, Cardoso VN, Ramaldes GA. Liposomes radiolabeled with 159Gd-DTPA-BMA: Preparation, physicochemical characterization, release profile and in vitro cytotoxic evaluation. Eur J Pharm Sci. 2011; 42:462469. [PubMed: 21296148]

20. Ghanbarzadeh S, Arami S, Pourmoazzen Z, Khorrami A. Improvement of the antiproliferative effect of rapamycin on tumor cell lines by poly (monomethylitaconate)-based $\mathrm{pH}$-sensitive, plasma stable liposomes. Colloids Surf, B. 2014; 115:323-330.

21. Kono K, Kaiden T, Yuba E, Sakanishi Y, Harada A. Synthesis of oligo(ethylene glycol)-modified hyperbranched poly(glycidol)s for dual sensitization of liposomes to $\mathrm{pH}$ and temperature. J Taiwan Inst Chem Eng. 2014; 45:3054-3061.

22. Massey JB. Effect of cholesteryl hemisuccinate on the interfacial properties of phosphatidylcholine bilayers. Biochimica et Biophysica Acta (BBA) - Biomembranes. 1998; 1415:193-204. [PubMed: 9858729]

23. Xu H, Hu M, Yu X, Li Y, Fu Y, Zhou X, Zhang D, Li J. Design and evaluation of pH-sensitive liposomes constructed by poly(2-ethyl-2-oxazoline)-cholesterol hemisuccinate for doxorubicin delivery. Eur J Pharm Biopharm. 2015; 91:66-74. [PubMed: 25660909]

24. Barbosa MV, Monteiro LOF, Carneiro G, Malagutti AR, Vilela JMC, Andrade MS, Oliveira MC, Carvalho-Junior AD, Leite EA. Experimental design of a liposomal lipid system: A potential strategy for paclitaxel-based breast cancer treatment. Colloids Surf, B. 2015; 136:553-561. 
25. Hu Y, Zhao Z, Ehrich M, Fuhrman K, Zhang C. In vitro controlled release of antigen in dendritic cells using pH-sensitive liposome-polymeric hybrid nanoparticles. Polymer. 2015; 80:171-179. [PubMed: 26622069]

26. Chang M, Lu S, Zhang F, Zuo T, Guan Y, Wei T, Shao W, Lin G. RGD-modified pH-sensitive liposomes for docetaxel tumor targeting. Colloids Surf, B. 2015; 129:175-182.

27. Paliwal SR, Paliwal R, Agrawal GP, Vyas SP. Hyaluronic acid modified $\mathrm{pH}$-sensitive liposomes for targeted intracellular delivery of doxorubicin. J Liposome Res. 2016Ahead of Print

28. Xu H, Paxton JW, Wu Z. Enhanced pH-responsiveness, cellular trafficking, cytotoxicity and longcirculation of PEGylated liposomes with post-insertion technique using gemcitabine as a model drug. Pharm Res. 2015; 32:2428-2438. [PubMed: 25663325]

29. Torres E, Mainini F, Napolitano R, Fedeli F, Cavalli R, Aime S, Terreno E. Improved paramagnetic liposomes for MRI visualization of $\mathrm{pH}$ triggered release. J Controlled Release. 2011; 154:196202.

30. Castelli DD, Boffa C, Giustetto P, Terreno E, Aime S. Design and testing of paramagnetic liposome-based CEST agents for MRI visualization of payload release on $\mathrm{pH}$-induced and ultrasound stimulation. JBIC, J Biol Inorg Chem. 2014; 19:207-214. [PubMed: 24037221]

31. Lee S-M, Lee O-S, O'Halloran TV, Schatz GC, Nguyen ST. Triggered release of pharmacophores from [Ni(HAsO3)]-loaded polymer-caged nanobin enhances pro-apoptotic activity: A combined experimental and theoretical study. ACS Nano. 2011; 5:3961-3969. [PubMed: 21466214]

32. Jelezova I, Drakalska E, Momekova D, Shalimova N, Momekov G, Konstantinov S, Rangelov S, Pispas S. Curcumin loaded $\mathrm{pH}$-sensitive hybrid lipid/block copolymer nanosized drug delivery systems. Eur J Pharm Sci. 2015; 78:67-78. [PubMed: 26159739]

33. Huang Y-F, Chiang W-H, Tsai P-L, Chern C-S, Chiu H-C. Novel hybrid vesicles co-assembled from a cationic lipid and PAAc-g-mPEG with $\mathrm{pH}$-triggered transmembrane channels for controlled drug release. Chem Commun (Cambridge, U K). 2011; 47:10978-10980.

34. Wang Y, Tu S, Pinchuk AN, Xiong MP. Active drug encapsulation and release kinetics from hydrogel-in-liposome nanoparticles. J Colloid Interface Sci. 2013; 406:247-255. [PubMed: 23809875]

35. Popescu M-T, Mourtas S, Pampalakis G, Antimisiaris SG, Tsitsilianis C. pH-responsive hydrogel/ liposome soft nanocomposites for tuning drug release. Biomacromolecules. 2011; 12:3023-3030. [PubMed: 21728314]

36. Sevimli S, Inci F, Zareie HM, Bulmus V. Well-defined cholesterol polymers with pH-controlled membrane switching activity. Biomacromolecules. 2012; 13:3064-3075. [PubMed: 22917061]

37. Zhou W, An X, Wang J, Shen W, Chen Z, Wang X. Characteristics, phase behavior and control release for copolymer-liposome with both $\mathrm{pH}$ and temperature sensitivities. Colloids Surf, A. 2012; 395:225-232.

38. Alves P, Hugo AA, Szymanowski F, Tymczyszyn EE, Gomez-Zavaglia A, Perez PF, Coelho JFJ, Simoes PN. Stabilization of polymer lipid complexes prepared with lipids of lactic acid bacteria upon preservation and internalization into eukaryotic cells. Colloids Surf, B. 2014; 123:446-451.

39. Barea MJ, Jenkins MJ, Lee YS, Johnson P, Bridson RH. Encapsulation of liposomes within pH responsive microspheres for oral colonic drug delivery. Int J Biomater. 2012:458712-458718. [PubMed: 22792110]

40. Lu T, Wang Z, Ma Y, Zhang Y, Chen T. Influence of polymer size, liposomal composition, surface charge, and temperature on the permeability of $\mathrm{pH}$-sensitive liposomes containing lipid-anchored poly(2-ethylacrylic acid). Int J Nanomed. 2012; 7:4917-4926.

41. Meng F, Zhong Z. Polymersomes spanning from nano- to microscales: Advanced vehicles for controlled drug delivery and robust vesicles for virus and cell mimicking. The Journal of Physical Chemistry Letters. 2011; 2:1533-1539.

42. Du Y, Chen W, Zheng M, Meng F, Zhong Z. pH-sensitive degradable chimaeric polymersomes for the intracellular release of doxorubicin hydrochloride. Biomaterials. 2012; 33:7291-7299. [PubMed: 22795540]

43. Chen P, Qiu M, Deng C, Meng F, Zhang J, Cheng R, Zhong Z. pH-responsive chimaeric pepsomes based on asymmetric poly(ethylene glycol)-b-poly(L-leucine)-b-poly(L-glutamic acid) triblock 
opolymer for efficient loading and active intracellular delivery of doxorubicin hydrochloride. Biomacromolecules. 2015; 16:1322-1330. [PubMed: 25759951]

44. Wang L, Geng D, Su H. Safe and efficient $\mathrm{pH}$ sensitive tumor targeting modified liposomes with minimal cytotoxicity. Colloids Surf, B. 2014; 123:395-402.

45. Yoshizaki Y, Yuba E, Sakaguchi N, Koiwai K, Harada A, Kono K. Potentiation of pH-sensitive polymer-modified liposomes with cationic lipid inclusion as antigen delivery carriers for cancer immunotherapy. Biomaterials. 2014; 35:8186-8196. [PubMed: 24969637]

46. Yuba E, Kanda Y, Yoshizaki Y, Teranishi R, Harada A, Sugiura K, Izawa T, Yamate J, Sakaguchi $\mathrm{N}$, Koiwai K, et al. pH-sensitive polymer-liposome-based antigen delivery systems potentiated with interferon- $\gamma$ gene lipoplex for efficient cancer immunotherapy. Biomaterials. 2015; 67:214224. [PubMed: 26222284]

47. Li Y, Liu R, Yang J, Shi Y, Ma G, Zhang Z, Zhang X. Enhanced retention and anti-tumor efficacy of liposomes by changing their cellular uptake and pharmacokinetics behavior. Biomaterials. 2015; 41:1-14. [PubMed: 25522960]

48. Li Y, Liu R, Yang J, Ma G, Zhang Z, Zhang X. Dual sensitive and temporally controlled camptothecin prodrug liposomes codelivery of siRNA for high efficiency tumor therapy. Biomaterials. 2014; 35:9731-9745. [PubMed: 25189519]

49. Liu Y, Gao F-P, Zhang D, Fan Y-S, Chen X-G, Wang H. Molecular structural transformation regulated dynamic disordering of supramolecular vesicles as $\mathrm{pH}$-responsive drug release systems. J Controlled Release. 2014; 173:140-147.

50. Hao W, Han X, Shang Y, Xu S, Liu H. Insertion of pH-sensitive bola-type copolymer into liposome as a "stability anchor" for control of drug release. Colloids Surf, B. 2015; 136:809-816.

51. Guo P, You J-O, Yang J, Jia D, Moses MA, Auguste DT. Inhibiting metastatic breast cancer cell migration via the synergy of targeted, $\mathrm{pH}$-triggered siRNA delivery and chemokine axis blockade. Mol Pharmaceutics. 2014; 11:755-765.

52. Chiang Y-T, Lo C-L. pH-responsive polymer-liposomes for intracellular drug delivery and tumor extracellular matrix switched-on targeted cancer therapy. Biomaterials. 2014; 35:5414-5424. [PubMed: 24709521]

53. Moku G, Gulla SK, Nimmu NV, Khalid S, Chaudhuri A. Delivering anti-cancer drugs with endosomal pH-sensitive anti-cancer liposomes. Biomater Sci. 2016 Ahead of Print.

54. Jiang L, Li L, He X, Yi Q, He B, Cao J, Pan W, Gu Z. Overcoming drug-resistant lung cancer by paclitaxel loaded dual-functional liposomes with mitochondria targeting and $\mathrm{pH}$-response. Biomaterials. 2015; 52:126-139. [PubMed: 25818419]

55. Sanchez M, Aranda FJ, Teruel JA, Ortiz A. New pH-sensitive liposomes containing phosphatidylethanolamine and a bacterial dirhamnolipid. Chem Phys Lipids. 2011; 164:16-23. [PubMed: 20932963]

56. Huang W, Zhang J, Dorn HC, Zhang C. Assembly of bio-nanoparticles for double controlled drug release. PLoS One. 2013; 8:e74679. [PubMed: 24040316]

57. Alam MI, Paget T, Elkordy AA. Formulation and advantages of furazolidone in liposomal drug delivery systems. Eur J Pharm Sci. 2016; 84:139-145. [PubMed: 26796143]

58. Caddeo C, Diez-Sales O, Pons R, Carbone C, Ennas G, Puglisi G, Fadda AM, Manconi M. Crosslinked chitosan/liposome hybrid system for the intestinal delivery of quercetin. J Colloid Interface Sci. 2016; 461:69-78. [PubMed: 26397912]

59. Yan L, Crayton SH, Thawani JP, Amirshaghaghi A, Tsourkas A, Cheng Z. A pH-responsive drugdelivery platform based on glycol chitosan-coated liposomes. Small. 2015; 11:4870-4874. [PubMed: 26183232]

60. Yao Y, Su Z, Liang Y, Zhang N. pH-Sensitive carboxymethyl chitosan-modified cationic liposomes for sorafenib and siRNA co-delivery. Int J Nanomedicine. 2015; 10:6185-6197. [PubMed: 26491291]

61. Mo R, Sun Q, Xue J, Li N, Li W, Zhang C, Ping Q. Multistage pH-responsive iposomes for mitochondrial-targeted anticancer drug delivery. Adv Mater (Weinheim, Ger). 2012; 24:36593665. S3659/3651-S3659/3619. 
62. Mo R, Sun Q, Li N, Zhang C. Intracellular delivery and antitumor effects of $\mathrm{pH}$-sensitive liposomes based on zwitterionic oligopeptide lipids. Biomaterials. 2013; 34:2773-2786. [PubMed: 23352118]

63. Xu X, Zhang L, Assanhou AG, Wang L, Zhang Y, Li W, Xue L, Mo R, Zhang C. Acid/redox dualactivated liposomes for tumor-targeted drug delivery and enhanced therapeutic efficacy. RSC Adv. 2015; 5:67803-67808.

64. Zhao Y, Ren W, Zhong T, Zhang S, Huang D, Guo Y, Yao X, Wang C, Zhang W-Q, Zhang X, et al. Tumor-specific $\mathrm{pH}$-responsive peptide-modified $\mathrm{pH}$-sensitive liposomes containing doxorubicin for enhancing glioma targeting and anti-tumor activity. J Controlled Release. 2016; 222:56-66.

65. Shi K, Long Y, Xu C, Wang Y, Qiu Y, Yu Q, Liu Y, Zhang Q, Gao H, Zhang Z, et al. Liposomes combined an integrin av $\beta 3$-specific vector with $\mathrm{pH}$-responsible cell-penetrating property for highly effective antiglioma therapy through the blood-brain barrier. ACS Appl Mater Interfaces. 2015; 7:21442-21454. [PubMed: 26371468]

66. Shi K, Li J, Cao Z, Yang P, Qiu Y, Yang B, Wang Y, Long Y, Liu Y, Zhang Q, et al. A pHresponsive cell-penetrating peptide-modified liposomes with active recognizing of integrin av $\beta 3$ for the treatment of melanoma. J Controlled Release. 2015; 217:138-150.

67. Burks SR, Legenzov EA, Martin EW, Li C, Lu W, Kao JPY. Co-encapsulating the fusogenic peptide INF7 and molecular imaging probes in liposomes increases intracellular signal and probe retention. PLoS One. 2015; 10:e0120982/0120981-e0120982/0120917. [PubMed: 25816348]

68. Su C, Xia Y, Sun J, Wang N, Zhu L, Chen T, Huang Y, Liang D. Liposomes physically coated with peptides: Preparation and characterization. Langmuir. 2014; 30:6219-6227. [PubMed: 24826785]

69. Gopi HN, Reja RM, Khan M, Singh SK, Misra R, Shiras A. pH sensitive coiled coils: A strategy for enhanced liposomal drug delivery. Nanoscale. 2016 Ahead of Print.

70. Bandekar A, Karve S, Chang M-Y, Mu Q, Rotolo J, Sofou S. Antitumor efficacy following the intracellular and interstitial release of liposomal doxorubicin. Biomaterials. 2012; 33:4345-4352. [PubMed: 22429980]

71. Sun T, Li Y, Zhang H, Li J, Xin F, Kong L, Hao A. pH-reversible vesicles based on the "supramolecular amphiphilies" formed by cyclodextrin and anthraquinone derivate. Colloids Surf, A. $2011 ; 375: 87-96$.

72. Samoshina NM, Liu X, Brazdova B, Franz AH, Samoshin VV, Guo X. Fliposomes: pH-sensitive liposomes containing a trans-2-morpholinocyclohexanol-based lipid that performs a conformational flip and triggers an instant cargo release in acidic medium. Pharmaceutics. 2011; 3:379-405. [PubMed: 24310586]

73. Samoshin AV, Veselov IS, Chertkov VA, Yaroslavov AA, Grishina GV, Samoshina NM, Samoshin VV. Fliposomes: New amphiphiles based on trans-3,4-bis(acyloxy)-piperidine able to perform a $\mathrm{pH}$-triggered conformational flip and cause an instant cargo release from liposomes. Tetrahedron Lett. 2013; 54:5600-5604.

74. Zheng Y, Liu X, Samoshina NM, Samoshin VV, Franz AH, Guo X. Trans-2-Aminocyclohexanolbased amphiphiles as highly efficient helper lipids for gene delivery by lipoplexes. Biochim Biophys Acta, Biomembr. 2015; 1848:3113-3125.

75. Viricel W, Mbarek A, Leblond J. Switchable lipids: Conformational change for fast $\mathrm{pH}$-triggered cytoplasmic delivery. Angew Chem, Int Ed. 2015; 54:12743-12747.

76. Xia GM, An ZJ, Wang Y, Zhao C, Li M, Li ZC, Ma J. Synthesis of a novel polymeric material folate-poly(2-ethyl-2-oxazoline)-distearoyl phosphatidyl ethanolamine tri-block polymer for dual receptor and pH-sensitive targeting liposome. Chem Pharm Bull. 2013; 61:390-398. [PubMed: 23385961]

77. Li J, Zhou Y, Li C, Wang D, Gao Y, Zhang C, Zhao L, Li Y, Liu Y, Li X. Poly(2-ethyl-2oxazoline)-doxorubicin conjugate-based dual endosomal $\mathrm{pH}$-sensitive micelles with enhanced antitumor efficacy. Bioconjugate Chem. 2015; 26:110-119.

78. Xu H, Zhang W, Li Y, Ye FF, Yin PP, Yu X, Hu MN, Fu YS, Wang C, Shang DJ. The bifunctional liposomes constructed by poly(2-ethyl-oxazoline)-cholesteryl methyl carbonate: An effectual approach to enhance liposomal circulation time, $\mathrm{pH}$-sensitivity and endosomal escape. Pharm Res. 2014; 31:3038-3050. [PubMed: 24805279] 
79. Zanta MA, Belguise-Valladier P, Behr J-P. Gene delivery: A single nuclear localization signal peptide is sufficient to carry DNA to the cell nucleus. Proc Natl Acad Sci U S A. 1999; 96:91-96. [PubMed: 9874777]

80. Xu Y, Szoka FC. Mechanism of DNA release from cationic liposome/DNA complexes used in cell transfection. Biochemistry. 1996; 35:5616-5623. [PubMed: 8639519]

81. Hong BJ, Chipre AJ, Nguyen ST. Acid-degradable polymer-caged lipoplex (PCL) platform for siRNA delivery: Facile cellular triggered release of siRNA. J Am Chem Soc. 2013; 135:1765517658. [PubMed: 24000948]

82. Chen H, Zhang H, Thor D, Rahimian R, Guo X. Novel pH-sensitive cationic lipids with linear ortho ester linkers for gene delivery. Eur J Med Chem. 2012; 52:159-172. [PubMed: 22480493]

83. Shin J, Shum P, Grey J, Fujiwara S-i, Malhotra GS, Gonzalez-Bonet A, Hyun S-H, Moase E, Allen TM, Thompson DH. Acid-labile mPEG-vinyl ether-1,2-dioleylglycerol lipids with tunable $\mathrm{pH}$ ensitivity: Synthesis and tructural effects on hydrolysis rates, DOPE liposome release performance, and pharmacokinetics. Mol Pharmaceutics. 2012; 9:3266-3276.

84. Kim H-K, Van den Bossche J, Hyun S-H, Thompson DH. Acid-triggered release via dePEGylation of fusogenic liposomes mediated by heterobifunctional phenyl-substituted vinyl ethers with tunable pH-sensitivity. Bioconjugate Chem. 2012; 23:2071-2077.

85. Koren E, Apte A, Jani A, Torchilin VP. Multifunctional PEGylated 2C5-immunoliposomes containing $\mathrm{pH}$-sensitive bonds and TAT peptide for enhanced tumor cell internalization and cytotoxicity. J Control Release. 2012; 160:264-273. [PubMed: 22182771]

86. Ding Y, Sun D, Wang G-L, Yang H-G, Xu H-F, Chen J-H, Xie Y, Wang Z-Q. An efficient PEGylated liposomal nanocarrier containing cell-penetrating peptide and $\mathrm{pH}$-sensitive hydrazone bond for enhancing tumor-targeted drug delivery. Int J Nanomedicine. 2015; 10:6199-6214. [PubMed: 26491292]

87. Chen D, Sun K, Mu H, Tang M, Liang R, Wang A, Zhou S, Sun H, Zhao F, Yao J, et al. pH and temperature dual-sensitive liposome gel based on novel cleavable mPEG-Hz-CHEMS polymeric vaginal delivery system. Int J Nanomed. 2012; 7:2621-2630.

88. Kolli S, Wong S-P, Harbottle R, Johnston B, Thanou M, Miller AD. pH-triggered nanoparticle mediated delivery of siRNA to liver cells in vitro and in vivo. Bioconjugate Chem. 2013; 24:314332.

89. Liu J, Ma H, Wei T, Liang X-J. CO2 gas induced drug release from $\mathrm{pH}$-sensitive liposome to circumvent doxorubicin resistant cells. Chem Commun (Cambridge, U K). 2012; 48:4869-4871.

90. Hatakeyama H, Murata M, Sato Y, Takahashi M, Minakawa N, Matsuda A, Harashima H. The systemic administration of an anti-miRNA oligonucleotide encapsulated $\mathrm{pH}$-sensitive liposome results in reduced level of hepatic microRNA-122 in mice. J Controlled Release. 2014; 173:43-50.

91. Hada T, Sakurai Y, Harashima H. Optimization of a siRNA carrier modified with a $\mathrm{pH}$-sensitive cationic lipid and a cyclic RGD peptide for efficiently targeting tumor endothelial cells. Pharmaceutics. 2015; 7:320-333. [PubMed: 26389942]

92. Fugit KD, Anderson BD. The role of $\mathrm{pH}$ and ring-opening hydrolysis kinetics on liposomal release of topotecan. J Controlled Release. 2014; 174:88-97.

93. Bersani S, Vila-Caballer M, Brazzale C, Barattin M, Salmaso S. pH-sensitive stearoyl-PEGpoly(methacryloyl sulfadimethoxine) decorated liposomes for the delivery of gemcitabine to cancer cells. Eur J Pharm Biopharm. 2014; 88:670-682. [PubMed: 25157908]

94. Pacheco-Torres J, Lopez-Larrubia P, Cerdan S, Mukherjee N, Walko M, Ballesteros P, Kocer A. Image guided drug release from $\mathrm{pH}$-sensitive Ion channel-functionalized stealth liposomes into an in vivo glioblastoma model. Nanomedicine. 2015; 11:1345-1354. [PubMed: 25888277]

95. Chen Q, Ding H, Zhou J, Zhao X, zhang j, Yang C, Li K, Qiao M, Hu H, Ding P, et al. Novel glycyrrhetinic acid conjugated $\mathrm{pH}$-sensitive liposomes for the delivery of doxorubicin and its antitumor activities. RSC Adv. 2016 Ahead of Print.

96. Liu Z, Tang S, Xu Z, Wang Y, Zhu X, Li L-c, Hong W, Wang X. Preparation and in vitro evaluation of a multifunctional iron silicate@liposome nanohybrid for $\mathrm{pH}$-sensitive doxorubicin delivery and photoacoustic imaging. J Nanomater. 2015

Wiley Interdiscip Rev Nanomed Nanobiotechnol. Author manuscript; available in PMC 2018 September 01. 
97. Tripathy N, Ahmad R, Ko HA, Khang G, Hahn Y-B. Enhanced anticancer potency using an acidresponsive ZnO-incorporated liposomal drug-delivery system. Nanoscale. 2015; 7:4088-4096. [PubMed: 25660501]

98. Murata K, Egami H, Kiyohara H, Oshima S, Kurizaki T, Ogawa M. Expression of group-II phospholipase A2 in malignant and non-malignant human gastric mucosa. Br J Cancer. 1993; 68:103-111. [PubMed: 8318399]

99. Arouri A, Mouritsen OG. Phospholipase A2-susceptible liposomes of anticancer double lipidprodrugs. Eur J Pharm Sci. 2012; 45:408-420. [PubMed: 21946258]

100. Linderoth L, Peters GH, Madsen R, Andresen TL. Drug delivery by an enzyme-mediated cyclization of a lipid prodrug with unique bilayer-formation properties. Angew Chem, Int Ed. 2009; 48:1823-1826.

101. Kaasgaard T, Andresen TL, Jensen SS, Holte RO, Jensen LT, Jorgensen K. Liposomes containing alkylated methotrexate analogues for phospholipase A2 mediated tumor targeted drug delivery. Chem Phys Lipids. 2009; 157:94-103. [PubMed: 19094974]

102. Linderoth L, Fristrup P, Hansen M, Melander F, Madsen R, Andresen TL, Peters GH. Mechanistic study of the sPLA2-mediated hydrolysis of a thio-ester pro anticancer ether lipid. J Am Chem Soc. 2009; 131:12193-12200. [PubMed: 19663381]

103. Arouri A, Hansen AH, Rasmussen TE, Mouritsen OG. Lipases, liposomes and lipid-prodrugs. Curr Opin Colloid Interface Sci. 2013; 18:419-431.

104. Pedersen PJ, Adolph SK, Subramanian AK, Arouri A, Andresen TL, Mouritsen OG, Madsen R, Madsen MW, Peters GH, Clausen MH. Liposomal formulation of retinoids designed for enzyme triggered release. J Med Chem. 2010; 53:3782-3792. [PubMed: 20405849]

105. Hansen AH, Mouritsen OG, Arouri A. Enzymatic action of phospholipase A2 on liposomal drug delivery systems. Int J Pharm (Amsterdam, Neth). 2015; 491:49-57.

106. Zhu G-D, Alhamhoom Y, Cummings BS, Arnold RD. Synthesis of lipids for development of multifunctional lipid-based drug carriers. Bioorg Med Chem Lett. 2011; 21:6370-6375. [PubMed: 21955941]

107. Xing H, Zhang CL, Ruan G, Zhang J, Hwang K, Lu Y. Multimodal detection of a small molecule target using stimuli-responsive liposome triggered by aptamer-enzyme conjugate. Anal Chem. 2016; 88:1506-1510. [PubMed: 26750765]

108. Thamphiwatana S, Gao W, Pornpattananangkul D, Zhang Q, Fu V, Li J, Li J, Obonyo M, Zhang L. Phospholipase A2-responsive antibiotic delivery via nanoparticle-stabilized liposomes for the treatment of bacterial infection. J Mater Chem B. 2014; 2:8201-8207.

109. Ferguson EL, De Luca E, Heenan RK, King SM, Griffiths PC. Time-resolved small-angle neutron scattering as a tool for studying controlled release from liposomes using polymer-enzyme conjugates. Macromol Rapid Commun. 2010; 31:1685-1690. [PubMed: 21567581]

110. Wymer NJ, Gerasimov OV, Thompson DH. Cascade liposomal triggering: Light-induced Ca2+ elease from diplasmenylcholine liposomes triggers PLA2-catalyzed hydrolysis and contents leakage from DPPC liposomes. Bioconjugate Chem. 1998; 9:305-308.

111. Shimanouchi T, Kawasaki H, Fuse M, Umakoshi H, Kuboi R. Membrane fusion mediated by phospholipase C under endosomal pH conditions. Colloids Surf, B. 2013; 103:75-83.

112. Wan Y, Han J, Fan G, Zhang Z, Gong T, Sun X. Enzyme-responsive liposomes modified adenoviral vectors for enhanced tumor cell transduction and reduced immunogenicity. Biomaterials. 2013; 34:3020-3030. [PubMed: 23360783]

113. Banerjee J, Hanson AJ, Gadam B, Elegbede AI, Tobwala S, Ganguly B, Wagh AV, Muhonen WW, Law B, Shabb JB, et al. Release of liposomal contents by cell-secreted matrix metalloproteinase-9. Bioconjugate Chem. 2009; 20:1332-1339.

114. Kulkarni PS, Haldar MK, Nahire RR, Katti P, Ambre AH, Muhonen WW, Shabb JB, Padi SKR, Singh RK, Borowicz PP, et al. MMP-9 responsive PEG cleavable nanovesicles for efficient elivery of chemotherapeutics to pancreatic cancer. Mol Pharmaceutics. 2014; 11:2390-2399.

115. Xu P, Meng Q, Sun H, Yin Q, Yu H, Zhang Z, Cao M, Zhang Y, Li Y. Shrapnel nanoparticles loading docetaxel inhibit metastasis and growth of breast cancer. Biomaterials. 2015; 64:10-20. [PubMed: 26106797] 
116. Yingyuad P, Mevel M, Prata C, Kontogiorgis C, Thanou M, Miller AD. Enzyme-triggered PEGylated siRNA-nanoparticles for controlled release of siRNA. J RNAi Gene Silencing. 2014; 10:490-499. 410. [PubMed: 24741375]

117. Yingyuad P, Mevel M, Prata C, Furegati S, Kontogiorgis C, Thanou M, Miller AD. Enzymetriggered PEGylated pDNA-nanoparticles for controlled release of pDNA in tumors. Bioconjugate Chem. 2013; 24:343-362.

118. Koren E, Apte A, Sawant RR, Grunwald J, Torchilin VP. Cell-penetrating TAT peptide in drug delivery systems: Proteolytic stability requirements. Drug Delivery. 2011; 18:377-384. [PubMed: 21438724]

119. Song SJ, Lee S, Lee Y, Choi JS. Enzyme-responsive destabilization of stabilized plasmid-lipid nanoparticles as an efficient gene delivery. Eur J Pharm Sci. 2016; 91:20-30. [PubMed: 27240779]

120. Wang Y, Zhang L, Guo S, Hatefi A, Huang L. Incorporation of histone derived recombinant protein for enhanced disassembly of core-membrane structured liposomal nanoparticles for efficient siRNA delivery. J Controlled Release. 2013; 172:179-189.

121. Jo S-M, Lee H-Y, Kim J-C. Glucose-sensitivity of liposomes incorporating conjugates of glucose oxidase and poly(N-isopropylacrylamide-co-methacrylic acid-co-octadecylacrylate). Int J Biol Macromol. 2009; 45:421-426. [PubMed: 19549540]

122. Hong YJ, Lee HY, Kim J-C. Alginate beads containing pH-sensitive liposomes and glucose oxidase: Glucose-sensitive release. Colloid Polym Sci. 2009; 287:1207-1214.

123. Jo S-M, Kim J-C. Glucose-triggered release from liposomes incorporating poly(Nisopropylacrylamide-co-methacrylic acid-co-octadecylacrylate) and glucose oxidase. Colloid Polym Sci. 2009; 287:379-384.

124. Jang WS, Park SC, Reed EH, Dooley KP, Wheeler SF, Lee D, Hammer DA. Enzymatically triggered rupture of polymersomes. Soft Matter. 2016; 12:1014-1020. [PubMed: 26616557]

125. Chandrawati R, Odermatt PD, Chong S-F, Price AD, Stadler B, Caruso F. Triggered cargo release by encapsulated enzymatic catalysis in capsosomes. Nano Lett. 2011; 11:4958-4963. [PubMed: 21992226]

126. Grinberg S, Kipnis N, Linder C, Kolot V, Heldman E. Asymmetric bolaamphiphiles from vernonia oil designed for drug delivery. Eur J Lipid Sci Technol. 2009; 112:137-151.

127. Ye T, Jiang X, Li J, Yang R, Mao Y, Li K, Li L, Chen F, Yao J, Wu Y, et al. Low molecular weight heparin mediating targeting of lymph node metastasis based on nanoliposome and enzymesubstrate interaction. Carbohydr Polym. 2015; 122:26-38. [PubMed: 25817639]

128. McCarley RL. Redox-responsive delivery systems. Annu Rev Anal Chem. 2012; 5:391-411.

129. Candiani G, Pezzoli D, Ciani L, Chiesa R, Ristori S. Bioreducible liposomes for gene delivery: from the formulation to the mechanism of action. PLoS One. 2010; 5 No pp. given.

130. Fu H, Shi K, Hu G, Yang Y, Kuang Q, Lu L, Zhang L, Chen W, Dong M, Chen Y, et al. Tumortargeted paclitaxel delivery and enhanced penetration using TAT-decorated liposomes comprising redox-responsive poly(ethylene glycol). J Pharm Sci. 2015; 104:1160-1173. [PubMed: 25449709]

131. Zhang S, Zhao Y. Controlled release from cleavable polymerized liposomes upon redox and $\mathrm{pH}$ stimulation. Bioconjugate Chem. 2011; 22:523-528.

132. Sun Q, Kang Z, Xue L, Shang Y, Su Z, Sun H, Ping Q, Mo R, Zhang C. A collaborative assembly strategy for tumor-targeted siRNA delivery. J Am Chem Soc. 2015; 137:6000-6010. [PubMed: 25869911]

133. Loew M, Forsythe JC, McCarley RL. Lipid nature and their influence on opening of redox-active liposomes. Langmuir. 2013; 29:6615-6623. [PubMed: 23698020]

134. McCarley RL, Forsythe JC, Loew M, Mendoza MF, Hollabaugh NM, Winter JE. Release rates of liposomal contents are controlled by kosmotropes and chaotropes. Langmuir. 2013; 29:1399113995. [PubMed: 24160736]

135. Mendoza MF, Hollabaugh NM, Hettiarachchi SU, McCarley RL. Human NAD(P)H:quinone oxidoreductase type I (hNQO1) activation of quinone propionic acid trigger groups. Biochemistry. 2012; 51:8014-8026. [PubMed: 22989153] 
136. Aytar BS, Muller JPE, Golan S, Kondo Y, Talmon Y, Abbott NL, Lynn DM. Chemical oxidation of a redox-active, ferrocene-containing cationic lipid: Influence on interactions with DNA and characterization in the context of cell transfection. J Colloid Interface Sci. 2012; 387:56-64. [PubMed: 22980739]

137. Kumar K, Vulugundam G, Kondaiah P, Bhattacharya S. Co-liposomes of redox-active alkylferrocene modified low MW branched PEI and DOPE for efficacious gene delivery in serum. $\mathbf{J}$ Mater Chem B. 2015; 3:2318-2330.

138. Vulugundam G, Kumar K, Kondaiah P, Bhattacharya S. Efficacious redox-responsive gene delivery in serum by ferrocenylated monomeric and dimeric cationic cholesterols. Org Biomol Chem. 2015; 13:4310-4320. [PubMed: 25762431]

139. Conceição D, Ferreira D, Ferreira L. Photochemistry and cytotoxicity evaluation of heptamethinecyanine near infrared (NIR) dyes. Int J Mol Sci. 2013; 14:18557. [PubMed: 24022690]

140. Yavlovich A, Smith B, Gupta K, Blumenthal R, Puri A. Light-sensitive lipid-based nanoparticles for drug delivery: Design principles and future considerations for biological applications. Mol Membr Biol. 2010; 27:364-381. [PubMed: 20939770]

141. Leung SJ, Romanowski M. Light-activated content release from liposomes. Theranostics. 2012; 2:1020-1036. [PubMed: 23139729]

142. Yavlovich A, Singh A, Tarasov S, Capala J, Blumenthal R, Puri A. Design of liposomes containing photopolymerizable phospholipids for triggered release of contents. J Therm Anal Calorim. 2009; 98:97-104. [PubMed: 20160877]

143. Yavlovich A, Singh A, Blumenthal R, Puri A. A novel class of photo-triggerable liposomes containing DPPC:DC8,9PC as vehicles for delivery of doxorubicin to cells. Biochim Biophys Acta, Biomembr. 2011; 1808:117-126.

144. Guo C, Liu S, Jiang C, Li W, Dai Z, Fritz H, Wu X. A promising drug controlled-release system based on diacetylene/phospholipid polymerized vesicles. Langmuir. 2009; 25:13114-13119. [PubMed: 19852472]

145. Sine J, Urban C, Thayer D, Charron H, Valim N, Tata DB, Schiff R, Blumenthal R, Joshi A, Puri A. Photo activation of HPPH encapsulated in "Pocket" liposomes triggers multiple drug release and tumor cell killing in mouse breast cancer xenografts. Int J Nanomed. 2015; 10:125-145.

146. Luo D, Carter KA, Razi A, Geng J, Shao S, Giraldo D, Sunar U, Ortega J, Lovell JF. Doxorubicin encapsulated in stealth liposomes conferred with light-triggered drug release. Biomaterials. 2016; 75:193-202. [PubMed: 26513413]

147. Carter KA, Wang S, Geng J, Luo D, Shao S, Lovell JF. Metal chelation modulates phototherapeutic properties of mitoxantrone-loaded porphyrin-phospholipid liposomes. Mol Pharmaceutics. 2016; 13:420-427.

148. Mahmoud G, Jedelska J, Strehlow B, Bakowsky U. Bipolar tetraether lipids derived from thermoacidophilic archaeon sulfolobus acidocaldarius for membrane stabilization of chlorin e6 based liposomes for photodynamic therapy. Eur J Pharm Biopharm. 2015; 95:88-98. [PubMed: 25936859]

149. Peng P-C, Hong R-L, Tsai Y-J, Li P-T, Tsai T, Chen C-T. Dual-effect liposomes encapsulated with doxorubicin and chlorin e6 augment the therapeutic effect of tumor treatment. Lasers Surg Med. 2015; 47:77-87. [PubMed: 25559348]

150. Reshetov V, Lassalle H-P, Francois A, Dumas D, Hupont S, Graefe S, Filipe V, Jiskoot W, Guillemin F, Zorin V, et al. Photodynamic therapy with conventional and PEGylated liposomal formulations of mTHPC (temoporfin): comparison of treatment efficacy and distribution characteristics in vivo. Int J Nanomed. 2012; 8:3817-3831.

151. Garrier J, Reshetov V, Graefe S, Guillemin F, Zorin V, Bezdetnaya L. Factors affecting the selectivity of nanoparticle-based photoinduced damage in free and xenografted chorioallantoic membrane model. J Drug Targeting. 2014; 22:220-231.

152. Randles EG, Bergethon PR. A photodependent switch of liposome stability and permeability. Langmuir. 2013; 29:1490-1497. [PubMed: 23286452] 
153. Pashkovskaya A, Kotova E, Zorlu Y, Dumoulin F, Ahsen V, Agapov I, Antonenko Y. Lighttriggered liposomal release: membrane permeabilization by photodynamic action. Langmuir. 2010; 26:5726-5733. [PubMed: 20000430]

154. Aygun A, Torrey K, Kumar A, Stephenson LD. Investigation of factors affecting controlled release from photosensitive DMPC and DSPC liposomes. Appl Biochem Biotechnol. 2012; 167:743-757. [PubMed: 22592778]

155. Rwei AY, Lee J-J, Zhan C, Liu Q, Ok MT, Shankarappa SA, Langer R, Kohane DS. Repeatable and adjustable on-demand sciatic nerve block with phototriggerable liposomes. Proc Natl Acad Sci U S A. 2015; 112:15719-15724. [PubMed: 26644576]

156. Kozikowski RT, Sorg BS. Delayed photolysis of liposomes: a strategy for the precision timing of bolus drug release using ex-vivo photochemical sensitization. Proc SPIE. 2012; 8221:82211I/ 82211-82211I/82218.

157. Teng IT, Chang Y-J, Wang L-S, Lu H-Y, Wu L-C, Yang C-M, Chiu C-C, Yang C-H, Hsu S-L, Ho $\mathrm{J}-\mathrm{aA}$. Phospholipid-functionalized mesoporous silica nanocarriers for selective photodynamic therapy of cancer. Biomaterials. 2013; 34:7462-7470. [PubMed: 23810081]

158. Tachikawa S, Sato S, Hazama H, Awazu K, Kaneda Y, Nakamura H. Localization-dependent cellkilling effects of protoporphyrin (PPIX)-lipid micelles and liposomes in photodynamic therapy. Bioorg Med Chem. 2015; 23:7578-7584. [PubMed: 26602828]

159. Araki T, Ogawara K-i, Suzuki H, Kawai R, Watanabe T-i, Ono T, Higaki K. Augmented EPR effect by photo-triggered tumor vascular treatment improved therapeutic efficacy of liposomal paclitaxel in mice bearing tumors with low permeable vasculature. J Controlled Release. 2015; 200:106-114.

160. Basoglu H, Bilgin MD, Demir MM. Protoporphyrin IX-loaded magnetoliposomes as a potential drug delivery system for photodynamic therapy: Fabrication, characterization and in vitro study. Photodiagn Photodyn Ther. 2016; 13:81-90.

161. Mir Y, Elrington SA, Hasan T. A new nanoconstruct for epidermal growth factor receptor-targeted photo-immunotherapy of ovarian cancer. Nanomedicine. 2013; 9:1114-1122. [PubMed: 23485748]

162. Tangutoori S, Spring BQ, Mai Z, Palanisami A, Mensah LB, Hasan T. Simultaneous delivery of cytotoxic and biologic therapeutics using nanophotoactivatable liposomes enhances treatment efficacy in a mouse model of pancreatic cancer. Nanomedicine (N Y, NY, U S). 2016; 12:223234.

163. Spring BQ, Bryan Sears R, Zheng LZ, Mai Z, Watanabe R, Sherwood ME, Schoenfeld DA, Pogue BW, Pereira SP, Villa E, et al. A photoactivable multi-inhibitor nanoliposome for tumour control and simultaneous inhibition of treatment escape pathways. Nat Nanotechnol. 2016 Ahead of Print.

164. Fang N-C, Cheng F-Y, Ho J-aA, Yeh C-S. Photocontrolled targeted drug delivery: Photocaged biologically active folic cid as a light-responsive tumor-targeting molecule. Angew Chem, Int Ed. 2012; 51:88068810,S8806/8801-S8806/8817.

165. Yang Y, Yang Y, Xie X, Wang Z, Gong W, Zhang H, Li Y, Yu F, Li Z, Mei X. Dual-modified liposomes with a two-photon-sensitive cell penetrating peptide and NGR ligand for siRNA targeting delivery. Biomaterials. 2015; 48:84-96. [PubMed: 25701034]

166. Xie XY, Yang YF, Yang Y, Mei XG. Photolabile-caged peptide-conjugated liposomes for siRNA delivery. J Drug Targeting. 2015; 23:789-799.

167. Lin W, Xie X, Yang Y, Liu H, Fu X, Chen Y, Liu H, Yang Y. Enhanced small interfering RNA delivery into cells by exploiting the additive effect between photo-sensitive peptides and targeting ligands. J Pharm Pharmacol. 2015; 67:1215-1231. [PubMed: 25880614]

168. Shemesh CS, Hardy CW, Yu DS, Fernandez B, Zhang H. Indocyanine green loaded liposome nanocarriers for photodynamic therapy using human triple negative breast cancer cells. Photodiagn Photodyn Ther. 2014; 11:193-203.

169. Li M, Teh C, Ang CY, Tan SY, Luo Z, Qu Q, Zhang Y, Korzh V, Zhao Y. Near-infrared lightabsorptive stealth liposomes for localized photothermal ablation of tumors combined with chemotherapy. Adv Funct Mater. 2015; 25:5602-5610. 
170. Guo F, Yu M, Wang J, Tan F, Li N. Smart IR780 theranostic nanocarrier for tumor-specific therapy: Hyperthermia-mediated bubble-generating and folate-targeted liposomes. ACS Appl Mater Interfaces. 2015; 7:20556-20567. [PubMed: 26322900]

171. Sano K, Nakajima T, Choyke PL, Kobayashi H. Markedly enhanced permeability and retention effects induced by photo-immunotherapy of tumors. ACS Nano. 2013; 7:717-724. [PubMed: 23214407]

172. Rengan AK, Jagtap M, De A, Banerjee R, Srivastava R. Multifunctional gold coated thermosensitive liposomes for multimodal imaging and photothermal therapy of breast cancer cells. Nanoscale. 2014; 6:916-923. [PubMed: 24281647]

173. Wu C, Yu C, Chu M. A gold nanoshell with a silica inner shell synthesized using liposome templates for doxorubicin loading and near-infrared photothermal therapy. Int J Nanomed. 2011; 6:807-813.

174. Wu G, Mikhailovsky A, Khant HA, Zasadzinski JA. Synthesis, characterization, and optical response of gold nanoshells used to trigger release from liposomes. Methods Enzymol. 2009; 464:279-307. [PubMed: 19903560]

175. Kojima C, Hirano Y, Kono K. Preparation of complexes of liposomes with gold nanoparticles. Methods Enzymol. 2009; 464:131-145. [PubMed: 19903553]

176. Forbes N, Zasadzinski JA. Photothermally activated drug release from liposomes coupled to hollow gold nanoshells. Proc SPIE. 2011; 7911:79110P/79111-79110P/79112.

177. Mathiyazhakan M, Yang Y, Liu Y, Zhu C, Liu Q, Ohl C-D, Tam KC, Gao Y, Xu C. Non-invasive controlled release from gold nanoparticle integrated photo-responsive liposomes through pulse laser induced microbubble cavitation. Colloids Surf, B. 2015; 126:569-574.

178. An X, Zhang F, Zhu Y, Shen W. Photoinduced drug release from thermosensitive AuNPsliposome using a AuNPs-switch. Chem Commun (Camb). 2010; 46:7202-7204. [PubMed: 20820547]

179. Li J, An X, Pan Z, Sun 1. Photoinduced drug release from complexes of liposome and fluorescent silver nanoparticles. RSC Adv. 2014; 4:9476-9479.

180. Kwon HJ, Byeon Y, Jeon HN, Cho SH, Han HD, Shin BC. Gold cluster-labeled thermosensitive liposmes enhance triggered drug release in the tumor microenvironment by a photothermal effect. J Controlled Release. 2015; 216:132-139.

181. Zhan C, Wang W, McAlvin JB, Guo S, Timko BP, Santamaria C, Kohane DS. Phototriggered local anesthesia. Nano Lett. 2016; 16:177-181. [PubMed: 26654461]

182. Guo H, Kim J-C. Photothermally induced release from liposome suspended in mixture solution of gold nanoparticle and thermo-sensitive polymer. Colloids Surf, A. 2015; 469:73-82.

183. You J, Zhang P, Hu F, Du Y, Yuan H, Zhu J, Wang Z, Zhou J, Li C. Near-infrared light-Sesnsitive liposomes for the enhanced photothermal tumor treatment by the combination with chemotherapy. Pharm Res. 2014; 31:554-565. [PubMed: 24022681]

184. Li Q, Tang Q, Zhang P, Wang Z, Zhao T, Zhou J, Li H, Ding Q, Li W, Hu F, et al. Human epidermal growth factor receptor- 2 antibodies enhance the specificity and anticancer activity of light-sensitive doxorubicin-labeled liposomes. Biomaterials. 2015; 57:1-11. [PubMed: 25956192]

185. Seo HJ, Kim J-C. 7-Acetoxycoumarin dimer-incorporated and folate-decorated liposomes: Photoresponsive release and in vitro targeting and efficacy. Bioconjugate Chem. 2014; 25:533542.

186. Ostrowski AD, Lin BF, Tirrell MV, Ford PC. Liposome encapsulation of a photochemical NO precursor for controlled nitric oxide release and simultaneous fluorescence imaging. Mol Pharmaceutics. 2012; 9:2950-2955.

187. Hester TJ, Dennison SR, Baker MJ, Snape TJ. Functionalising the azobenzene motif delivers a light-responsive membrane-interactive compound with the potential for photodynamic therapy applications. Org Biomol Chem. 2015; 13:8067-8070. [PubMed: 26134592]

188. Meerovich I, Muthukrishnan N, Johnson GA, Erazo-Oliveras A, Pellois J-P. Photodamage of lipid bilayers by irradiation of a fluorescently labeled cell-penetrating peptide. Biochim Biophys Acta, Gen Subj. 2014; 1840:507-515. 
189. Wang H, Liu Z, Wang S, Dong C, Gong X, Zhao P, Chang J. MC540 and upconverting nanocrystal coloaded polymeric liposome for near-infrared light-triggered photodynamic therapy and cell fluorescent imaging. ACS Appl Mater Interfaces. 2014; 6:3219-3225. [PubMed: 24511877]

190. Huang H-L, Lu P-H, Yang H-C, Li H-R, Liao K-C, Lee G-D. Fiber-optic triggered release of liposome in vivo: Implication of personalized chemotherapy. Int J Nanomedicine. 2015; 10:5171-5184. [PubMed: 26316748]

191. Wang X, Debefve E, Ris H-B, Perentes JY, Gronchi F, Bensimon M, Wagnieres G, Mercier T, Decosterd LA, Letovanec I, et al. Treatment of pleural malignancies by photo-induction combined to systemic chemotherapy: Proof of concept on rodent lung tumors and feasibility study on porcine chest cavities. Lasers Surg Med. 2015; 47:807-816. [PubMed: 26415084]

192. Arai S, Lee C-LK, Chang Y-T, Sato H, Sou K. Thermosensitive nanoplatforms for photothermal release of cargo from liposomes under intracellular temperature monitoring. RSC Adv. 2015; 5:93530-93538. 


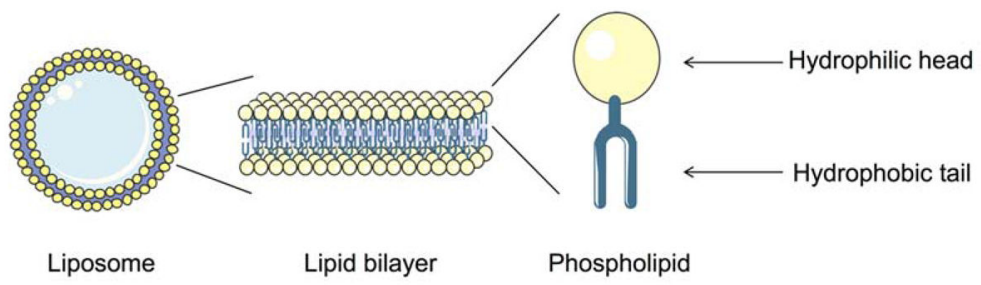

Fig. 1.

Schematic diagram of a liposome comprised of a spherical phospholipid lipid bilayer. 


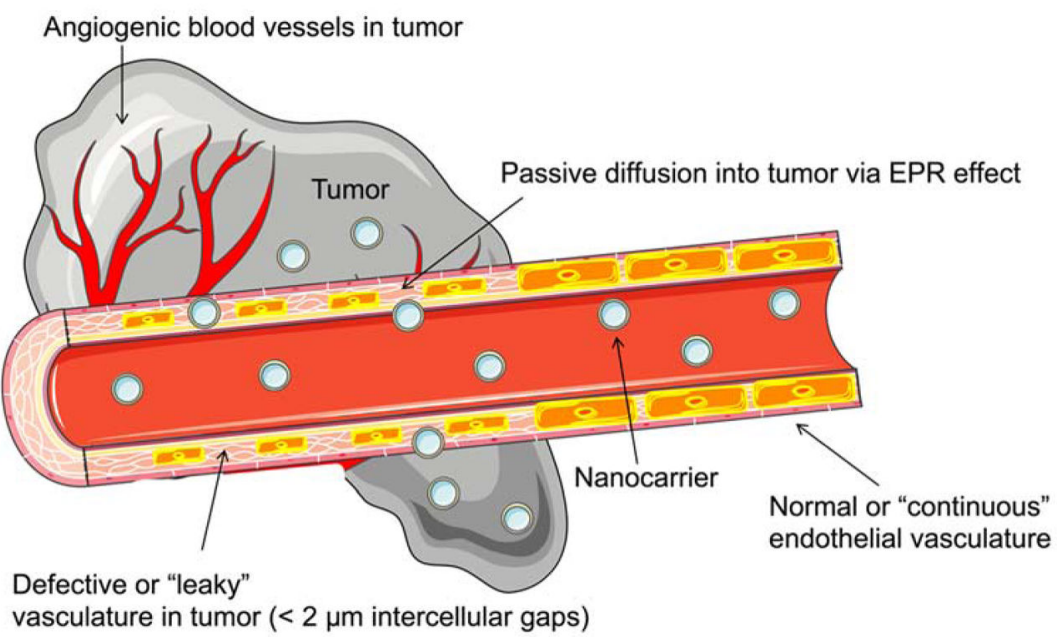

Fig. 2.

Enhanced permeability and retention (EPR) effect. The vasculature in the tumor environment is poorly formed, enabling nanocarriers to enter the surrounding tumor tissue passively through "leaky" endothelial cell junctions. 


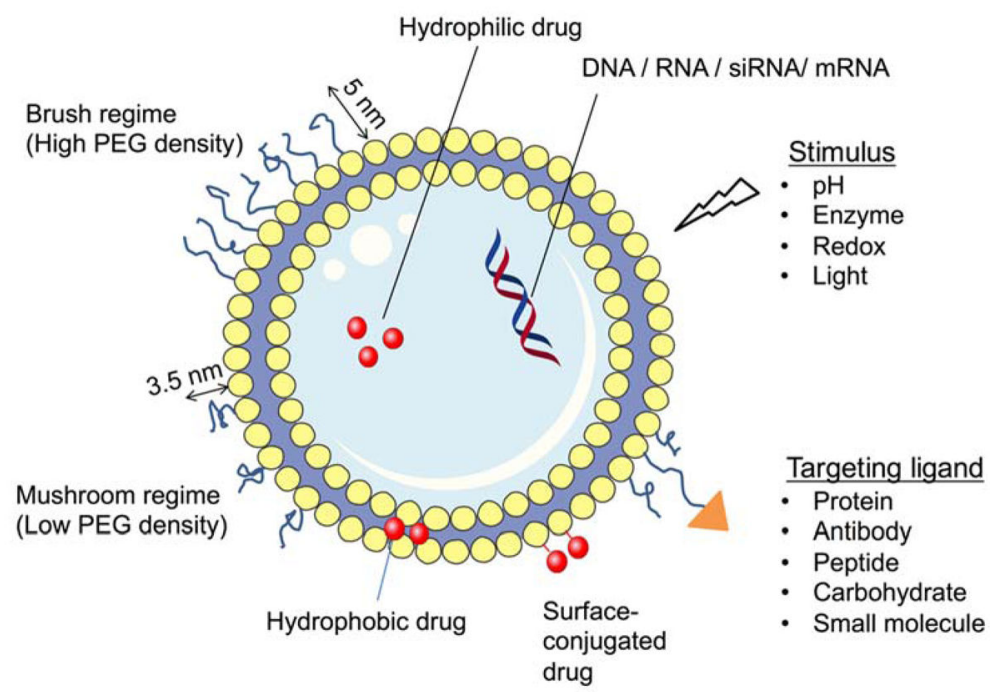

Fig. 3.

Different liposomal designs for targeted drug delivery. Drugs can be incorporated within the aqueous core or bilayer membrane depending on the drug properties. The degree of PEGylation (the dimensions shown are for PEG2000) can be adjusted to vary the stealth characteristics of the liposome formulation. Ligands can be introduced to present on the surface to manage specific binding while drug release rate can be controlled by designing in sensitivity to specific stimuli. 


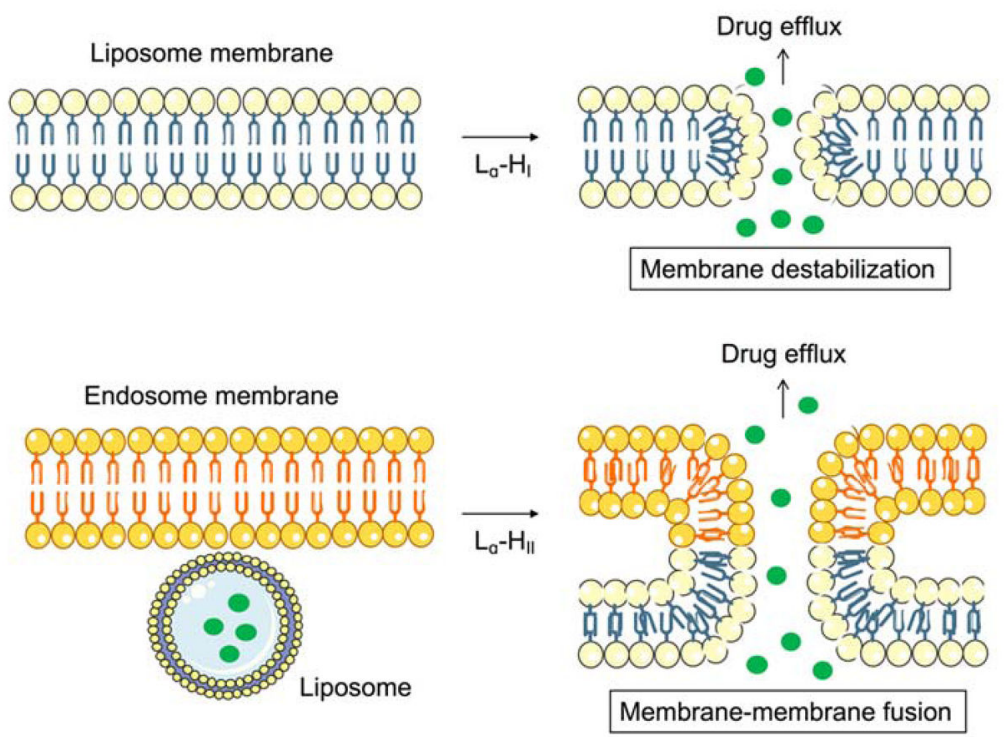

Fig. 4.

Liposome permeability changes that can occur upon intracellular activation of liposome membrane destabilization or membrane-membrane fusion. Similarly, extracellular activation can also increase membrane permeability to release drug cargo in the cell microenvironment. 


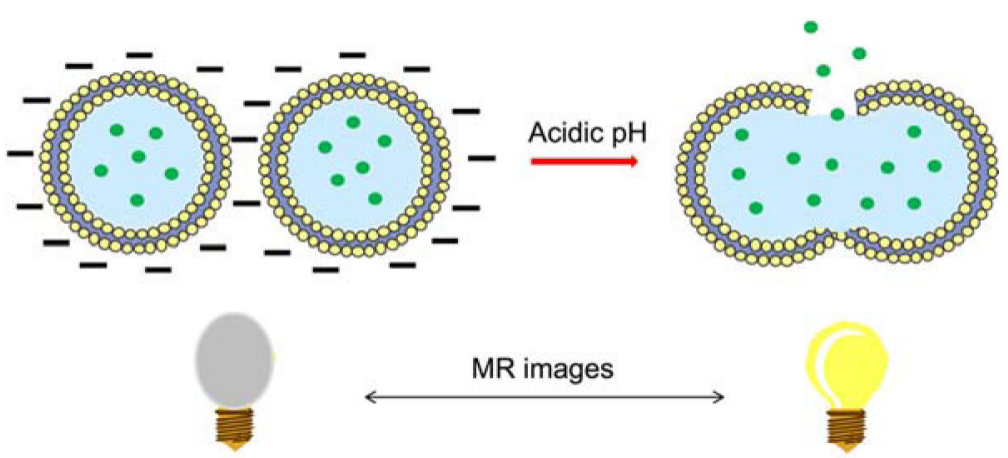

Fig. 5.

Gadolinium-based complexes release from the fusogenic liposomes upon acidification to enhance the relaxivity for better visualization. 

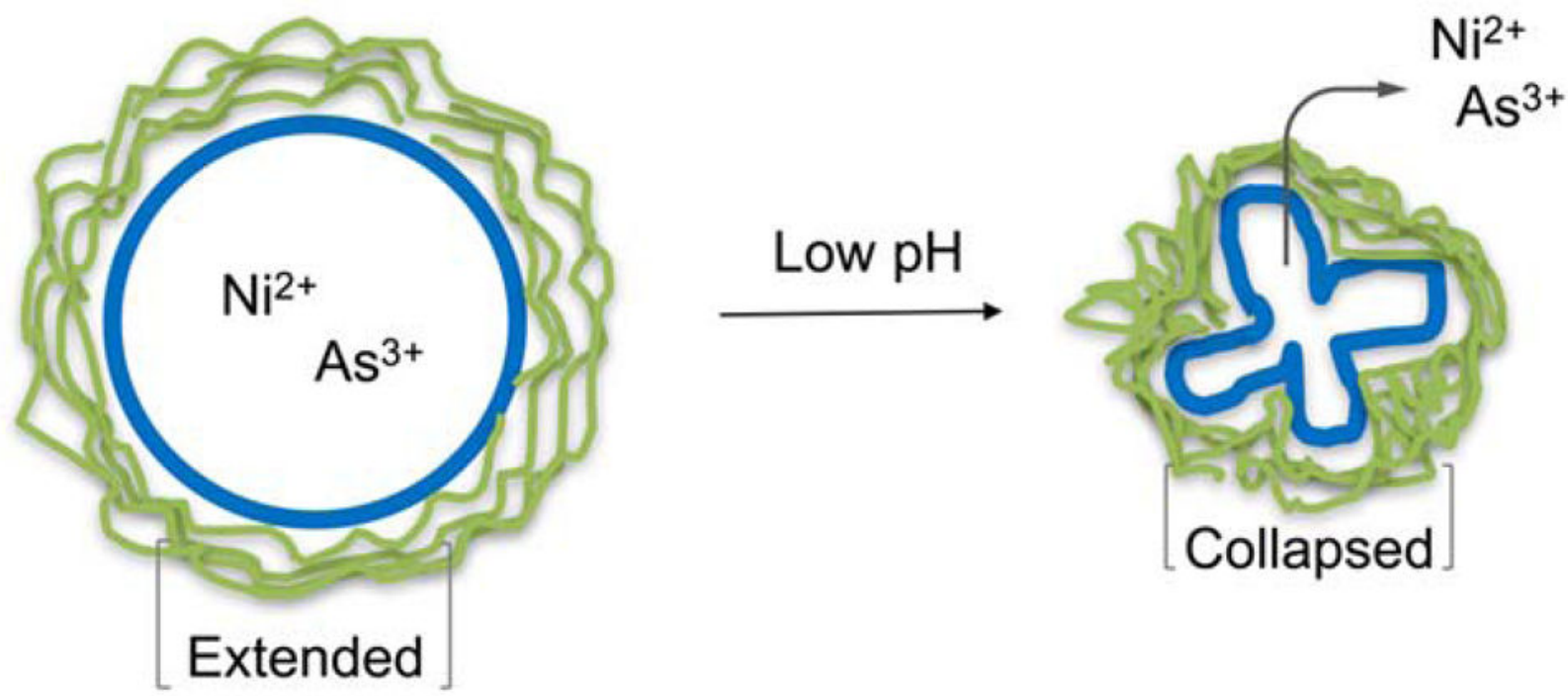

Fig. 6.

Change in the chemical structures of the model polymers at acidic $\mathrm{pH}$ via protonation. 


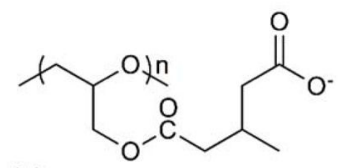

(a)

(b)

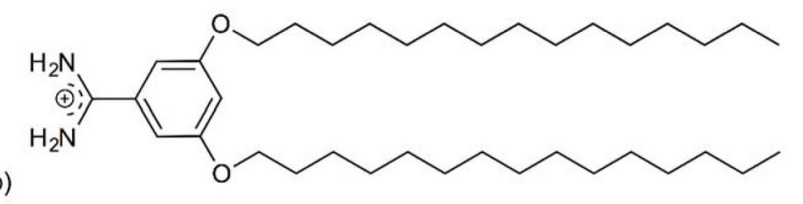

Fig. 7.

Chemical structure of (a) 3-methylglutarylated poly(glycidol) (MGlu-HG) and (b) 3,5Didodecyloxybenzamidine (TRX). 

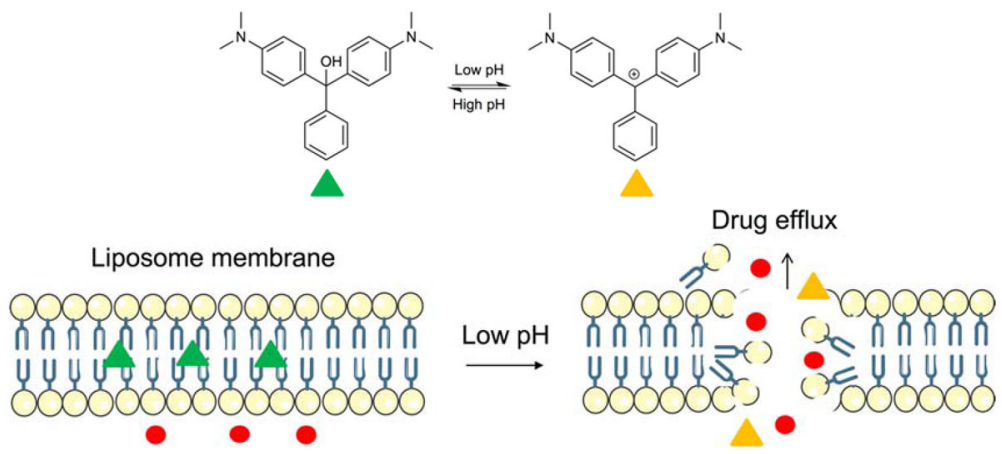

Fig. 8.

The neutral malachite green carbiniol base $(\mathrm{MG})$ becomes into carbocation state $\left(\mathrm{MG}^{+}\right)$ upon acidification which causes membrane destabilization and contents release. 


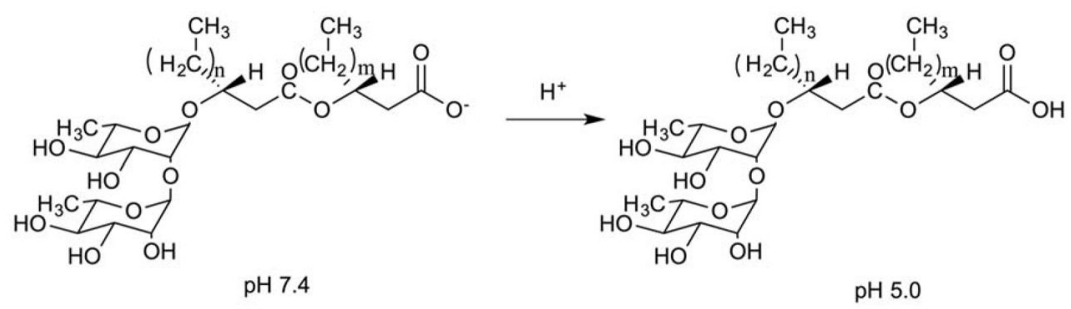

Fig. 9.

Pseudomonas aeruginosa dirhamnolipids (diRL) contain a carboxylate group that is negatively charged at neutral $\mathrm{pH}$, but neutral at acidic $\mathrm{pH}$. 


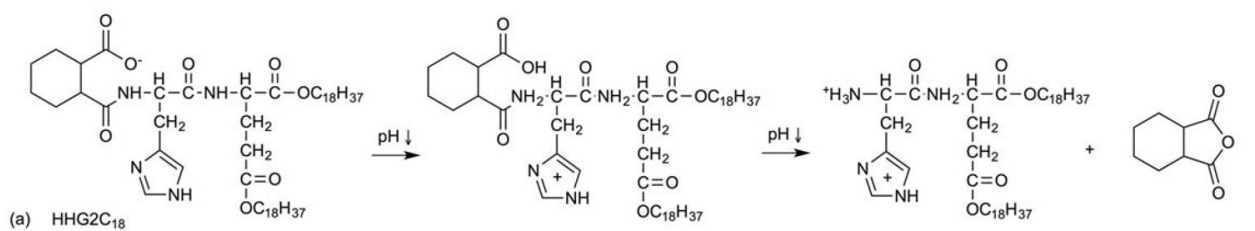

(b) PEGHG2C 18

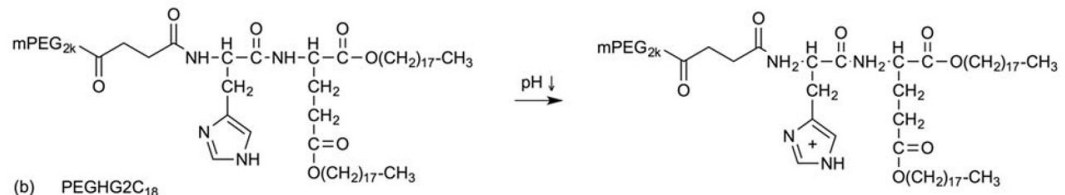

Fig. 10.

Multistage pH-responsive mechanisms based on (a) $\mathrm{HHG}_{2} \mathrm{C}_{18}$ and (b) PEGHG2C 18 . 
(a)

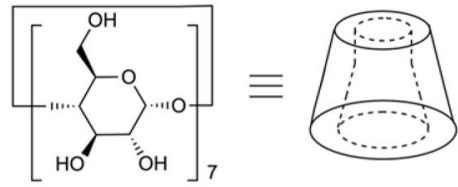

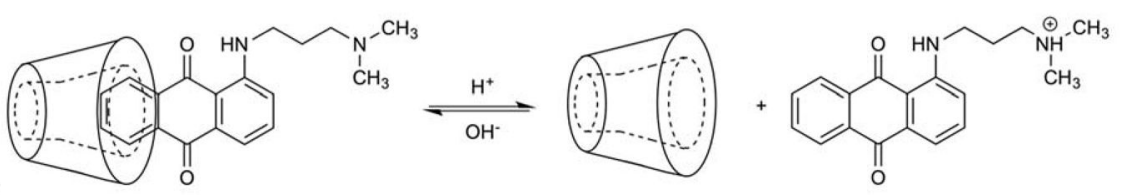

Fig. 11.

Chemical structure of (a) $\beta-C D$ and (b) anthraquinone derivative. (c) Supramolecular amphiphile consists of hydrophilic head and hydrophobic tail groups that undergo a $\mathrm{pH}-$ dependent, reversible complexation. 
(a)

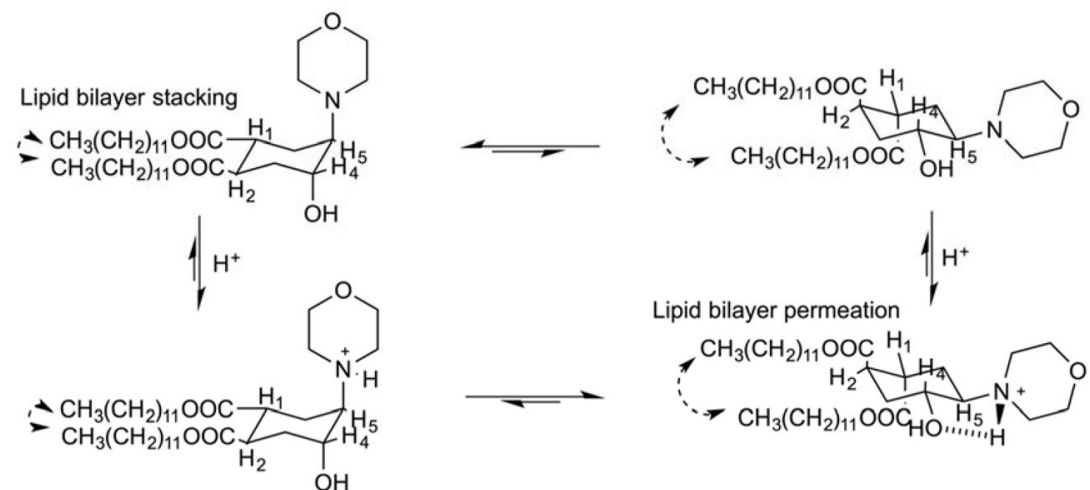

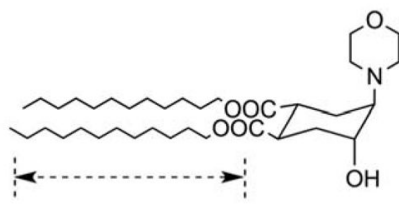

(b) Lipid bilayer stacking
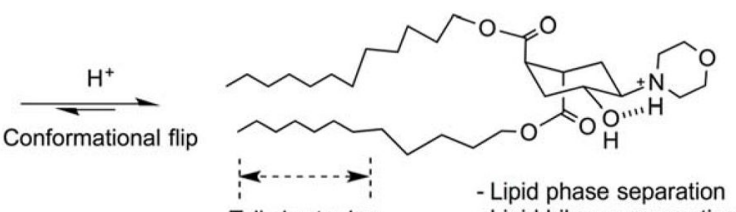

Fig. 12.

(a) Protonation-induced conformational switch of lipid tails in an amphiphile. (b) Protonation-induced conformational flip, shortening of the lipid tails causes rapid perturbation of the lipid bilayer, lipid phase separation, and fast release from the fliposomes.

Wiley Interdiscip Rev Nanomed Nanobiotechnol. Author manuscript; available in PMC 2018 September 01. 

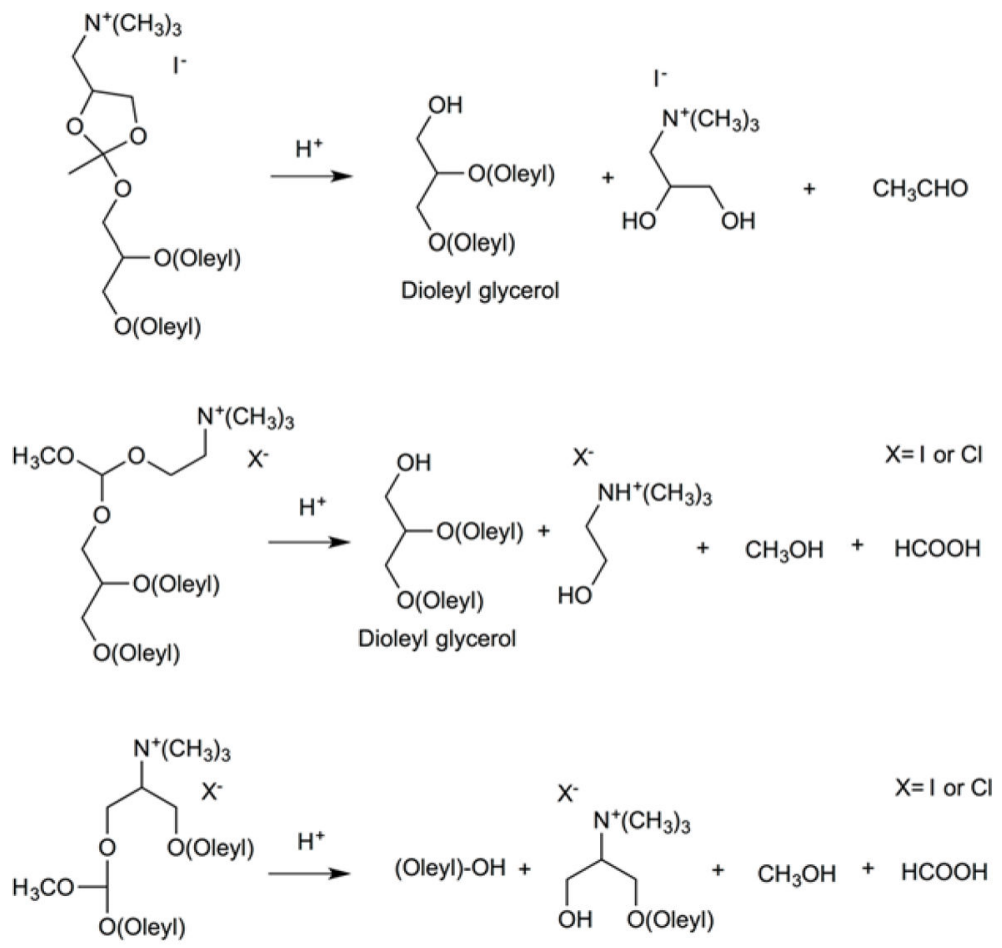

Fig. 13.

Acid-catalyzed hydrolysis of the cationic ortho ester lipids.

Wiley Interdiscip Rev Nanomed Nanobiotechnol. Author manuscript; available in PMC 2018 September 01. 


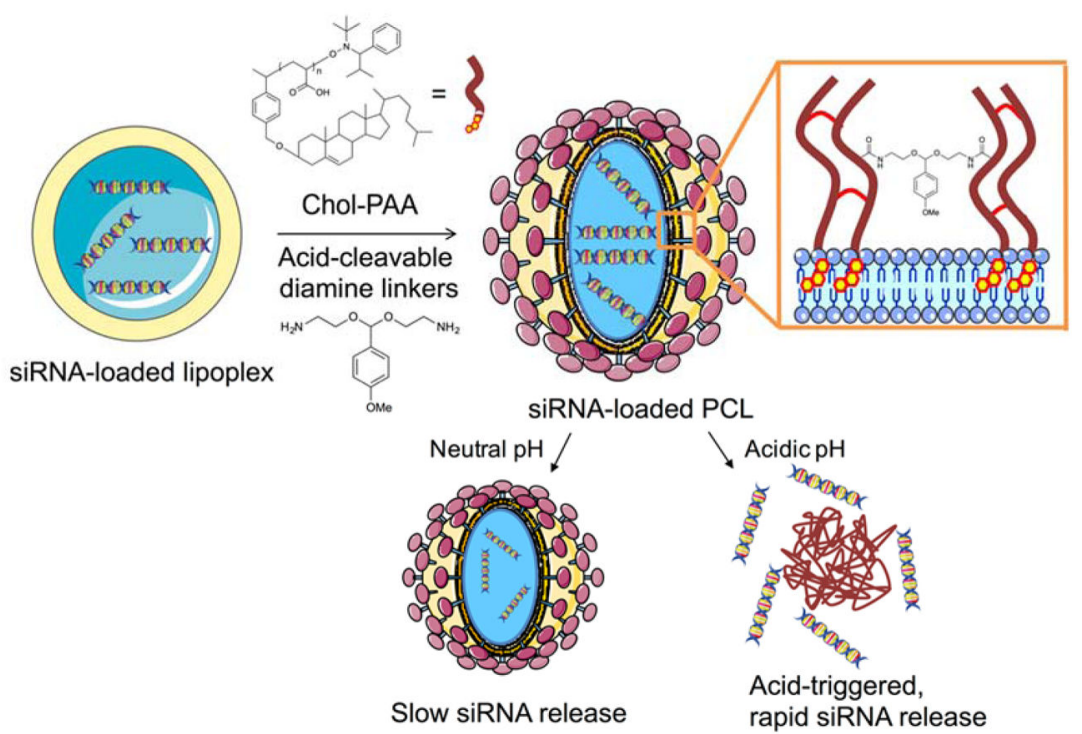

Fig. 14.

Schematic representation of an acid-degradable siRNA-loaded polymer-caged lipoplex (PCL) and its releasing mechanism. 

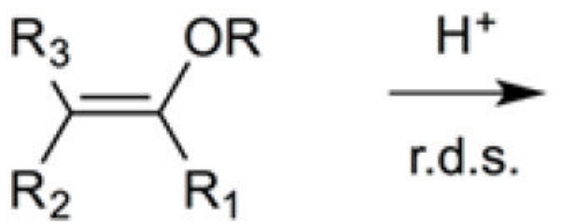

$\mathrm{R}_{3} \quad \mathrm{OR}$<smiles>[AlH]</smiles><smiles>C1CCCC1</smiles>

$\mathrm{R}_{2} \quad \mathrm{R}_{1}$

Oxo-stabilized Carbocation Intermediate

fast $\downarrow \mathrm{H}_{2} \mathrm{O},-\mathrm{H}^{+}$
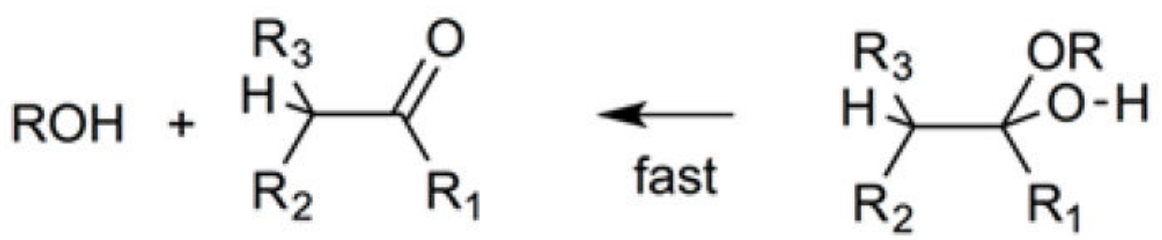

Fig. 15.

Acid-catalyzed vinyl ether hydrolysis mechanism involving a protonation of the $\beta$-carbon in a rate-determining step (r.d.s.). 


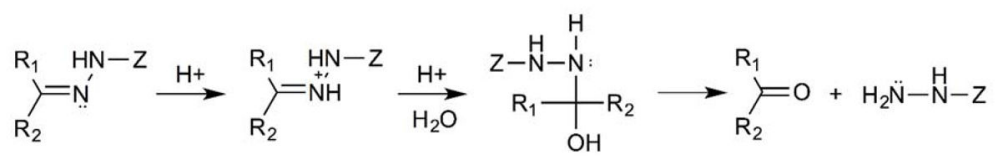

Fig. 16.

Hydrazone bond hydrolysis mechanism 


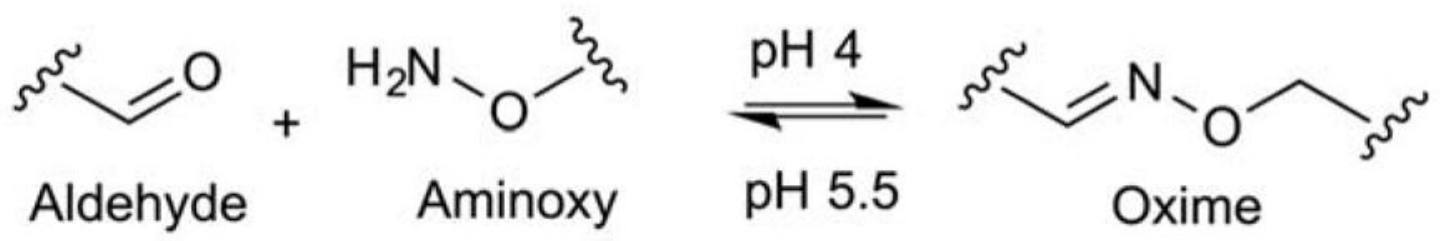

Fig. 17.

Reversible reactions of oxime formation at $\mathrm{pH} 4.0$ and oxime hydrolysis at $\mathrm{pH} 5.5$. 

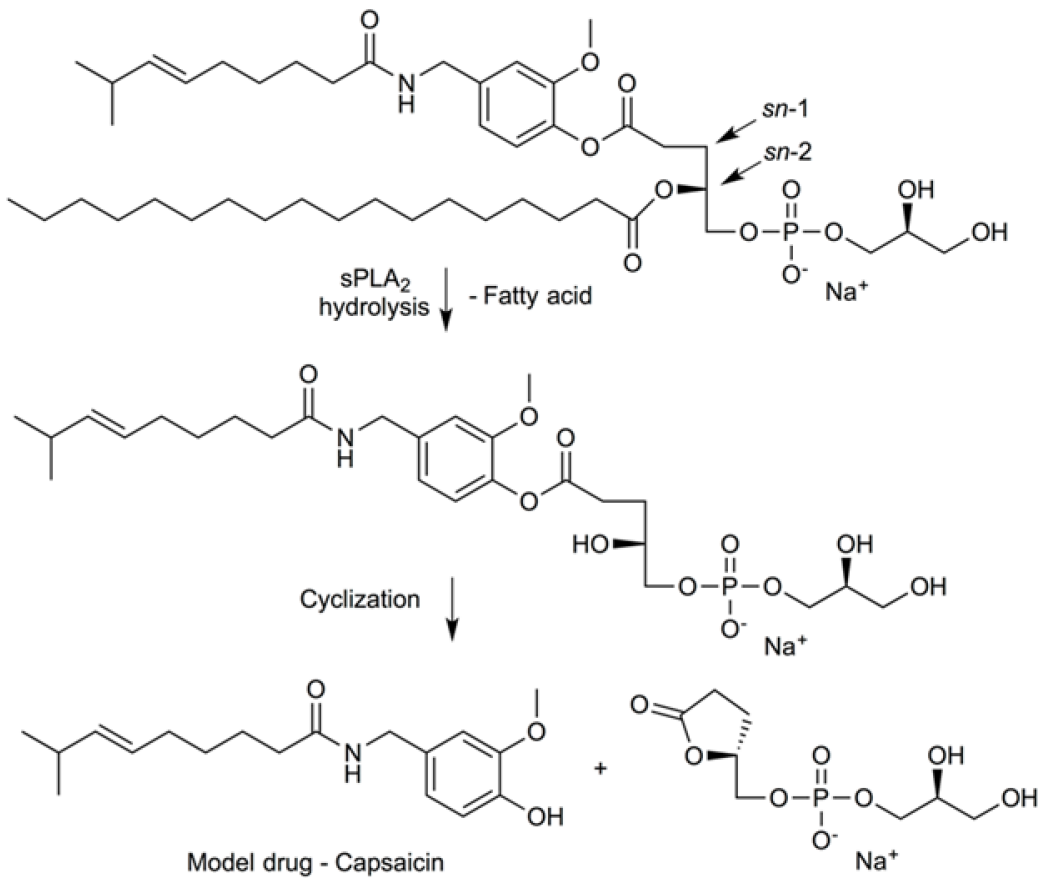

Fig. 18.

Enzyme-mediated intramolecular cyclization to release the lipid-based prodrug of capsaicin. 

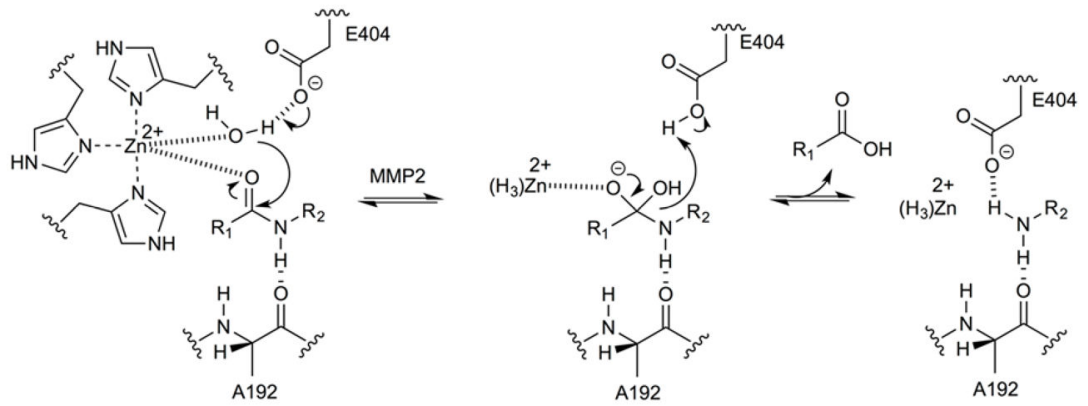

Fig. 19.

Mechanism of catalytic Zn(II)-mediated peptide link hydrolysis involving Ala192 and Glu404. 
<smiles>CC(C)C</smiles>

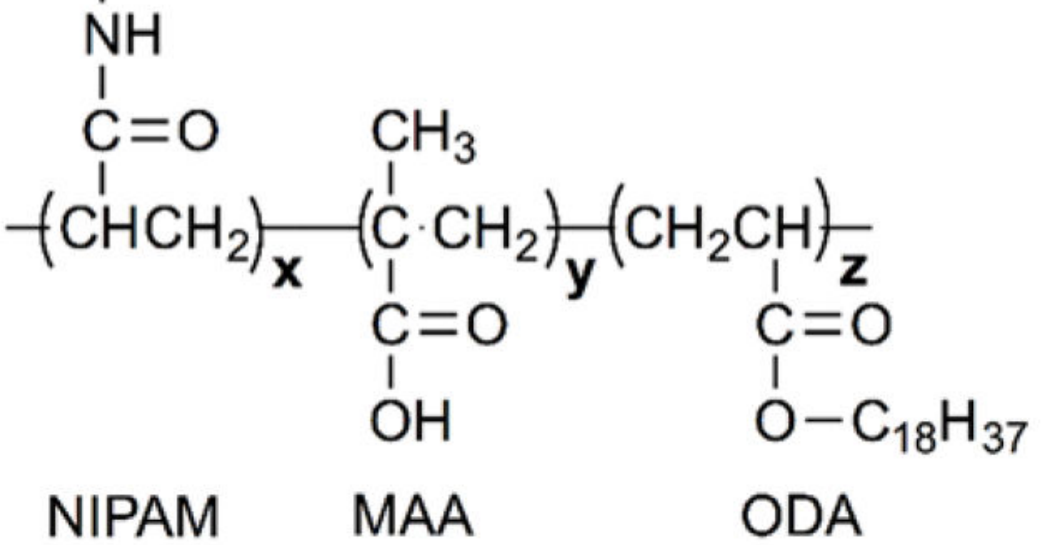

Fig. 20.

Structure of the copolymer NIPAM/MAA/ODA (mass ratio of x: NIPAM, y: MAA, z: ODA). 

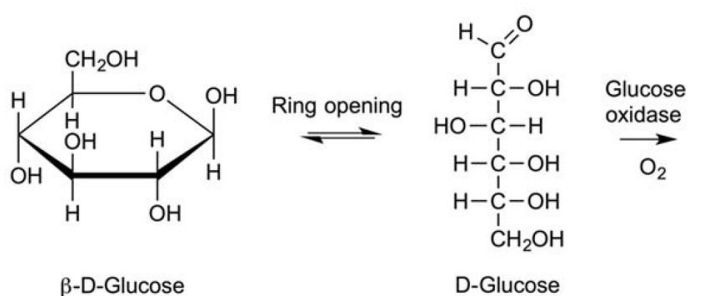

$$
\begin{gathered}
\mathrm{HO}-\mathrm{C}^{\prime \prime} \\
\mathrm{I} \\
\mathrm{H}-\mathrm{C}-\mathrm{OH} \\
\mathrm{I}-\mathrm{C}-\mathrm{H} \\
\mathrm{HO}+\mathrm{I}-\mathrm{OH} \\
\mathrm{H}-\mathrm{C}-\mathrm{OH} \\
\mathrm{I}-\mathrm{C}-\mathrm{OH} \\
\mathrm{I}-\mathrm{O} \mathrm{O}_{2} \\
\mathrm{CH}_{2} \mathrm{OH} \\
\text { D-Gluconic acid }
\end{gathered}
$$

Fig. 21.

Conversion of glucose to gluconic acid in the presence of glucose oxidase. 

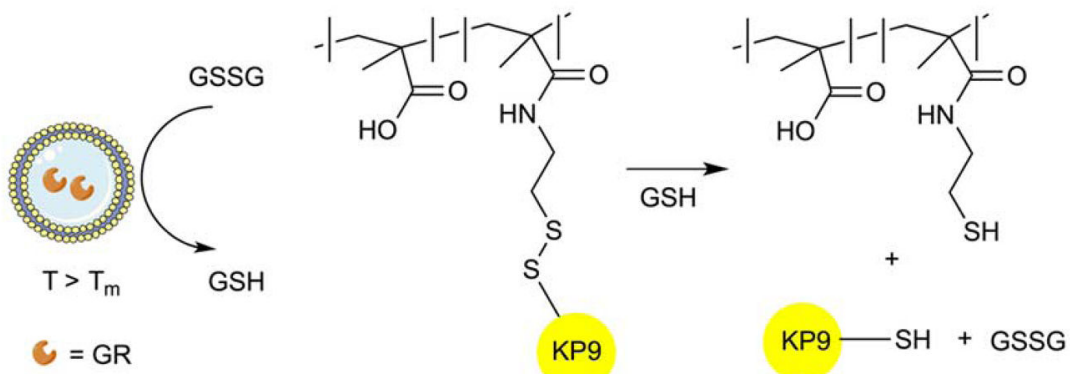

PMA-KP9

Fig. 22.

Glutathione reductase (GR) induces the conversion of GSSG to GSH that facilitates the release of encapsulated peptide due to the cleavage of the disulfide bond linking the polymer carrier (PMA) and the peptide (KP9). 
(a)
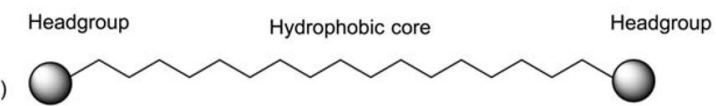

(b)<smiles>CCOC(=O)C[N+](C)(Cl)CCOC(C)=O</smiles>

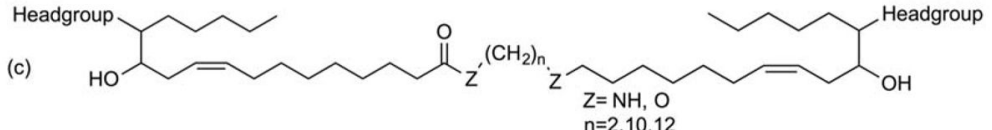

(d)

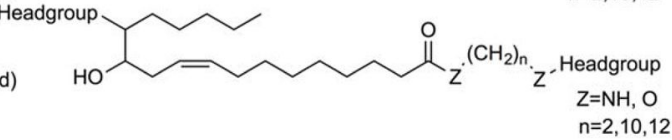

Fig. 23.

General structure of (a) bolaamphiphilic compound (b) choline ester headgroup (c) symmetric bolaamphiphilic compound (d) asymmetric bolaamphiphilic compound. 


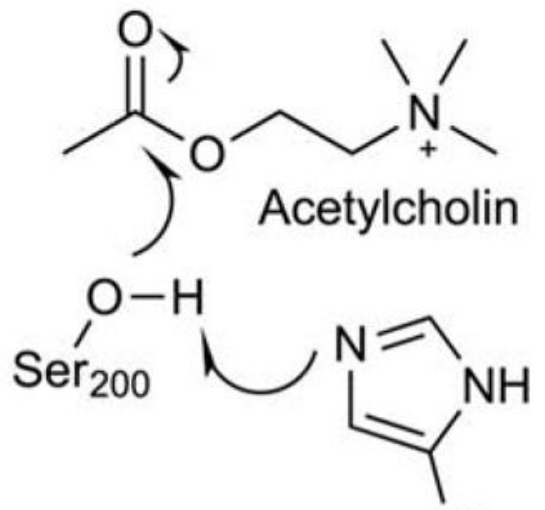

$\mathrm{His}_{440}$

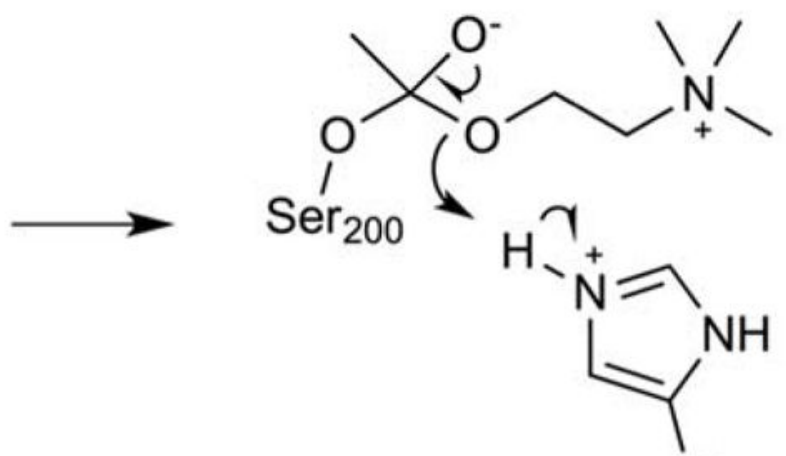

$\mathrm{His}_{440}$

Acetate
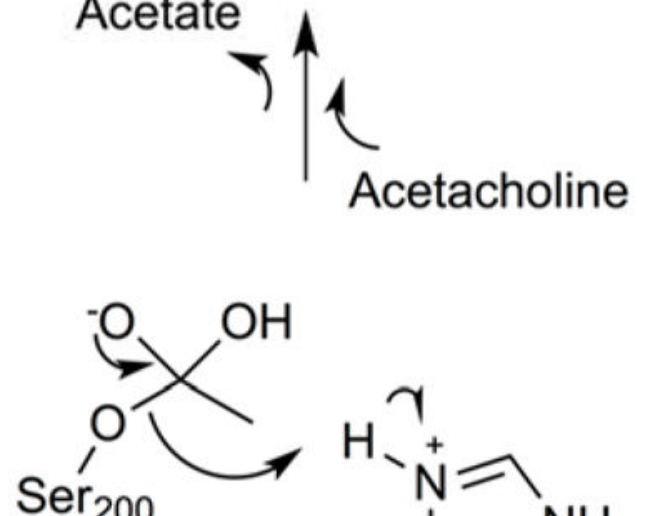

200

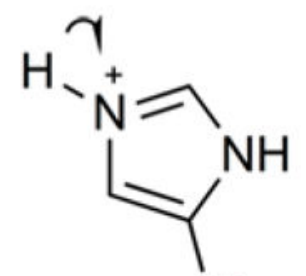

$\mathrm{His}_{440}$

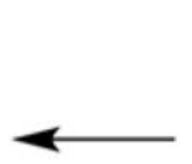

Fig. 24.

Generalized mechanism for $\mathrm{AChE}$ hydrolysis of acetylcholine.
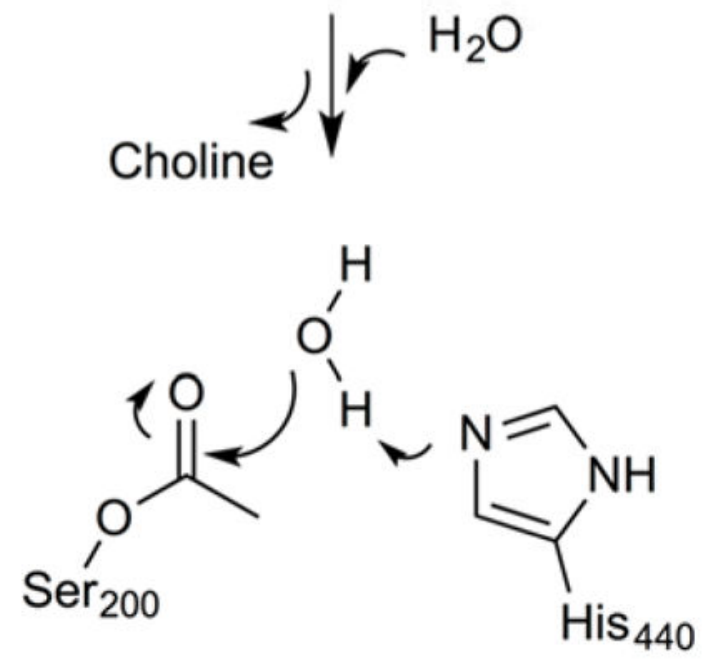
General Reaction
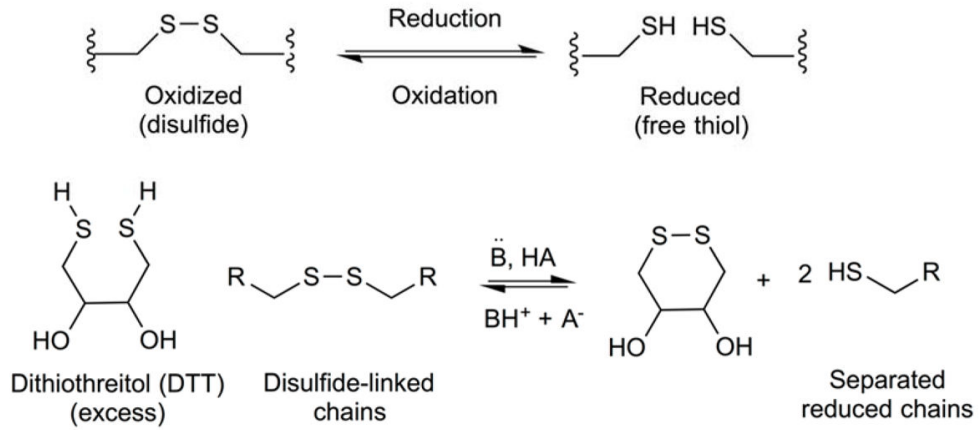

Fig. 25.

Schematic representation of dithiothreitol (DTT)-induced disruption of disulfide bonds through reduction. 


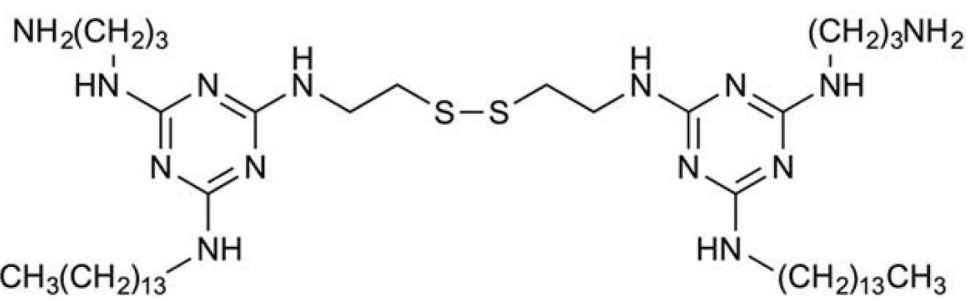

Fig. 26.

Chemical structure of SS14. 

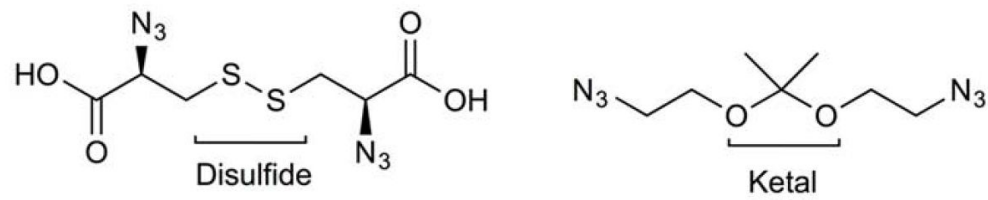

Fig. 27.

Chemical structures of disulfide- and ketal-containing cleavable linkers. 


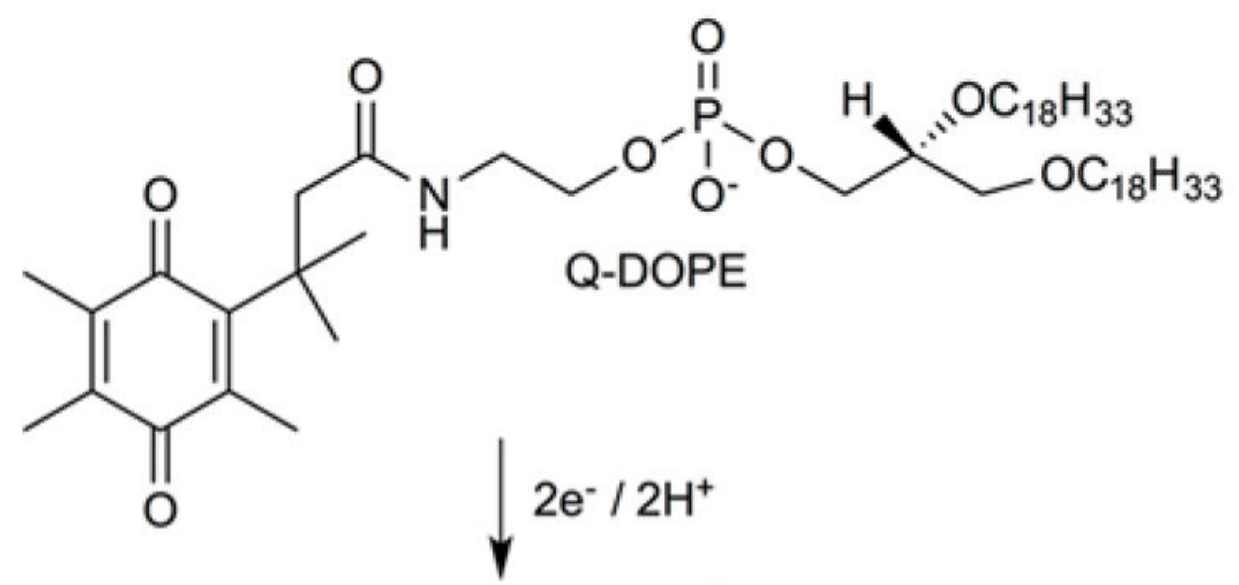

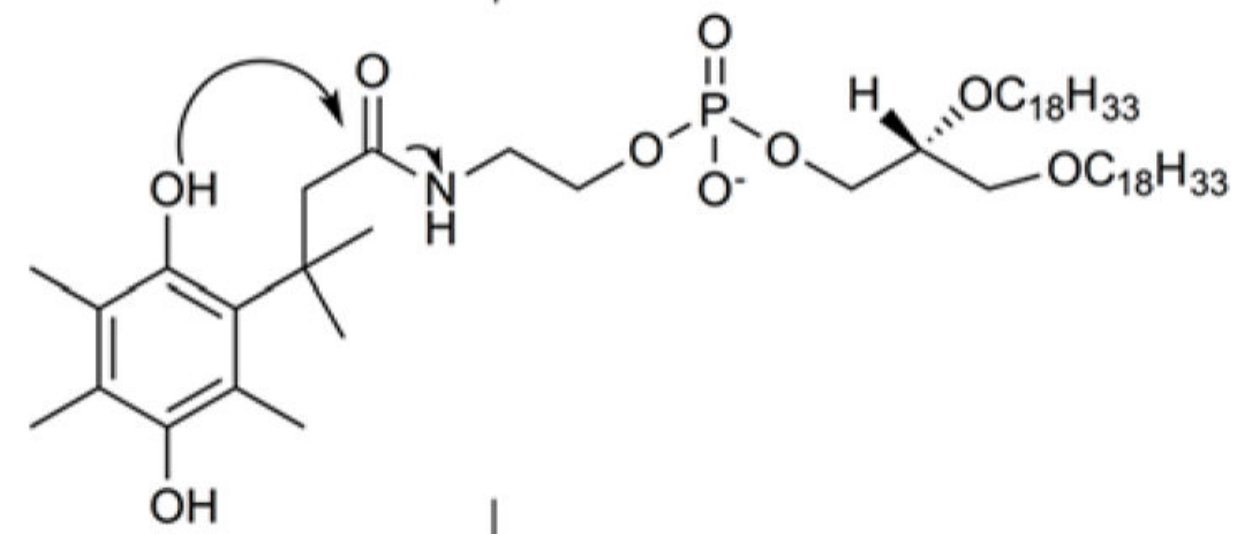<smiles>Cc1c(C)c2c(c(C)c1O)C(C)(C)CC(=O)O2</smiles>

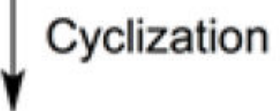

Fig. 28.

Chemical mechanism of reduction and intramolecular cyclization of Quinone Propionic Acid (QPA) trigger group to trigger the cleavage of linker. 


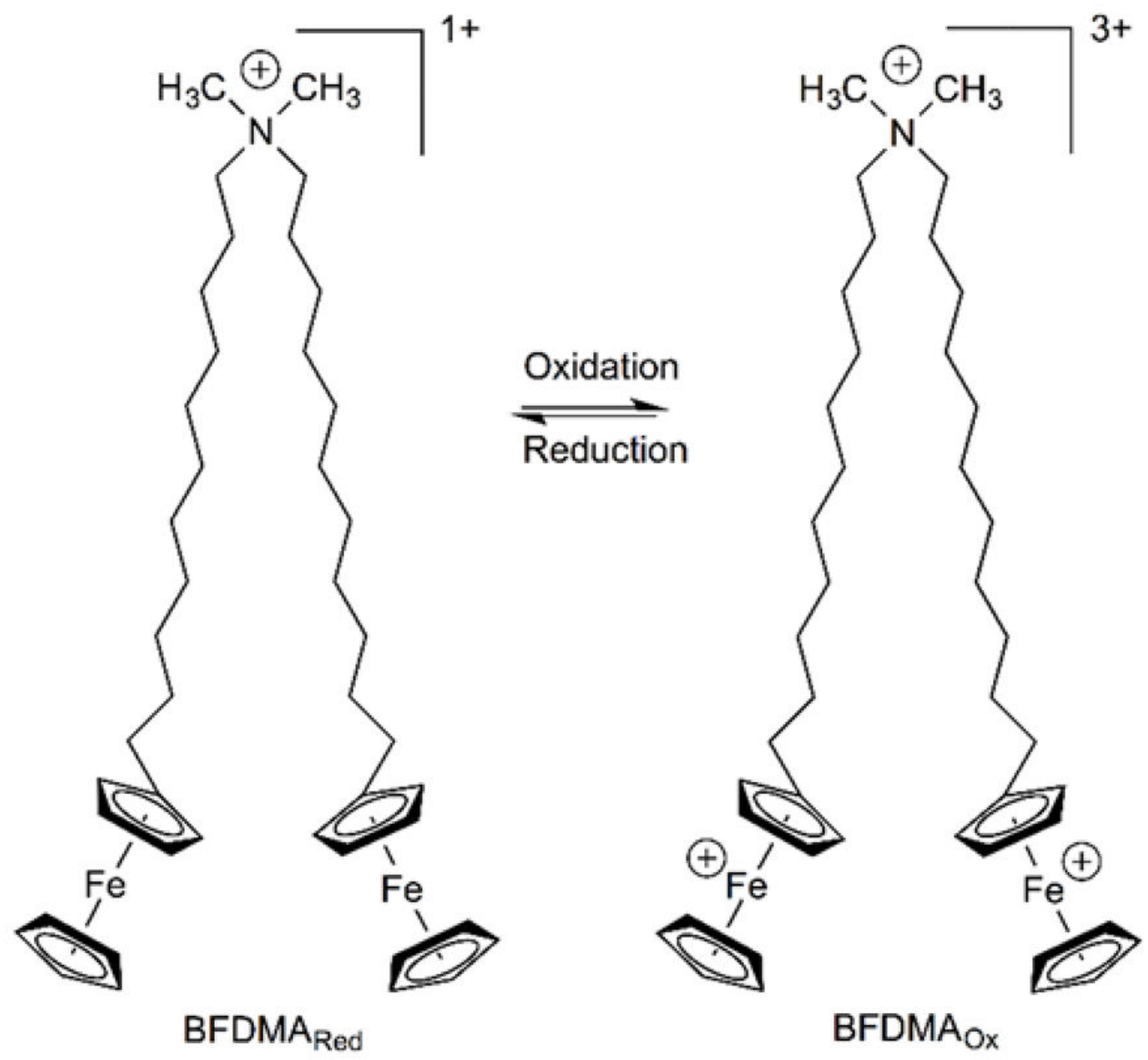

Fig. 29.

Chemical structure of bis(11-ferrocenylundecyl)dimethylammonium bromide (BFDMA) and reversible redox mechanism. 


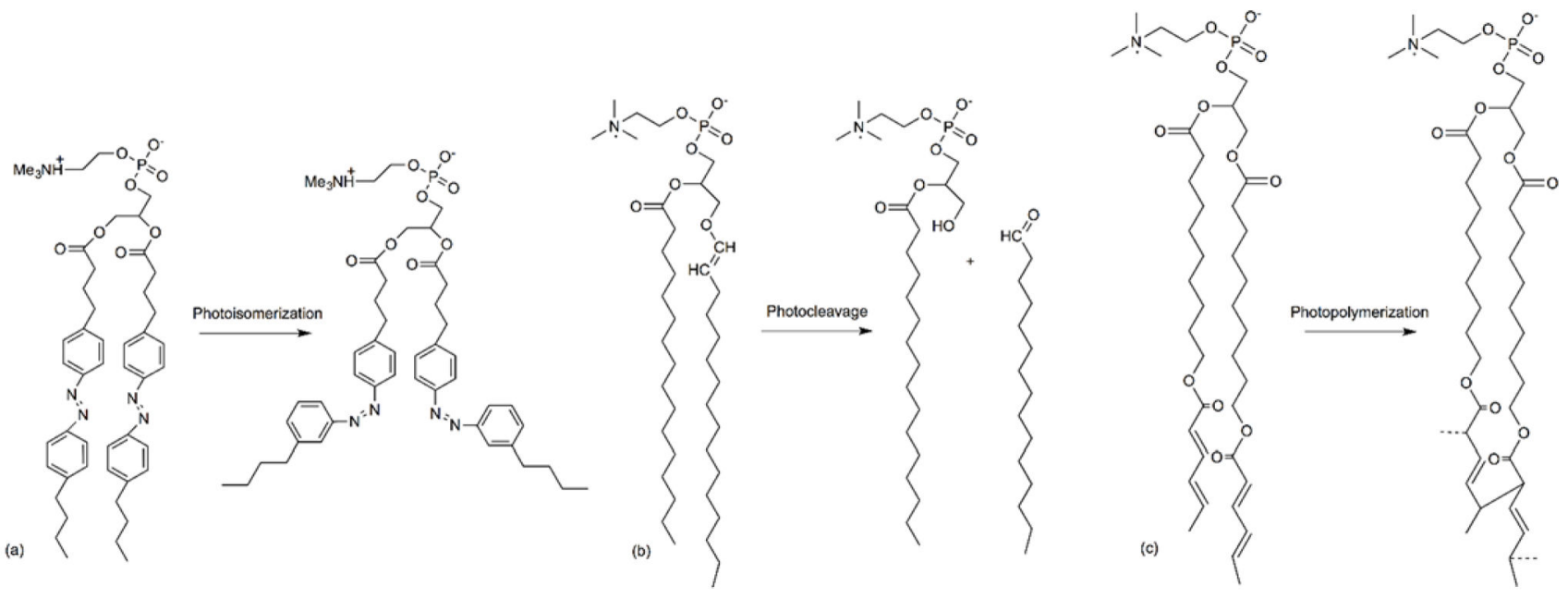

Fig. 30.

Schematic reactions of (a) photo-induced cis-trans conformational changes, (b) photocleavage of lipids upon exposure to light-mediated formation of ROS, and (c) photopolymerization of lipids containing double or triple bonds. 
(a)

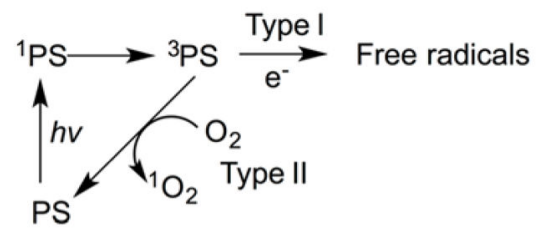

(b)

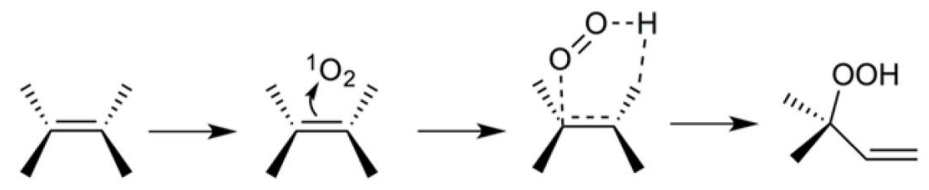

Fig. 31.

General mechanisms of photooxidation. (a) Type I: electron transfer reaction catalyzing the formation of radical species. Type II: energy transfer reaction catalyzing the formation of singlet oxygen. Photosensitizer (PS): ground state, ${ }^{1} \mathrm{PS}$ : singlet, ${ }^{3} \mathrm{PS}$ : triplet states. Oxygen $\left(\mathrm{O}_{2}\right)$ : ground state, ${ }^{1} \mathrm{O}_{2}$ : singlet excited state. (b) Formation of lipid hydroperoxide by ene reaction between the lipid double bond and singlet oxygen. 


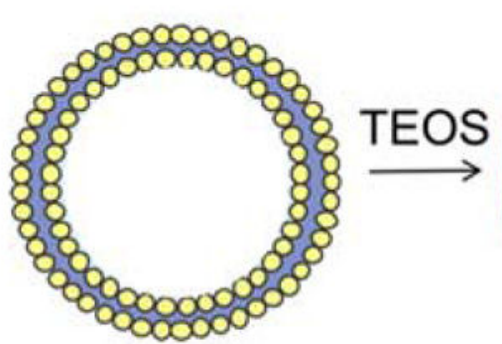

Liposome

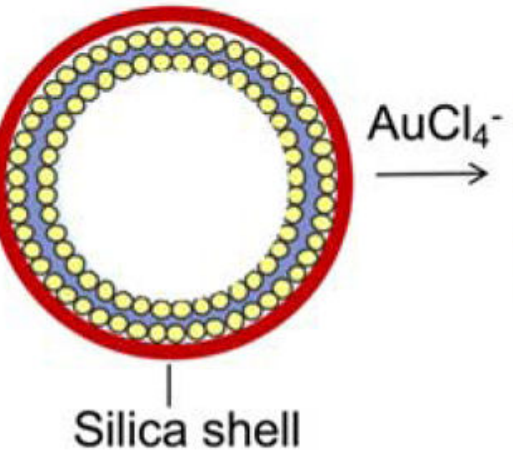

Silica shell

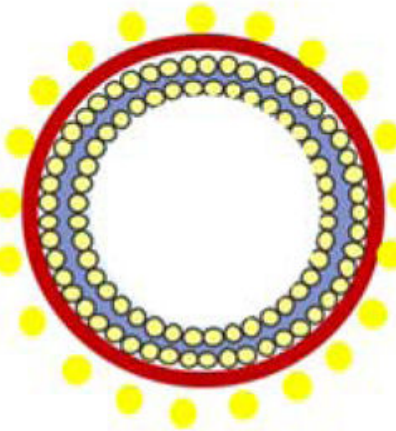

$\mathrm{NH}_{2} \mathrm{OH}$
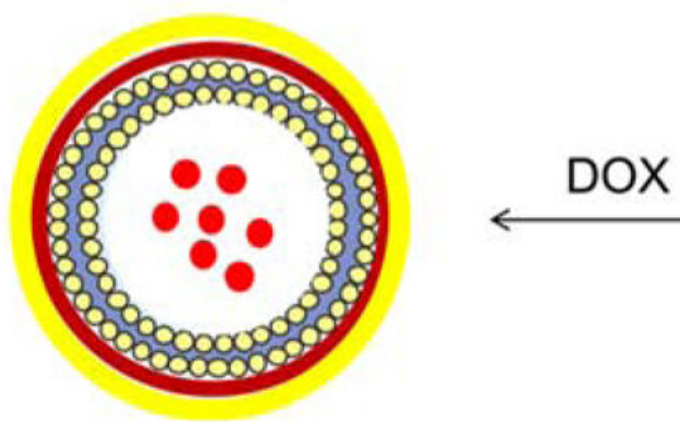

DOX-loaded liposome/ $/ \mathrm{SiO}_{2} / \mathrm{Au}$

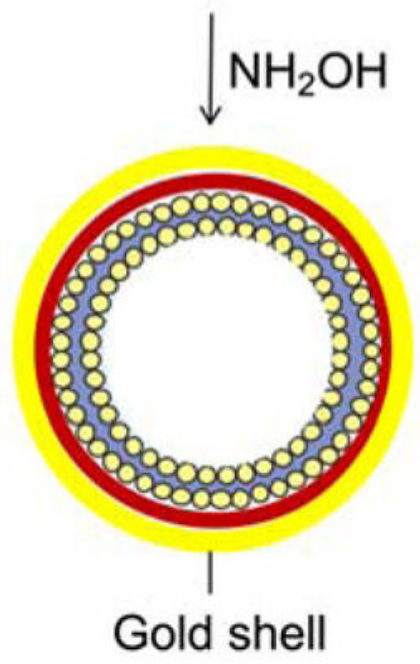

Fig. 32.

Schematic representation of the DOX-loaded gold nanoshell (DOX-loaded liposome/ $\mathrm{SiO}_{2} / \mathrm{Au}$ ) formation. Silica shell formed through the hydrolyzation of TEOS then coated with Au shell through the reaction of Au chloride tetrahydrate and hydroxylamine. TEOS: tetraethyl orthosilicate. 


\section{Table 1}

Comparison on CF release from different liposome-Au nanoshell formulas.

\begin{tabular}{|c|c|c|}
\hline \multicolumn{1}{|c|}{ Laser } & Solution & Release (\%) \\
\hline \multirow{4}{*}{ Pulsed femtosecond NIR } & $\mathrm{CF}$ & $0 \pm 2$ \\
\cline { 2 - 3 } & $\mathrm{CF}+$ Au nanoshell & $1 \pm 2$ \\
\cline { 2 - 3 } & CF-liposome & $-1 \pm 2$ \\
\cline { 2 - 3 } & CF-liposome-Au nanoshell (Free) & $28 \pm 2$ \\
\cline { 2 - 3 } & CF-liposome-Au nanoshell (Inside) & $71 \pm 1$ \\
\cline { 2 - 3 } & CF-liposome-Au nanoshell (Outside) & $93 \pm 2$ \\
\hline Continuous-wave laser & CF-liposome-Au nanoshell (Inside) & $-1 \pm 2$ \\
\hline
\end{tabular}




\section{Table 2}

Comparison of cell growth inhibition rates from different liposomal combinations.

\begin{tabular}{|l|c|c|}
\hline Laser & Sample & Cell growth inhibition rate (\%) \\
\hline Without NIR & $\mathrm{DOX}$ & $13.08 \pm 3.97$ \\
\hline With NIR & $\mathrm{DOX}$ & $12.91 \pm 5.85$ \\
\hline Without NIR & liposome $/ \mathrm{SiO}_{2} / \mathrm{Au}$ & $7.63 \pm 3.80$ \\
\hline With NIR & liposome $/ \mathrm{SiO}_{2} / \mathrm{Au}$ & $57.76 \pm 9.36$ \\
\hline Without NIR & DOX-loaded liposome $/ \mathrm{SiO}_{2} / \mathrm{Au}$ & $12.27 \pm 2.47$ \\
\hline With NIR & DOX-loaded liposome $/ \mathrm{SiO}_{2} / \mathrm{Au}$ & $81.63 \pm 4.03$ \\
\hline
\end{tabular}

